\title{
Inflammatory Bowel Diseases \\ The inflammatory bowel disease drug azathioprine induces autophagy via mTORC1 and the unfolded protein response sensor PERK \\ --Manuscript Draft--
}

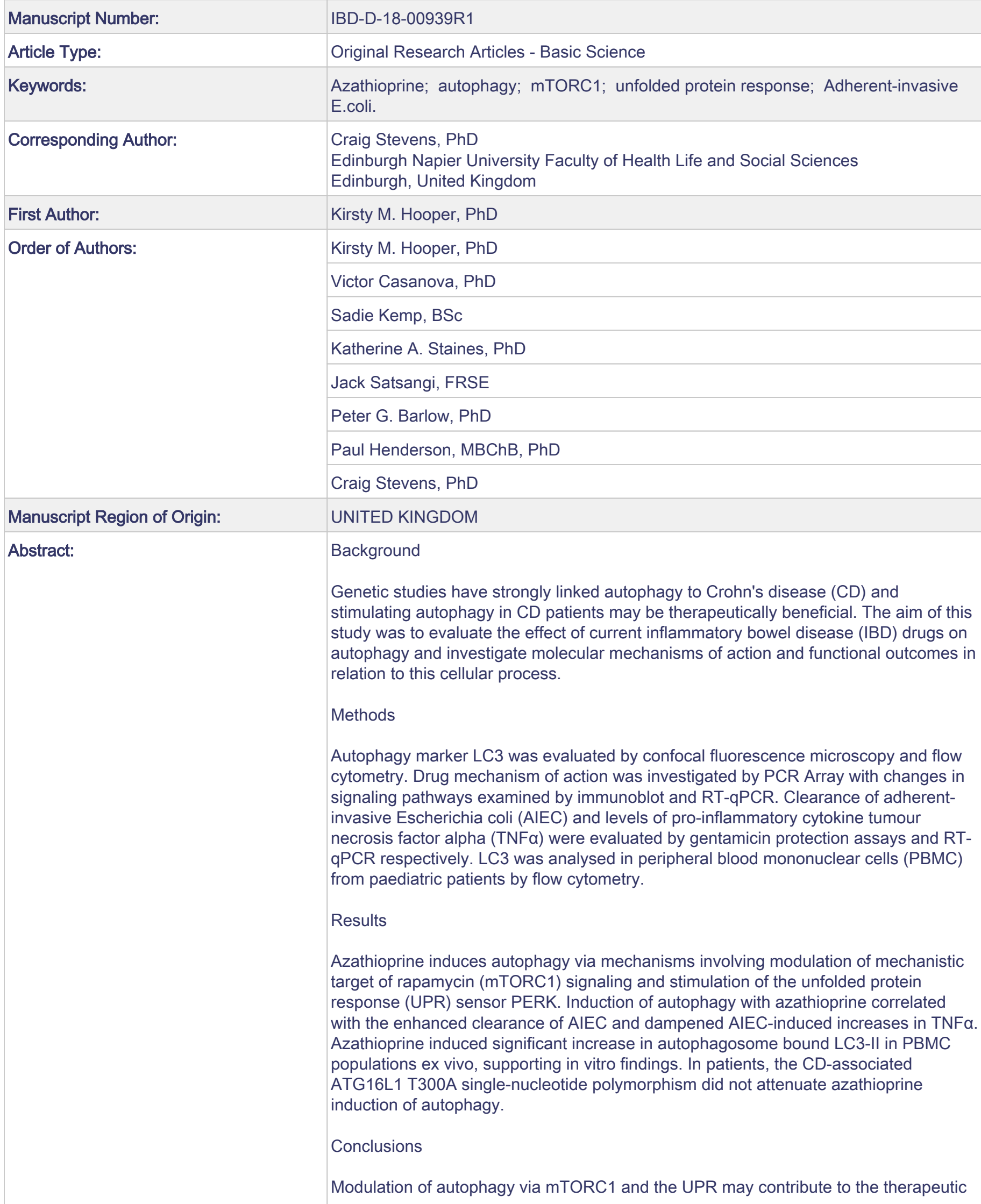


efficacy of azathioprine in IBD.

Powered by Editorial Manager ${ }^{\circledR}$ and ProduXion Manager ${ }^{\circledR}$ from Aries Systems Corporation 
1 The inflammatory bowel disease drug azathioprine induces

2 autophagy via mTORC1 and the unfolded protein response

3 sensor PERK

4 Kirsty M. Hooper, $\mathrm{PhD}^{1}$, Victor Casanova, $\mathrm{PhD}^{1}$, Sadie Kemp, BSc${ }^{1}$, Katherine A.

5 Staines, $\mathrm{PhD}^{1}$, Jack Satsangi, $\mathrm{FRSE}^{2,5}$, Peter G. Barlow, $\mathrm{PhD}^{1}$, Paul Henderson, $6 \mathrm{MBChB}, \mathrm{PhD}^{3,4}$ and Craig Stevens, $\mathrm{PhD}^{1 \uparrow *}$.

7 1. School of Applied Sciences, Edinburgh Napier University, Sighthill Campus, Sighthill Court, 8 Edinburgh, EH11 4BN.

9 2. Centre for Genomic \& Experimental Medicine, University of Edinburgh, Western General 10 Hospital Campus, Crewe Road, Edinburgh EH4 2XU.

11 3. Child Life and Health, University of Edinburgh, Edinburgh, EH9 1 UW.

12 4. Department of Pediatric Gastroenterology and Nutrition, Royal Hospital for Sick Children, 13 Edinburgh, EH9 1LF.

14 5. Translational Gastroenterology Unit, Nuffield Department of Medicine, John Radcliffe 15 Hospital, Oxford OX3 9DU.

16 IJoint senior authors 
1

2

3 8

17 Short title: The CD drug azathioprine induces autophagy

\section{Address for correspondence}

$20 *$ Dr Craig Stevens

21 School of Applied Sciences, Edinburgh Napier University, Sighthill Campus, Sighthill Court, 22 Edinburgh, EH11 4BN.

\section{Email: C.Stevens@napier.ac.uk}

24 Tel: 00441314552930

25

26 Summary

27

28 The aim of this study was to evaluate the effect of current inflammatory bowel disease drugs

29 on autophagy and investigate molecular mechanisms of action and functional outcomes in

30 relation to this cellular process. 


\begin{abstract}
32 Abstract
33 Background: Genetic studies have strongly linked autophagy to Crohn's disease (CD) and

34 stimulating autophagy in CD patients may be therapeutically beneficial. The aim of this study 35 was to evaluate the effect of current inflammatory bowel disease (IBD) drugs on autophagy 36 and investigate molecular mechanisms of action and functional outcomes in relation to this 37 cellular process.
\end{abstract}

38 Methods: Autophagy marker LC3 was evaluated by confocal fluorescence microscopy and 39 flow cytometry. Drug mechanism of action was investigated by PCR Array with changes in 40 signaling pathways examined by immunoblot and RT-qPCR. Clearance of adherent-invasive 41 Escherichia coli (AIEC) and levels of pro-inflammatory cytokine tumour necrosis factor alpha 42 (TNF $\alpha$ ) were evaluated by gentamicin protection assays and RT-qPCR respectively. LC3 was 43 analysed in peripheral blood mononuclear cells (PBMC) from pediatric patients by flow 44 cytometry.

Results: Azathioprine induces autophagy via mechanisms involving modulation of mechanistic target of rapamycin (mTORC1) signaling and stimulation of the unfolded protein

47 response (UPR) sensor PERK. Induction of autophagy with azathioprine correlated with the 48 enhanced clearance of AIEC and dampened AIEC-induced increases in TNFa. Azathioprine 49 induced significant increase in autophagosome bound LC3-II in PBMC populations ex vivo, 50 supporting in vitro findings. In patients, the CD-associated ATG16L1 T300A single-nucleotide 51 polymorphism did not attenuate azathioprine induction of autophagy. 
52 Conclusions: Modulation of autophagy via mTORC1 and the UPR may contribute to the 1 4 8

54 Keywords: Azathioprine, autophagy, mTORC1, unfolded protein response, Adherent-invasive 55 E.coli. 


\section{Introduction}

58

59 The inflammatory bowel diseases (IBD), Crohn's disease (CD), ulcerative colitis (UC) and IBD-

60 unclassified (IBDU), are characterized by chronic inflammation of the gastrointestinal (GI)

61 tract and have a prevalence of up to 400 per 100,000 people in the United Kingdom ${ }^{1}$. The

62 pathogenesis of IBD is multifactorial in nature, with genetic predisposition, breakdown of the

63 intestinal epithelial barrier, and concomitant interaction with environmental triggers in the

64 lumen contributing to disease ${ }^{2}$. A dysregulated immune response to intestinal microflora has

65 been heavily implicated, and examination of the disease-associated microbiome has

66 identified several potentially causative agents ${ }^{3}$. Most notably Escherichia coli (E.coli) strains

67 with an adherent and invasive phenotype (AIEC) have been consistently isolated by

68 independent investigators from CD patients with ileal disease ${ }^{4}$.

69 Genome-wide association studies (GWAS) have identified 240 IBD susceptibility loci to date ${ }^{5}$

70 and have confirmed association with previously recognized susceptibility genes including

$71 \quad$ Nucleotide-binding oligomerisation domain-containing protein 2 (NOD2). Amongst genes

72 identified are several linked to autophagy including autophagy-related protein (ATG)16L1,

73 Immunity-related GTPase family M protein (IRGM) and leucine rich repeat kinase $2\left(\right.$ LRRK2) ${ }^{6}$.

74 Autophagy is an intracellular homeostatic process that involves the formation and maturation

75 of double membrane vesicles, known as autophagosomes, which engulf cargo that is 76 degraded upon fusion with lysosomes ${ }^{7}$. Autophagy can be an important survival mechanism

77 that is induced in response to a myriad of stresses. Autophagy plays an essential role in the 78 innate and adaptive immune responses and the timely resolution of inflammation ${ }^{8}$, and loss 79 of immune regulation is a key event leading to the chronic inflammation observed in $\mathrm{CD}^{9}$. 80 Notably, impaired autophagy responses have been observed in a range of cell types derived 
81 from CD patients including the specialized intestinal epithelial cells (IECS) Paneth cells and

82 goblet cells, and leukocytes, such as macrophages and dendritic cells (DC) ${ }^{10}$.

83 Evidence suggests that inducing autophagy may have therapeutic benefit for the treatment

84 of IBD $^{9}$. Mechanistic target of rapamycin complex 1 (mTORC1) is a master regulator of cell 85 growth and a potent inhibitor of autophagy ${ }^{10}$, therefore inhibition of mTORC1 with 86 rapamycin or its analogues, sirolimus and everolimus, strongly induces autophagy. In 87 previously reported case studies sirolimus improved symptoms and intestinal healing in a 88 patient with severe refractory $C D^{11}$ and everolimus controlled symptoms for 18 months in a 89 patient with refractory UC ${ }^{12}$. In a study of refractory pediatric IBD, sirolimus induced clinical 90 remission in $45 \%$ of UC patients and $100 \%$ of CD patients ${ }^{13}$.

91 Drugs currently approved for clinical use for IBD, including corticosteroids, 92 immunomodulators, aminosalicylates (5-ASAs) and biologics, target the immune system to 93 reduce inflammation and induce remission, however response to treatment often diminishes 94 over time, with $10-35 \%$ of $C D$ patients requiring surgery within a year of diagnosis and up to $9561 \%$ by 10 years ${ }^{14}$. A National Health Service review estimated IBD treatment costs of $£ 720$ 96 million $(\$ 940 \mathrm{~m})$ per year in the United Kingdom alone ${ }^{1}$, with roughly a quarter of these costs 97 directly attributed to drug treatments ${ }^{15}$. The Crohn's and Colitis Foundation has recently 98 highlighted the need for research into optimizing existing medical therapies ${ }^{16}$, with patient 99 stratification of key importance in this context ${ }^{13}$. In order to optimize therapies, a more 100 comprehensive understanding of drug mechanisms of action is required.

101 We aimed to evaluate current IBD drugs in the context of autophagy and show that the 102 immunomodulator azathioprine induces autophagy via mechanisms involving modulation of 
103 mTORC1 and stimulation of the unfolded protein response (UPR) sensor PERK. Our results 1

2

2104 suggest that in addition to well-characterized effects on DNA/RNA synthesis and T4

5105 lymphocytes ${ }^{17,18}$, modulation of autophagy and the UPR may contribute to the therapeutic 106 efficacy of azathioprine. 
108 Materials and Methods

3109 Cell culture, transfection, plasmids and reagents

4

5

6

HEK293 cells were grown in Dulbecco's modified Eagle medium (DMEM) (Gibco,

118 For transfection of HEK293 cells, a Nucleofector Kit V (Lonza Ltd, Manchester, UK) was used 119 according to the manufacturer's instructions. The GFP-LC3 ${ }^{19}$, GFP-RFP-LC3 ${ }^{20}$ and $x$-light EGFP $120{ }^{21}$ plasmids have been described previously. All reagents used are detailed in supplementary 121 (Table S1). For nutrient deprivation, cells were incubated with Earle's Balanced Salt Solution 122 (EBSS) (Gibco).

\section{Immunoblotting}

124 Cells were lysed in ice-cold extraction buffer (50mM Tris [pH 7.6], 150mM NaCl, 5mM EDTA, $1250.5 \%$ NP-40, $5 \mathrm{mM} \mathrm{NaF}, 1 \mathrm{mM}$ sodium vanadate, $1 \times$ Pierce Protease Inhibitor Cocktail [Thermo 126 Scientific]) for $30 \mathrm{~min}$ followed by centrifugation. Protein lysates were resolved by denaturing 127 electrophoresis on acrylamide/bisacrylamide gels and electro-transferred to Immobilon-FL 128 PVDF membrane (Merck Millpore EMD, Watford, UK). Membranes were incubated with 
primary antibodies overnight at $4^{\circ} \mathrm{C}$, and after washing, were incubated with a secondary antibody for $1 \mathrm{hr}$ at room temperature (RT). Antibody details are provided in (Table S2). Proteins were visualized by incubation with an ECL western blotting analysis system (GE Healthcare) and imaged using a G: BOX system (Syngene, Cambridge, UK). Relative intensity 133 of bands were measured using Image J software ${ }^{22}$ (National Institutes of Health, Bethesda, 134 MD, USA).

\section{Confocal fluorescence microscopy}

136 Cells were seeded on 21-mm borosilicate glass cover slips, 8 chamber polystyrene vessel 137 CultureSlides (Falcon, Fisher Scientific, Loughborough, UK) or 35mm imaging dishes (Ibidi, 138 Thistle Scientific, Uddingston, UK). Images were captured using Carl Zeiss LSM880 confocal 139 microscope (Jena, Germany) and images were analysed using Image J software ${ }^{18}$ (National 140 Institutes of Health).

141 For fixed cell imaging: Cells were fixed with 4\% paraformaldehyde (PFA) for 15 min, 142 permeabilized with PBS/0.2\% Triton X-100 (Sigma Aldrich) and blocked with PBS containing $14310 \%$ goat's serum (Gibco) and 2.5\% Human TruStain FcX (BioLegend, San Diego, USA). Primary 144 antibodies (Table S2) were incubated overnight at $4^{\circ} \mathrm{C}$ and conjugated secondary antibodies 145 for $1 \mathrm{hr}$ at RT. Where appropriate, cells were counterstained with $4^{\prime}, 6^{\prime}$-diamidino-2146 phenylindole (DAPI) or mounted with Vectashield mounting medium for fluorescence with 147 DAPI (Vector Laboratories, Peterborough, UK).

148 For live cell imaging: Cells were grown in 35mm imaging dishes (Ibidi) and maintained at $37^{\circ} \mathrm{C}$ 149 and $5 \% \mathrm{CO}_{2}$ in live-cell imaging chamber attached to Carl Zeiss LSM880 confocal microscope. 150 Images were captured every 2 minutes at $x 40$ magnification over a $12 \mathrm{hr}$ time period. 
For autophagy assays in HEK293 GFP-LC3 stable cells: The basal threshold number of GFP-LC3 puncta per cell was established as 5 , and cells exhibiting $\geq 5$ puncta were regarded as having enhanced autophagy activity.

For tandem fluorescent-tagged GFP-RFP-LC3 assays: Cells were transiently transfected with the GFP-RFP-LC3 plasmid and following designated treatments, the fluorescent autophagy markers GFP-RFP-LC3 or RFP-LC3 were observed using a confocal microscope and the number of (RFP+GFP+) and (RFP+GFP-) puncta per cell determined.

\section{Flow cytometry}

Peripheral blood mononuclear cells (PBMC) were seeded in 96-well U-bottom plates and cell lines were seeded in 12-well plates. After treatments, cells were gently detached using $0.05 \%$ trypsin or Cell Dissociation Solution Non-enzymatic (Sigma Aldrich) at $37^{\circ} \mathrm{C}$ for $10 \mathrm{~min}$. Cells were acquired using the BD Biosciences (Oxford, UK) Celesta flow cytometer or the FACSCalibur (BD) and data analysis performed using BD FACsDiva Software or FlowJo software.

Autophagy assay: For HEK293 GFP-LC3, cells were collected then washed in $0.05 \% \mathrm{w} / \mathrm{v}$ saponin (Sigma), diluted in PBS to remove the unbound cytosolic LC3 ${ }^{23}$, which does not alter expression of membrane antigens ${ }^{24}$, prior to acquisition. For PBMC, cells were collected and blocked with 2.5\% Human TruStain FCX in PBS for 20 min, then incubated with PBMC surface markers or IgG isotypes diluted in Brilliant Stain Buffer (BD Horizon) for 25 min, both at RT.

Cells were then washed in $0.05 \% \mathrm{w} / \mathrm{v}$ saponin, diluted in PBS to remove the unbound cytosolic LC3, and fixed with $1 \%$ PFA for 20 min at $4^{\circ} \mathrm{C}$. Cells were washed again with $10 \%$ goat serum in $0.05 \%$ saponin before overnight incubation with primary LC3 antibody or Rb IgG Isotype 
173

1

2

control (Invitrogen) in $1 \%$ goat serum in $0.05 \%$ saponin at $4^{\circ} \mathrm{C}$. Secondary antibody in $1 \%$ goat serum in $0.05 \%$ saponin was incubated for $30 \mathrm{~min}$ at $4^{\circ} \mathrm{C}$ prior to washing and acquisition.

Annexin-V/PI assay. Cells were stained using the FITC Annexin V Apoptosis Detection Kit I (BD Pharmingen) according to manufacturer's instructions.

\section{RT-qPCR}

178 Cells were scraped into RNAzol RT (Sigma-Aldrich) and total RNA extracted according to 179 manufacturer's instructions. Total RNA was quantified using a NanoDrop 2000 180 Spectrophotometer (Thermo Scientific) and integrity was assessed using an Agilent 2100 181 Bioanalyzer (Agilent Technologies, Stockport, UK) with RNA Nano Chips and Agilent RNA 6000 182 Nano Reagents (Agilent Technologies). mRNA was converted to cDNA using nanoScript 2, 183 Reverse Transcription Premix (PrimerDesign Ltd, Chandler's Ford, UK) according to 184 manufacturer's instructions. For qPCR analysis of gene expression PrecisionPLUS Mastermix 185 with SYBR green and ROX with inert blue dye (PrimerDesign) was used according to 186 manufacturer's instructions with RT-PCR Grade Water (Invitrogen) and the StepOnePlus Real187 time PCR System (Applied Biosystems, ThermoFisher). Primers are detailed in supplementary 188 (Table S3). A geNorm kit (PrimerDesign) was used for the selection of appropriate reference 189 genes (RPL13A [Ribosomal Protein L13a] and Actin) with the qbase+ software ${ }^{25} .2^{- \text {ddCT }}$ was 190 used for relative quantification of gene expression ${ }^{26}$. The $\mathrm{RT}^{2}$ Profiler PCR Array of Human 191 Autophagy genes (Qiagen, Crawley, UK) was performed according to manufacturer 192 instructions. 


\section{Bacterial infection assays}

194 For growth curves: LB was inoculated with E. coli strain CUICD541-10 ${ }^{27}$ isolated from the 195 ileum of a patient with CD (a kind gift from Prof Kenny Simpson, Cornell University, USA), from 196 an overnight culture to an optical density of 0.05 at $600 \mathrm{nM}$. Cultures were treated 197 appropriately, incubated at $37^{\circ} \mathrm{C}$ with $200 \mathrm{rpm}$ shaking, and optical density was measured at $198600 \mathrm{nM}$ every $30 \mathrm{~min}$.

199 For intracellular survival: Cells were infected with CUICD541-10 E. coli at a multiplicity of 200 infection (MOI) of $10 \mathrm{for} 3 \mathrm{hr}$, incubated for $1 \mathrm{hr}$ in $100 \mu \mathrm{g} / \mathrm{ml}$ gentamicin (Gibco) to kill 201 extracellular bacteria, then maintained for a further $24 \mathrm{hr}$ in $20 \mathrm{\mu g} / \mathrm{ml}$ gentamicin, with 202 addition of appropriate treatments for the final 6hr. For colony forming unit (CFU) 203 enumeration, cells were lysed for 10 min using $1 \%$ Triton X100 in PBS. Lysates were serially 204 diluted and plated on LB agar plates for overnight incubation at $37^{\circ} \mathrm{C}$.

205 For immunofluorescence: CUICD541-10 E. coli transformed with an x-light mCherry plasmid 206 were used and $30 \mathrm{~min}$ prior to immunostaining cells were incubated with $0.1 \mathrm{mM}$ isopropyl $\beta$ -

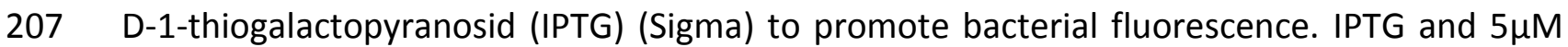
208 Cell Tracker Green BODIPY (Invitrogen) were added for the duration of the live-cell imaging 209 of infected cells.

\section{Patients}

211 Patient recruitment and sample collection was performed at the Royal Hospital for Sick 212 Children in Edinburgh, and processing and analysis was performed at Edinburgh Napier 213 University. 

7

214 Inclusion criteria were: (1) aged 6-18 years on date of colonoscopy; (2) already confirmed CD, 215 UC or IBDU ${ }^{28}$ or undergoing first upper and lower $\mathrm{Gl}$ endoscopy due to gastrointestinal 216 symptoms suggestive of possible bowel inflammation (e.g. abdominal pain, peri-rectal (PR) 217 bleeding, weight loss). Non-IBD patients were defined as those with both microscopically and 218 macroscopically normal colonoscopy. Patients were excluded if they had previously 219 undergone colonoscopy for anything other than known IBD, were diagnosed with anything 220 other than IBD following a full investigative cycle, or who could not provide written consent.

221 Whole blood samples (maximum $15 \mathrm{ml}$ ), and saliva samples were collected from patients: 20 222 IBD cases and 9 non-IBD controls (Table S4). PBMC were isolated from whole blood using 223 Ficoll-Paque PLUS (GE Healthcare Bio-Sciences AB, Uppsala, Sweden) and cultured in RPMI 224 growth media. Saliva samples were collected using Oragene DNA kits (DNA Genotek, Ontario, 225 Canada).

\section{Genotyping}

227 Saliva samples were sent to the Wellcome Trust Clinical Research Facility in Edinburgh for 228 analysis. Once recruitment was completed, DNA was extracted using Isohelix kit and Taqman 229 genotyping for each sample was performed for the following SNPs: ATG16L1 T300A 230 (rs2241880), NOD2 L1007f/s (p.Leu1007fsX1008) (rs2066847), NOD2 R702W (rs2066844) and 231 NOD2 G908R (rs2066845).

232 Statistical analysis 
233 Results are reported as the mean \pm SEM assuming normally distributed variables with 1

2 3 4 6 7 8 9 10

234 statistical analysis conducted by using one-way or two-way ANOVA, or paired t-test as

235 appropriate, with GraphPad Prism version 7.0 (GraphPad Software, CA, USA).

236 Ethics

237 All samples were collected with local institutional and NHS ethical approvals (reference 238 16/WW/0210). Eligible patients were approached at least 48hr prior to colonoscopy and 239 following consent were recruited to the study.

240 Data availability

241 The datasets generated during and/or analysed during the current study are available from 242 the corresponding author on reasonable request. 


\section{$244 \quad$ Results}

2

3

4

5

\section{Azathioprine induces autophagosome accumulation}

246 To evaluate the modulation of autophagy by IBD drugs we used HEK293 cells, a well247 characterized cell line used in autophagy research ${ }^{29}$ that were engineered to stably express 248 the autophagy marker LC3 fused to green fluorescent protein (GFP-LC3) ${ }^{30}$. GFP-LC3 puncta 249 accumulation was measured by live-cell imaging (Figure 1A). Significant increases in GFP-LC3 250 puncta number were observed after treatment with the immunomodulator azathioprine 251 (Figure $1 \mathrm{~A}$, panel iv and ix) and the biologic infliximab (Figure $1 \mathrm{~A}$, panel $\mathrm{v}$ and ix) with an 252 optimal time-point of $6 \mathrm{hr}$ for both drugs (Figure 1A, panel $\mathrm{x}$ and xi). Significant increases in 253 GFP-LC3 puncta were also observed with EBSS to induce nutrient deprivation, a strong 254 activator of the autophagy pathway (Figure 1A, panel iii and ix). In contrast, the 255 immunomodulator methotrexate (Figure 1A, panel vi, ix and xii), the corticosteroid 256 methylprednisolone (Figure 1A, panel vii, ix and xiii) and the aminosalicylate sulfasalazine 257 (Figure 1A, panel viii, ix and xiv) had no significant effects on GFP-LC3 puncta accumulation.

\section{Azathioprine activates the autophagy pathway}

259 Autophagosomes can accumulate due to activation or inhibition of the autophagy pathway. 260 To distinguish between these processes, we first employed flow cytometric analysis. To 261 facilitate measurement of autophagy activation by flow cytometry, HEK293 GFP-LC3 cells 262 were washed with the glycoside saponin to permeabilize cell plasma membranes prior to 263 analysis. Plasma membrane permeabilization releases inactive cytosolic LC3, with only the 264 active lipidated form of LC3-II, which is tightly associated with autophagosome membranes, 
being retained ${ }^{23}$ (Supplementary Figure 1). Additionally, Bafilomycin A1 (BafA1), an inhibitor

of autophagosome-lysosome fusion ${ }^{30}$, was used to augment LC3-II accumulation. Under these conditions azathioprine clearly enhanced the accumulation of autophagosome-bound GFP-

LC3-II (Figure 2A, panel ii and quantified in iv). In contrast, infliximab had only minor additional effect on GFP-LC3-II accumulation (Figure 2A, panel iii and iv).

To further validate that azathioprine-mediated activation of the autophagy pathway, we employed a tandem RFP-GFP-LC3 plasmid ${ }^{31}$. This RFP-GFP-LC3 plasmid utilises the $\mathrm{pH}$ difference between the acidic autolysosome (formed by fusion of an autophagosome and lysosome) and the neutral autophagosome, with the $\mathrm{pH}$ sensitivity differences exhibited by GFP (labile at acidic $\mathrm{pH}$ ) and RFP (stable at acidic $\mathrm{pH}$ ). Thus, this plasmid can be used to monitor progression from the autophagosome (RFP+GFP+) to the autolysosome (RFP+GFP-). HEK293 cells were transfected with RFP-GFP-LC3 plasmid and treated with BafA1, EBSS or azathioprine. As expected, all three treatments caused autophagosomes to accumulate (Figure 2B, panel xvi). Inhibition of autophagosome-lysosome fusion with BafA1 resulted in the accumulation of (RFP+GFP+) puncta, which appear as yellow in the merged image (Figure 2B, panel $x$, xiii and quantified in xvii), while activation of the pathway with EBSS resulted in an accumulation of (RFP+GFP-) puncta indicating that complete progression through the pathway was taking place (Figure 2B, panel xi, xiv and xvii). Azathioprine treatment resulted in an accumulation of (RFP+GFP-) puncta relative to untreated control (Figure 2B, panel xii, xV and xvii) indicating that azathioprine activates the autophagy pathway.

285 Azathioprine induces autophagosome accumulation in macrophages 286 independent of apoptosis 
287 As with other biological processes, autophagy is cell-type specific and it is therefore essential 288 to determine how azathioprine modulates the autophagy pathway in cell types of direct 289 relevance to IBD. For this purpose, macrophages derived from THP-1 cells were treated with 290 azathioprine and endogenous LC3 puncta accumulation measured by fixed-cell confocal 291 fluorescence microscopy. In line with our previous results (Figure 1A), azathioprine treatment 292 significantly increased the number of LC3 puncta in THP-1 derived macrophages (Figure 3A, 293 panel iv and v). Autophagy and apoptosis are intimately linked ${ }^{32}$, therefore it was also 294 important to determine the effect of azathioprine on apoptosis in these cells. Analysis of 295 Annexin V/PI staining by flow cytometry revealed that azathioprine had no effect on cell 296 viability at either $6 \mathrm{hr}$ or $24 \mathrm{hr}$ treatment (Figure 3B, panel ii, iv, and v). Together, these results 297 demonstrate that azathioprine induces autophagosome accumulation in THP-1 derived 298 macrophages independent of apoptosis.

\section{Azathioprine stimulates the UPR}

300 To gain insight into azathioprine mechanism of action, we used the Human Autophagy $\mathrm{RT}^{2}$ 301 Profiler PCR Array. Gene expression was compared in THP-1 derived macrophages either left 302 untreated or treated with azathioprine (Figure S3). Among the genes significantly up303 regulated by azathioprine was the UPR-regulating kinase EIF2AK3 (also known as PERK). As 304 endoplasmic reticulum (ER)-stress/UPR genes are strongly associated with IBD this was 305 investigated further ${ }^{33}$. A time-course RT-qPCR experiment identified $6 \mathrm{hr}$ as the optimum 306 time-point for up regulation of PERK, which occurred in a dose-dependent manner (Figure 4, 307 panel $\mathrm{i}$ and ii). The expression of genes downstream from PERK (ATF4, and CHOP; Figure 4, 308 panel iii and iv), and the ER stress chaperon protein disulphide isomerase (PDI) (Figure 4, panel 
vi) were also up regulated after $6 \mathrm{hr}$ of azathioprine treatment in a dose dependent manner. 310 In contrast, expression of the ER stress chaperone protein binding immunoglobulin protein/78-kDa glucose-regulated protein (BiP/Grp78) was not affected by azathioprine treatment after $6 \mathrm{hr}$ (Figure 4, panel vii) however a minor increase was observed after $24 \mathrm{hr}$. These results indicate that azathioprine stimulates the UPR.

\section{Azathioprine modulates mTORC1 signaling}

mTORC1 is a major regulatory hub balancing cell growth and protein translation with control of autophagy ${ }^{34}$. When active, mTORC1 is a potent inhibitor of autophagy. Therefore, levels of phosphorylated ribosomal protein S6 (p-rpS6), a surrogate marker of mTORC1 activity, were evaluated in THP-1 derived macrophages treated with increasing concentrations of azathioprine. Azathioprine treatment caused a dramatic decrease in p-rpS6 in a dose dependent manner (Figure 5A, lanes 3-6 and quantified in ii). These results suggest that azathioprine treatment inhibits mTORC1 activity.

\section{Azathioprine modulates mTORC1 signaling independent of PERK}

PERK has been shown to inhibit mTORC1 in response to ER stress as part of a mechanism to induce autophagy ${ }^{34-36}$. To test whether modulation of mTORC1 observed in response to azathioprine is dependent on PERK, THP-1 derived macrophages were treated in the absence or presence of a pharmacologic inhibitor of PERK. Azathioprine again caused a decrease in $p$ rpS6, and the PERK inhibitor did not significantly alter this effect (Figure 5B, panel i, compare lanes 3 and 8, and quantified in ii). To confirm PERK inhibitor activity, phosphorylation of elF2a, a well-characterized substrate of PERK, was assessed (Figure 5B, lanes 6-10 and 
quantified in iii). These results suggest that modulation of mTORC1 signaling by azathioprine

331 occurs independent of PERK.

\section{Azathioprine-induced autophagy is modulated by PERK}

333 To determine whether PERK is required for azathioprine-induced autophagy, THP-1 derived 334 macrophages were treated with azathioprine or EBSS in the absence or presence of PERK 335 inhibitor. In the presence of PERK inhibitor, azathioprine-induced autophagy was specifically attenuated (Figure 5C, compare panel ii and v, and quantified in vii) compared to EBSSinduced autophagy (Figure 5C, compare panel iii and vi, and quantified in vii). These results indicate that PERK is an important factor regulating azathioprine-induced autophagy.

\section{Azathioprine enhances clearance of intracellular AIEC}

Evidence suggests that AIEC play a putative role in $\mathrm{CD}^{37}$. Therefore, we evaluated the survival of the CD mucosa-associated AIEC strain CUICD541-10 ${ }^{27}$ in THP-1 derived macrophages. Initially, it was determined that azathioprine had no direct effect on bacterial growth (Figure S3). Azathioprine treatment did however cause a significant decrease in bacterial CFU in AIEC infected cells (Figure 6A). Furthermore, immunofluorescence analysis showed a decrease in the percentage of cells infected with bacteria (Figure $6 \mathrm{~B}$ and $\mathrm{C}$, compare panels iii and iv and quantified in v), which correlated with an increased accumulation of LC3 puncta (Figure 6C panel v) indicating that autophagy was being induced.

Infection of cells with AIEC elicits a strong inflammatory response; therefore, RT-qPCR was used to assess expression of the pro-inflammatory cytokine TNF $\alpha$ in THP-1 derived macrophages infected with AIEC. Expression was significantly up regulated by AIEC infection 
351

and this was reduced when cells were treated with azathioprine (Figure 6D, panel i). Azathioprine also reduced the expression of TNF $\alpha$ in cells treated with bacterial lipopolysaccharide (LPS) (Figure 6D, panel ii) suggesting that azathioprine may affect TNFa expression independent of decreased intracellular bacteria. These results demonstrate that azathioprine enhances the clearance of intracellular AIEC and dampens the elevated cytokine levels observed in response to infection.

\section{Azathioprine activates autophagy in PBMC and monocytes from} pediatric patients

Non-IBD, CD and UC patients were genotyped for the CD-associated NOD2 (R702W, G908R, L1007fs) and ATG16L1 T300A SNPs (Table 1). PBMC from the patient groups were then assessed for autophagy activity by flow cytometry. No significant differences in basal autophagy activity were observed, and azathioprine treatment resulted in an accumulation of autophagosome-bound LC3-II in PBMC from all patient groups (Figure 7A, panel i). Analysis of basal autophagy activity in untreated monocytes revealed no difference across the patient groups and azathioprine treatment again enhanced the accumulation of autophagosomebound LC3-II (Figure 7A, panel ii). Similar results were observed in monocyte subsets, in addition to T cells, B cells and NK cells (Figure S4). Interestingly, activation of autophagy by azathioprine was not attenuated in PBMC heterozygous or homozygous for the ATG16L1 T300A SNP (Figure 7A, panel iii). The low frequency of NOD2 SNPs present in the cohort precluded analysis of effect on azathioprine-induced autophagy. Taken together, these results demonstrate that azathioprine activates autophagy in primary cells ex vivo, supporting our in vitro findings. 


\section{Discussion}

The strong association of $C D$ with autophagy genes has led to a substantial amount research demonstrating several key functions for autophagy including regulation of the innate and adaptive immune responses, regulation of the intestinal microbiome and resolution of ERstress ${ }^{9,10}$. Impaired autophagy responses have been observed in a range of cell types derived from $C D$ patients ${ }^{10}$, and there is mounting evidence that inducing autophagy can have therapeutic benefits for the treatment of IBD in both pediatric and adult patients, with several recent studies investigating the utility of $\mathrm{mTORC} 1$ inhibitors ${ }^{12,13,38}$. Despite these advances in understanding, there is still little known about how drugs currently approved for clinical use in IBD affect autophagy function.

To evaluate current IBD drugs in the context of autophagy we initially screened for the accumulation of autophagosomes using live cell imaging and identified azathioprine and infliximab as potential modulators of autophagy. However, further investigation using flow cytometry to measure the active, lipidated form of LC3-II revealed that only azathioprine activated the autophagy pathway. Furthermore, results with the GFP-RFP-LC3 plasmid demonstrate that autophagic flux is enhanced in the presence of azathioprine.

Thiopurines are a class of immunosuppressant drugs that includes azathioprine, mercaptopurine (6-MP), and thioguanine (6-TG). It is well-established that thiopurines can inhibit DNA/RNA synthesis and deactivate pro-inflammatory T-lymphocytes ${ }^{17,18}$, however, their mechanism of action is not fully understood. Interestingly, several previous studies have also found that thiopurines can activate autophagy primarily via DNA mismatched repair processes in response to DNA damage ${ }^{9}$. To date, only one study has shown autophagy 
induction mediated by azathioprine, in colorectal carcinoma cells ${ }^{39}$. The authors suggest that

increased autophagy associated with thiopurine exposure is a survival mechanism to compensate for a primary effect on apoptosis and mitochondrial damage. Mechanistically, we show an alternative autophagy-associated process whereby azathioprine increased the expression of several UPR genes including PERK, ATF4 and CHOP as well as expression of the ER-stress chaperone protein PDI. Importantly, we demonstrate that azathioprine induces autophagy independent of apoptosis.

The ER-stress/UPR pathways play an essential role in the maintenance of intestinal homeostasis and genetic studies have identified several ER-stress/UPR genes associated with IBD ${ }^{33}$. Significantly, ER-stress levels are increased in ileal and colonic biopsies from CD patients ${ }^{40-43}$. The UPR acts to maintain ER-homeostasis, and cells that naturally secrete large amounts of protein, such as Paneth cells strongly linked to ileal CD are more susceptible to ER-stress and therefore rely heavily on the UPR ${ }^{44}$.

The UPR and autophagy are intimately linked processes ${ }^{45}$, to relieve ER-stress the UPR can induce autophagy to degrade misfolded proteins and protein aggregates ${ }^{46-50}$. Importantly, the major risk factors for CD, NOD2 and ATG16L1, functionally intersect with ER-stress and the UPR ${ }^{51}$ 22, and ER stress is a significant risk when autophagy or the UPR is not functional. The convergence between autophagy and UPR pathways provides new opportunity for the treatment of IBD and the modulation of the UPR in combination with autophagy is a promising therapeutic strategy. In support of this idea, several recent studies have demonstrated beneficial effects of enhancing UPR function for intestinal homeostasis ${ }^{53-55}$.

We also show that azathioprine modulates mTORC1 signaling. A growing body of work suggests that the UPR is regulated by diverse stimuli independently of ER-stress ${ }^{56}$ and 
stressors such as nutrient deprivation and hypoxia have been shown to activate UPR signaling and inhibit mTORC1 ${ }^{57}$. UPR activation can occur both upstream and downstream of mTORC1 57, and mTORC1 inhibitors, including rapamycin, are reported to induce PERK and elF2 $\alpha$ activation ${ }^{58}$. Our finding that PERK inhibition did not affect the mTORC1 response to azathioprine suggests that mTORC1 may be acting upstream or in parallel to PERK. Significantly, azathioprine-induced autophagy was reduced in the presence of PERK inhibitor, supporting others findings that PERK regulates LC3B and ATG5 expression ${ }^{59}$. Our results suggest that azathioprine is acting through a pathway that involves both mTORC1 and PERK, and may have synergistic outcomes; mTORC1 inhibition and PERK-elF2 $\alpha$ stimulation may work together to inhibit global protein translation, while mTORC1 inhibition together with increased expression of autophagy genes by PERK ${ }^{60,61}$, may result in a general increase in autophagic activity.

AIEC are prevalent in ileal mucosa of CD patients ${ }^{62}$ and are able to survive and replicate within macrophages, resulting in sustained inflammatory responses ${ }^{63}$ and granuloma formation ${ }^{64}$. Using a CD mucosa-associated strain of AIEC we show that azathioprine enhances the clearance of intracellular bacteria from THP-1 derived macrophages independent of direct effects on bacterial growth. Importantly, AIEC clearance correlated with increased autophagy and reduced pro-inflammatory cytokine gene expression. These combined effects of azathioprine may make it a preferred therapeutic option for subsets of patients with confirmed AIEC infection.

Finally, we carried out an observational study of a clinical cohort of children. PBMC from nonIBD patients or patients with the diagnosis of IBD were analysed to determine basal autophagy levels and response to azathioprine treatment ex vivo. Our flow cytometry results 
revealed that basal autophagy levels and azathioprine-induced autophagy were similar in all patient groups. Similar results were also observed when we analysed subsets of monocytes, T cells, B cells and NK cells. Importantly, it has been shown that autophagy is required for the differentiation of monocytes to macrophages ${ }^{65}$, and for the induction of macrophages which display immunosuppressive and wound healing properties ${ }^{66}$. Our results suggest that enhancing autophagy with azathioprine may promote the induction of macrophages with an anti-inflammatory phenotype irrespective of diagnosis.

Greater understanding of the genetic factors that underlie $C D$ pathogenesis are leading to improvements in treatment, and genotyping for key SNPs in genes involved in both the autophagy and ER-stress/UPR pathways may help to predict patient response to drugs. For example, recent studies have identified an association between ATG16L1 T300A SNP and an enhanced therapeutic effect of thiopurines ${ }^{67}$ and anti-TNF- $\alpha$ therapy ${ }^{68}$. Interestingly, the immunoregulatory effects of these drugs were associated with autophagy stimulation $66,67,69$. For instance, cytoskeletal defects that reduced mobility in autophagy-deficient DC harbouring the ATG16L1 T300A SNP were reversed by thiopurine inhibition of Ras-related C3 botulinum toxin substrate 1 (RAC1) ${ }^{67}$. Significantly, analysis of ATG16L1 genotype in our pediatric cohort revealed that the autophagy response to azathioprine was not attenuated in PBMC from patients carrying the CD-associated T300A SNP. The ATG16L1 T300A risk variant confers greater risk for $C D$ in pediatric patients than in adult patients ${ }^{70,71}$, therefore it will be interesting to compare results in PBMC from an adult cohort. Collectively, our studies suggest that patients harbouring the ATG16L1 risk variant may benefit from thiopurines via mechanisms involving RAC1 inhibition and the induction of autophagy.

\section{Conclusion}


2 3 4

466 Breakdown of the ER-stress/UPR and autophagy pathways has been strongly linked to 467 pathogenesis of IBD. Together, our results suggest that stimulation of autophagy and the UPR 468 may contribute to the therapeutic efficacy of azathioprine. Additional studies are now 469 required to further elucidate how thiopurines modulate these converging pathways; results 470 of these studies may pave the way for development of the next generation of drugs aimed at 471 modulation of the UPR in combination with autophagy.

472 Autophagy is a cell type specific process, therefore it is essential to assess whether 473 thiopurines modulate autophagy and the UPR in other cell types of direct relevance to IBD, 474 such as Paneth cells strongly linked to ileal CD. Specifically, studies conducted in cells from 475 patients with known CD-associated mutations in the genes regulating the ER-stress/UPR and 476 autophagy pathways will help to identify patients that are most likely to respond. 


\section{Acknowledgements}

482 We thank Prof Kenny Simpson (Cornell University, USA) for E.coli strains, Prof Ilan Rosenshine,

483 (The Hebrew University of Jerusalem) for the $\mathrm{x}$-light EGFP plasmid and David Hoole (Royal 484 Hospital for Sick Children) for Infliximab. We thank Dr Clare Taylor (Edinburgh Napier 485 University) for advice and continued support. This work was supported by a Crohn's in 486 Childhood Research Association (CICRA) PhD studentship to KMH and by an NHS Research 487 Scotland (NRS) Career Researcher Fellowship to PH.

\section{Authors contributions}

$489 \mathrm{KMH}, \mathrm{VC}$ and SK conducted the experiments; PH collected clinical specimens.

$490 \mathrm{KMH}$ and CS wrote the manuscript.

$491 \mathrm{KMH}, \mathrm{VC}, \mathrm{SK}, \mathrm{KS}, \mathrm{JS}, \mathrm{PGB}, \mathrm{PH}$ and CS made substantial contributions to conception and 492 design, and/or analysis and interpretation of data.

$493 \mathrm{KMH}, \mathrm{VC}, \mathrm{SK}, \mathrm{KS}, \mathrm{JS}, \mathrm{PGB}, \mathrm{PH}$ and CS reviewed the manuscript critically for important 494 intellectual content.

496 Competing interests and financial disclosure

497 The authors declare that we have no competing interests. We have no financial

498 relationships with any organisations that might have an interest in the submitted work. 
5

2

3

4

5503

504

9505

10506

11

12

13

1. NHS CB. 2013/14 NHS Standard Contract for Colorectal: Complex Inflammatory Bowel Disease (Adult). 2013.

2. Boyapati R, Satsangi J, Ho GT. Pathogenesis of Crohn's disease. F1000Prime Rep. 2015;7:44.

3. Frank DN, Robertson $\mathrm{CE}$, Hamm CM, et al. Disease phenotype and genotype are associated with shifts in intestinal-associated microbiota in inflammatory bowel diseases. Inflamm. Bowel Dis. 2011;17:179-184.

4. Darfeuille-Michaud A, Boudeau J, Bulois $P$, et al. High prevalence of adherent-invasive Escherichia coli associated with ileal mucosa in Crohn's disease. Gastroenterology. 2004;127:412-421.

5. Lange KM de, Moutsianas L, Lee JC, et al. Genome-wide association study implicates immune activation of multiple integrin genes in inflammatory bowel disease. Nat. Genet. 2017;49:256-261.

6. Franke A, McGovern DP, Barrett JC, et al. Genome-wide meta-analysis increases to 71 the number of confirmed Crohn's disease susceptibility loci. Nat Genet. 2010;42:1118-25.

7. Lamb CA, Yoshimori T, Tooze SA. The autophagosome: origins unknown, biogenesis complex. Nat. Rev. Mol. Cell Biol. 2013;14:759-774.

8. Deretic V, Saitoh T, Akira S. Autophagy in infection, inflammation and immunity. Nat ReV Immunol. 2013;13:722-37.

9. Hooper KM, Barlow PG, Stevens C, et al. Inflammatory Bowel Disease Drugs: A Focus on Autophagy. J. Crohns Colitis. 2017;11:118-127.

10. Ke P, Shao B-Z, Xu Z-Q, et al. Intestinal Autophagy and Its Pharmacological Control in Inflammatory Bowel Disease. Front. Immunol. 2017;7.

11. Massey DC, Bredin F, Parkes M. Use of sirolimus (rapamycin) to treat refractory Crohn's disease. Gut. 2008;57:1294-6.

12. Dumortier J, Lapalus M-G, Guillaud O, et al. Everolimus for refractory Crohn's disease: A case report: Inflamm. Bowel Dis. 2008;14:874-877.

13. Mutalib M, Borrelli O, Blackstock S, et al. The use of sirolimus (rapamycin) in the management of refractory inflammatory bowel disease in children. J. Crohns Colitis. 2014;8:1730-1734.

14. Bernstein CN, Loftus EV Jr, Ng SC, et al. Hospitalisations and surgery in Crohn's disease. Gut. 2012;61:622-9. 
535

1536

2

3

4537

5538

6

7539

8

9540

10541

11

12542

13

15. Bassi A, Dodd S, Williamson $P$, et al. Cost of illness of inflammatory bowel disease in the UK: a single centre retrospective study. Gut. 2004;53:1471-8.

16. Denson LA, Long MD, McGovern DP, et al. Challenges in IBD research: update on progress and prioritization of the CCFA's research agenda. Inflamm Bowel Dis. 2013;19:677-82.

17. Tiede I, Fritz G, Strand S, et al. CD28-dependent Rac1 activation is the molecular target of azathioprine in primary human CD4+ T lymphocytes. J. Clin. Invest. 2003;111:11331145.

18. Swann PF, Waters TR, Moulton DC, et al. Role of Postreplicative DNA Mismatch Repair in the Cytotoxic Action of Thioguanine. Science. 1996;273:1109-1111.

19. Kabeya $\mathrm{Y}$, Mizushima N, Ueno T, et al. LC3, a mammalian homologue of yeast Apg8p, is localized in autophagosome membranes after processing. EMBO J. 2000;19:5720-5728.

20. Kimura S, Noda T, Yoshimori T. Dissection of the autophagosome maturation process by a novel reporter protein, tandem fluorescent-tagged LC3. Autophagy. 2007;3:452-460.

21. Mills E, Baruch K, Aviv G, et al. Dynamics of the type III secretion system activity of enteropathogenic Escherichia coli. MBio. 2013;4:e00303-13.

22. Schindelin J, Arganda-Carreras I, Frise E, et al. Fiji: an open-source platform for biologicalimage analysis. Nat. Methods. 2012;9:676-682.

23. Eng KE, Panas MD, Karlsson Hedestam GB, et al. A novel quantitative flow cytometrybased assay for autophagy. Autophagy. 2010;6:634-641.

24. Jacob MC, Favre M, Bensa JC. Membrane cell permeabilization with saponin and multiparametric analysis by flow cytometry. Cytometry. 1991;12:550-558.

25. Vandesompele J, De Preter K, Pattyn F, et al. Accurate normalization of real-time quantitative RT-PCR data by geometric averaging of multiple internal control genes. Genome Biol. 2002;3:research0034.

26. Livak KJ, Schmittgen TD. Analysis of relative gene expression data using real-time quantitative PCR and the 2(-Delta Delta C(T)) Method. Methods San Diego Calif. 2001;25:402-408.

27. Simpson KW, Dogan B, Rishniw M, et al. Adherent and invasive Escherichia coli is associated with granulomatous colitis in boxer dogs. Infect. Immun. 2006;74:4778-4792.

28. Levine A, Koletzko S, Turner D, et al. ESPGHAN revised porto criteria for the diagnosis of inflammatory bowel disease in children and adolescents. J. Pediatr. Gastroenterol. Nutr. 2014;58:795-806.

29. Musiwaro $P$, Smith $M$, Manifava $M$, et al. Characteristics and requirements of basal autophagy in HEK 293 cells. Autophagy. 2013;9:1407-1417. 
569

1570

2

3

4571

5572

6

7573

874

10

30. Klionsky DJ, Abdelmohsen K, Abe A, et al. Guidelines for the use and interpretation of assays for monitoring autophagy (3rd edition). Autophagy. 2016;12:1-222.

31. Mizushima N, Yoshimori T, Levine B. Methods in Mammalian Autophagy Research. Cell. 2010;140:313-326.

32. Mariño G, Niso-Santano M, Baehrecke EH, et al. Self-consumption: the interplay of autophagy and apoptosis. Nat. Rev. Mol. Cell Biol. 2014;15:81-94.

33. McGuckin MA, Eri RD, Das I, et al. ER stress and the unfolded protein response in intestinal inflammation. Am. J. Physiol. - Gastrointest. Liver Physiol. 2010;298:G820-G832.

34. Laplante M, Sabatini DM. mTOR Signaling in Growth Control and Disease. Cell. 2012;149:274-293.

35. Avivar-Valderas A, Bobrovnikova-Marjon E, Diehl JA, et al. Regulation of autophagy during ECM detachment is linked to a selective inhibition of mTORC1 by PERK. Oncogene. 2013;32:4932-4940.

36. Ji G, Yu N, Xue X, et al. PERK-mediated Autophagy in Osteosarcoma Cells Resists ER Stressinduced Cell Apoptosis. Int. J. Biol. Sci. 2015;11:803-812.

37. Palmela C, Chevarin C, Xu Z, et al. Adherent-invasive Escherichia coli in inflammatory bowel disease. Gut. 2017:gutjnl-2017-314903.

38. Anon. Massey, D C OBredin, FParkes, MengG0800383/Medical Research Council/United KingdomEnglandGut. 2008 Sep;57(9):1294-6. doi.

39. Chaabane W, Appell ML, Chaabane W, et al. Interconnections between apoptotic and autophagic pathways during thiopurine-induced toxicity in cancer cells: the role of reactive oxygen species. Oncotarget. 2016;7:75616-75634.

40. Deuring JJ, de Haar C, Koelewijn CL, et al. Absence of ABCG2-mediated mucosal detoxification in patients with active inflammatory bowel disease is due to impeded protein folding. Biochem. J. 2012;441:87-93.

41. Kaser A, Lee A-H, Franke A, et al. XBP1 Links ER Stress to Intestinal Inflammation and Confers Genetic Risk for Human Inflammatory Bowel Disease. Cell. 2008;134:743-756.

42. Rolhion N, Barnich N, Bringer M-A, et al. Abnormally expressed ER stress response chaperone Gp96 in CD favours adherent-invasive Escherichia coli invasion. Gut. 2010;59:1355-1362.

43. Shkoda A, Ruiz PA, Daniel H, et al. Interleukin-10 Blocked Endoplasmic Reticulum Stress in Intestinal Epithelial Cells: Impact on Chronic Inflammation. Gastroenterology. 2007;132:190-207.

44. Adolph TE, Tomczak MF, Niederreiter $L$, et al. Paneth cells as a site of origin for intestinal inflammation. Nature. 2013;503(7475):272-6. 
45. Hooper KM, Barlow PG, Henderson P, et al. Interactions Between Autophagy and the Unfolded Protein Response: Implications for Inflammatory Bowel Disease. Inflamm. Bowel Dis. 2018; doi: 10.1093/ibd/izy380.

46. Hart LS, Cunningham JT, Datta T, et al. ER stress-mediated autophagy promotes Mycdependent transformation and tumor growth. J. Clin. Invest. 2012;122:4621-4634.

47. Li J, Ni M, Lee B, et al. The unfolded protein response regulator GRP78/BiP is required for endoplasmic reticulum integrity and stress-induced autophagy in mammalian cells. Cell Death Differ. 2008;15:1460-1471.

48. Ogata M, Hino S, Saito A, et al. Autophagy is activated for cell survival after endoplasmic reticulum stress. Mol Cell Biol. 2006;26:9220-31.

49. Shimodaira $Y$, Takahashi S, Kinouchi $Y$, et al. Modulation of endoplasmic reticulum (ER) stress-induced autophagy by C/EBP homologous protein (CHOP) and inositol-requiring enzyme $1 \alpha(\operatorname{IRE} 1 \alpha)$ in human colon cancer cells. Biochem. Biophys. Res. Commun. 2014;445:524-533.

50. Wang $\mathrm{W}$, Kang $\mathrm{H}$, Zhao $\mathrm{Y}$, et al. Targeting autophagy sensitizes BRAF-mutant thyroid cancer to vemurafenib. J. Clin. Endocrinol. Metab. 2016:jc.2016-1999.

51. Keestra-Gounder AM, Byndloss MX, Seyffert N, et al. NOD1 and NOD2 signalling links ER stress with inflammation. Nature. 2016;532:394-397.

52. Deuring JJ, Fuhler GM, Konstantinov SR, et al. Genomic ATG16L1 risk allele-restricted Paneth cell ER stress in quiescent Crohn's disease. Gut. 2014;63:1081-1091.

53. Cao SS, Zimmermann EM, Chuang B, et al. The Unfolded Protein Response and Chemical Chaperones Reduce Protein Misfolding and Colitis in Mice. Gastroenterology. 2013;144:989-1000.e6.

54. Boyce M, Bryant KF, Jousse C, et al. A selective inhibitor of elF2alpha dephosphorylation protects cells from ER stress. Science. 2005;307:935-939.

55. Okazaki T, Nishio A, Takeo M, et al. Inhibition of the dephosphorylation of eukaryotic initiation factor $2 \alpha$ ameliorates murine experimental colitis. Digestion. 2014;90:167178.

56. Rutkowski DT, Hegde RS. Regulation of basal cellular physiology by the homeostatic unfolded protein response. J. Cell Biol. 2010;189:783-794.

57. Appenzeller-Herzog C, Hall MN. Bidirectional crosstalk between endoplasmic reticulum stress and mTOR signaling. Trends Cell Biol. 2012;22:274-282.

58. Freis $P$, Bollard J, Lebeau J, et al. mTOR inhibitors activate PERK signaling and favor viability of gastrointestinal neuroendocrine cell lines. Oncotarget. 2017;8:20974-20987. 
59. Rouschop KMA, Beucken $T$ van den, Dubois $L$, et al. The unfolded protein response protects human tumor cells during hypoxia through regulation of the autophagy genes MAP1LC3B and ATG5. J. Clin. Invest. 2010;120:127-141.

60. B'chir W, Maurin A-C, Carraro V, et al. The elF2 $\alpha$ /ATF4 pathway is essential for stressinduced autophagy gene expression. Nucleic Acids Res. 2013;41:7683-7699.

61. Kouroku Y, Fujita E, Tanida I, et al. ER stress (PERK/elF2 [alpha] phosphorylation) mediates the polyglutamine-induced LC3 conversion, an essential step for autophagy formation. Cell Death Differ. 2007;14:230.

62. Thomazini CM, Samegima DAG, Rodrigues MAM, et al. High prevalence of aggregative adherent Escherichia coli strains in the mucosa-associated microbiota of patients with inflammatory bowel diseases. Int. J. Med. Microbiol. 2011;301:475-479.

63. Lapaquette P, Bringer M-A, Darfeuille-Michaud A. Defects in autophagy favour adherentinvasive Escherichia coli persistence within macrophages leading to increased proinflammatory response. Cell. Microbiol. 2012;14:791-807.

64. Meconi S, Vercellone A, Levillain F, et al. Adherent-invasive Escherichia coli isolated from Crohn's disease patients induce granulomas in vitro. Cell. Microbiol. 2007;9:1252-1261.

65. Zhang Y, Morgan MJ, Chen K, et al. Induction of autophagy is essential for monocytemacrophage differentiation. Blood. 2012;119:2895-2905.

66. Levin AD, Koelink PJ, Bloemendaal FM, et al. Autophagy Contributes to the Induction of Anti-TNF Induced Macrophages. J. Crohns Colitis. 2016;10:323-329.

67. Wildenberg ME, Koelink PJ, Diederen K, et al. The ATG16L1 risk allele associated with Crohn's disease results in a Rac1-dependent defect in dendritic cell migration that is corrected by thiopurines. Mucosal Immunol. 2017;10:352-360.

68. Wildenberg M, Levin A, Vos C, et al. P668 ATG16L1 genotype is associated with response to anti-TNF in vitro. J. Crohns Colitis. 2013;7:S279.

69. Vos ACW, Wildenberg ME, Arijs I, et al. Regulatory macrophages induced by infliximab are involved in healing in vivo and in vitro. Inflamm. Bowel Dis. 2012;18:401-408.

70. Amre DK, Mack DR, Morgan K, et al. Autophagy gene ATG16L1 but not IRGM is associated with Crohn's disease in Canadian children. Inflamm. Bowel Dis. 2009;15:501-507.

71. Zhang H-F, Qiu L-X, Chen Y, et al. ATG16L1 T300A polymorphism and Crohn's disease susceptibility: evidence from 13,022 cases and 17,532 controls. Hum. Genet. 2009;125:627-631.

72. Levine A, Griffiths A, Markowitz J, et al. Pediatric modification of the Montreal classification for inflammatory bowel disease: the Paris classification. Inflamm. Bowel Dis. 2011;17:1314-1321. 
$1^{674}$

2

3

4

5

9

10

11

12

13

14

15

16

17

18

19

20

21

22

23

24

25

26

27

28

29

30

31

32

33

34

35

36

37

38

39

40

41

42

43

44

45

46

47

48

49

50

51

52

53

54

55

56

57

58

59

60

61

62

63

64

65 


\section{Abbreviations}

2

3

4

8

11

12

13

14
Aminosalicylates

Adherent Invasive $E$. coli

Activating transcription factor 6

Autophagy-related protein 16-1

Bafilomycin A1

Binding immunoglobulin protein/78-kDa glucose-regulated protein

Crohn's disease

Colony forming units

4',6'-diamidino-2-phenylindole

Dendritic cell

Dulbecco's modified Eagle medium

Earle's Balanced Salt Solution

Escherichia coli

Eukaryotic translation initiation factor $2 \mathrm{~A}$

Endoplasmic Reticulum

Foetal bovine serum

Gastrointestinal tract

Genome-wide association studies

Inflammatory Bowel Disease

IBD-unclassified

isopropyl $\beta$-D-1-thiogalactopyranosid

Inositol-requiring enzyme $1 \alpha$ 
1

2 3 4 6 7 8

9

10

698 IRGM Immunity-related GTPase family M protein

699 LC3 MAP1LC3B

700 mTORC1 Mechanistic target of rapamycin

$701 \mathrm{MOI} \quad$ Multiplicity of infection

702 NOD2 Nucleotide-binding oligomerisation domain-containing protein 2

703 PBMC Peripheral blood mononuclear cells

704 PDI Protein disulphide isomerase

705 PERK Protein kinase R (PKR)-like endoplasmic reticulum kinase

706 PFA Paraformaldehyde

707 PMA Phorbol myristate acetate

708 RAC1 Ras-related C3 botulinum toxin substrate 1

709 p-rpS6 Phosphorylated ribosomal protein S6

710 TNF- $\alpha \quad$ Tumour necrosis factor alpha

711 UC Ulcerative colitis

712 UPR Unfolded protein response

713 XBP1 $\quad x$-box-binding protein 1

\section{Table 1. Pediatric patient genotype}

716 CD Crohn's disease, UC Ulcerative colitis, IBDU IBD unclassified. ATG16L1 T300A genotype:

717 rs2241880. *NOD2 genotype SNPs: L1007fs (rs2241880), G908R (rs2066845) and R702W 718 (rs2066844). 


\begin{tabular}{|c|c|c|c|c|}
\hline & Non-IBD & CD & UC & IBDU \\
\hline Cohort $(n=29)$ & 9 & 12 & 7 & 1 \\
\hline \multicolumn{5}{|c|}{ Genotype ATG16L1 T300A (n=26) } \\
\hline Wildtype & 1 & 2 & 1 & N/A \\
\hline Heterozygous risk & 3 & 6 & 3 & N/A \\
\hline Homozygous risk & 3 & 4 & 3 & N/A \\
\hline \multicolumn{5}{|c|}{ Genotype NOD2 L1007fs (n=27) } \\
\hline Wildtype & 8 & 12 & 7 & N/A \\
\hline Heterozygous risk & 0 & 0 & 0 & N/A \\
\hline Homozygous risk & 0 & 0 & 0 & N/A \\
\hline \multicolumn{5}{|c|}{ Genotype NOD2 G908R ( $\mathrm{n}=27)$} \\
\hline Wildtype & 8 & 11 & 7 & N/A \\
\hline Heterozygous risk & 0 & 0 & 0 & N/A \\
\hline Homozygous risk & 0 & 1 & 0 & N/A \\
\hline \multicolumn{5}{|c|}{ Genotype NOD2 R702W (n=27) } \\
\hline Wildtype & 7 & 11 & 6 & N/A \\
\hline Heterozygous risk & 0 & 1 & 0 & N/A \\
\hline Homozygous risk & 1 & 0 & 1 & N/A \\
\hline
\end{tabular}




\section{Figure Legends}

2 3

\section{Figure 1: Modulation of autophagy by current IBD drugs}

722 HEK293 GFP-LC3 cells were untreated (i) or treated with DMSO (ii), EBSS (iii), 120 $\mu M$ 723 Azathioprine (iv and $\mathrm{x}$ ), $100 \mu \mathrm{g} / \mathrm{ml}$ Infliximab ( $v$ and $\mathrm{xi}$ ), $120 \mu \mathrm{M}$ Methotrexate (vi and xii), $724100 \mu \mathrm{M}$ methylprednisolone (vii and xiii) or $150 \mu \mathrm{M}$ sulfasalazine (viii and xiv) and assessed by 725 live-cell confocal microscopy up to $12 \mathrm{hr}$. 50 cells counted from 3 fields of view and percentage 726 cells with $>5$ GFP-LC3 puncta quantified (+/- SEM) for all time-points ( $x$-xiv) with 6hr time727 point highlighted $* * p<0.01 ; * * * * p<0.0001$ (ix).

728 Figure 2: Azathioprine activates the autophagy pathway

729 A) HEK293 GFP-LC3 cells were treated for 6hr with 160nM BafA1 only or BafA1 plus EBSS (i), 730 BafA1 plus $120 \mu \mathrm{M}$ azathioprine (ii) or BafA1 plus $100 \mu \mathrm{g} / \mathrm{ml}$ Infliximab (iii). Geometric mean 731 of GFP-LC3-II intensity was assessed by flow cytometry. Fold-change in GFP-LC3-II geometric 732 mean from BafA1 only was quantified (+/-SEM) (iv).

733 B) HEK293 cells were transfected with GFP-RFP-LC3 plasmid and left untreated (i, v, ix) or 734 treated with 160nM BafA1 (ii, vi, x), EBSS (iii, vii, xi), or 120 $\mu$ M azathioprine (iv, viii, xii) for 6hr, 735 and imaged by confocal microscopy. Percentage of transfected cells exhibiting $>10$ LC3 puncta 736 was quantified (+/-SEM) $(n=5)(x i i i) * p<0.05$. Number of (RFP+GFP+) and (RFP+GFP-) LC3 737 puncta were quantified (+/-SEM) $(n=5)(x i v) * * p<0.01, * * * p<0.001$.

738 Figure 3: Azathioprine induces autophagosome accumulation independent of apoptosis 
A) THP-1-derived macrophages were untreated (i), or treated with DMSO (ii), EBSS (iii), or $120 \mu \mathrm{M}$ azathioprine (iv) for $6 \mathrm{hr}$. Cells were then immunostained for endogenous LC3 and imaged by confocal microscopy. 30 cells were counted from 3 fields of view and percentage cells with $>5$ GFP-LC3 puncta quantified (+/- SEM) $* p<0.05 ; * *<0.01(v)$.

B) THP-1-derived macrophages were left untreated (i, v) or treated with DMSO (ii, vi), 120 $\mu \mathrm{M}$ azathioprine (iii, vii) or $30 \mu \mathrm{M}$ camptothecin (iv, viii) for $6 \mathrm{hr}$ (i-iv) and $24 \mathrm{hr}$ (v-vii). Cells were stained with Annexin-V/PI and analysed by flow cytometry. Mean percentage population in each quadrant was quantified (+/- SEM) ${ }^{* *}$ p value $<0.01,{ }^{* * *}$ p value $<0.001, * * * * p$ value $<0.0001$ (ix) compared to untreated for corresponding time-point and quadrant.

\section{Figure 4: Azathioprine stimulates the UPR}

THP-1-derived macrophages were left untreated, or treated with DMSO, $60 \mu \mathrm{M}$ or $120 \mu \mathrm{M}$ azathioprine, or EBSS for 2, 4, 6, 16 and 24hr. Expression of PERK was determined by RT-qPCR and is displayed in $\log _{10}$ scale (i). 6hr time-point, including treatment with $0.5 \mu \mathrm{g} / \mathrm{ml}$ Brefeldin A quantification (+/- SEM) is shown for PERK (ii), ATF4 (iii), CHOP (iv), PDI (vi) and BiP (vii). Using $2^{\text {-ddct }}: * p<0.05, * * p<0.01, * * * * p<0.0001$

Figure 5: Azathioprine modulates autophagy via mechanisms involving mTORC1 and PERK.

A) THP-1-derived macrophages were left untreated or treated with DMSO, azathioprine (60$120 \mu \mathrm{M})$, EBSS or the mTORC1 inhibitor rapamycin $(100 \mathrm{nM})$ for $6 \mathrm{hr}$. Protein lysates were immunoblotted for rpS6, phosphorylated rpS6 (p-rpS6 (S235/236)) and actin (i). rpS6/p-rpS6 density normalized to actin was quantified as a percentage of untreated (ii). Representative blot from $n=3$. 
760

B) THP-1-derived macrophages were left untreated, or treated with DMSO, $120 \mu \mathrm{M}$ azathioprine, EBSS, or $0.5 \mu \mathrm{g} / \mathrm{ml}$ Brefeldin A for $6 \mathrm{hr}$ in the absence or presence of PERK inhibitor. Protein lysates were immunoblotted for $\mathrm{rpS6}$, phosphorylated rpS6 (p-rpS6 (S235/236)), phosphorylated elF2 $\alpha$ (p-elF2 $\alpha$ (S51) and tubulin (i). rpS6/p-rpS6 density (ii) and p-elF2 $\alpha$ density (iii) normalized to tubulin was quantified. Representative blot from $n=3$.

C) THP-1-derived macrophages were left untreated, or treated with $120 \mu \mathrm{M}$ azathioprine, or EBSS for $6 \mathrm{hr}$ in the absence (i-iii) and presence (iv-vi) of PERK inhibitor and immunostained for LC3. 100 cells were counted per treatment and percentage cells with >5 GFP-LC3 puncta quantified (+/- SEM) *p $<0.05$ (vii).

Figure 6: Azathioprine enhances clearance of intracellular AIEC and dampens the inflammatory response.

A) THP-1-derived macrophages were infected with AIEC and gentamicin protection assay performed in the absence or presence of DMSO or $120 \mu \mathrm{M}$ azathioprine. CFU/ml of cell lysates were enumerated, and fold-change mean $\mathrm{CFU} / \mathrm{ml}$ from untreated was calculated (+/- SEM), $* * p<0.01$.

B and C) THP-1-derived macrophages were infected with AIEC-mCherry and gentamicin protection assay performed in the absence or presence of DMSO or $120 \mu \mathrm{M}$ azathioprine. Fluorescent AIEC were enumerated and percentage cells with intracellular bacteria quantified (+/- SEM), *p $<0.05, * * p<0.01, * * * p<0.001$

D) THP-1-derived macrophages were infected with AIEC (i) or treated with $200 \mathrm{ng} / \mathrm{ml}$ LPS (ii) and left untreated or treated with DMSO or $120 \mu \mathrm{M}$ azathioprine for 6hr. Expression of TNF- $\alpha$ 
was normalized to untreated and mean fold-change expression quantified from $n=3$ (+/- SEM)

782 (i-ii). Using $2^{- \text {ddct }: * p<0.05 . ~}$

Figure 7: Azathioprine activates autophagy in PBMC and monocytes from pediatric patients.

784 PBMC isolated from non-IBD control and IBD patients were left untreated or treated with

\section{Table S4: Pediatric patient demographics} populations and for endogenous LC3-II. Geometric mean of LC3-II intensity was quantified by flow cytometry and mean of LC3-II geometric mean (+/-SEM) is shown for total PBMC (I, iii) and total monocytes (ii) for each non-IBD and IBD patient group (i-ii) and each ATG16L1 genotype (iii). One-way ANOVA with Tukey's multiple comparison was used to compare LC3II geometric mean between patient groups in untreated cells. Within each patient group paired, two tailed t test was used to compare LC3-II geometric mean of untreated and azathioprine-treated cells. ${ }^{*} p<0.05,{ }^{* *} p<0.01$

\section{Table S1: Concentration and manufacturer details of reagents used for cell treatments.}

Working concentrations were diluted in appropriate growth media.

Table S2: Antibody details

WB western blot, IF immunofluorescent staining, $F$ flow cytometry, IHC immunohistochemistry. All primary and secondary antibodies were prepared in 1\% FBS or goat serum.

\section{Table S3: qPCR Primer Details}

$F W$ forward and $R V$ reverse primer sequences. 
$C D$ Crohn's disease, UC Ulcerative colitis, IBDU IBD unclassified. SD Standard deviation. *NonIBD diagnosis included normal (4 patients), mild constipation (1 patient), Irritable Bowel Syndrome (IBS) (3 patients) and threadworms (1 patient). aparis Classification for CD: L1 ileal, L2 colonic, $L 3$ ileocolonic, $L 4 a$ upper disease proximal to ligament of Treitz; B1 non-stricturing and non-penetrating, B2 stricturing, B3 penetrating, $p$ perianal disease modifier ${ }^{72}$. ${ }^{6}$ Paris Classification for UC: E1 ulcerative proctitis, E2 left-sided UC (distal to splenic flexure), E3 extensive (hepatic flexure distally), E4 pancolitis (proximal to hepatic flexure); SO never severe, $\mathrm{S} 1$ ever severe as defined by Pediatric Ulcerative Colitis Activity Index (PUCAI) ${ }^{72} .5-$ ASA 5-aminosalisylates.

\section{Figure S1: GFP-LC3 Flow Cytometry in HEK293 GFP-LC3 cells.}

Schematic diagram showing cell permeabilization with $0.05 \%$ saponin to remove cytosolic GFP-LC3 to allow flow cytometery analysis ${ }^{23}$ (i). HEK293 GFP-LC3 cells were either untreated or treated with 160nM bafilomycin for 6 hours. Cells were washed without (ii) or with (iii) cell permeabilization with $0.05 \%$ saponin to remove cytosolic GFP-LC3 before fixation. Geometric mean of GFP-LC3 fluorescent intensity of cells was quantified by flow cytometry and analysed using FlowJo software (ii-iii).

Figure S2: Differentially Expressed Genes from $\mathrm{RT}^{2}$ Profiler ${ }^{\mathrm{TM}} \mathrm{PCR}$ Array for Human Autophagy Genes when treated with Azathioprine

THP-1-derived macrophages were untreated or treated with $120 \mu \mathrm{M}$ azathioprine for 6 hours. mRNA was extracted and converted to cDNA for RT-qPCR analysis using the RT ${ }^{2}$ Profiler $^{\mathrm{TM}}$ PCR Array for Human Autophagy genes according to manufacturer instructions. The calibrating sample was untreated cells and relative expression for azathioprine treatment is displayed as fold-change, with upregulated genes calculated as $2^{\text {-ddCT }}$ and downregulated genes as $2^{\text {ddCT}}$. Differentially expressed genes are shown, with 1.5-fold change in expression considered as the threshold for differential expression.

Figure S3: Effect of azathioprine on growth of AIEC, clearance of intracellular AIEC and proinflammatory cytokine responses 
829 LB broth was inoculated from an overnight culture of AIEC to an optical density of 0.05 at $830600 \mathrm{~nm}$. The cultures were untreated, or treated with DMSO, or $120 \mu \mathrm{M}$ of azathioprine and 831 incubated at $37^{\circ} \mathrm{C}$ with shaking at 200RPM. Optical density at $600 \mathrm{~nm}$ was measured every 0.5 832 hours and plotted in logarithmic scale to show growth phases.

833 Figure S4: Azathioprine activates autophagy in monocyte subsets, T cells, B cells and NK 834 cells from pediatric patients.

835 PBMC isolated from non-IBD control and IBD patients were left untreated or treated with $836120 \mu \mathrm{M}$ azathioprine for 6h. PBMC were stained with surface markers for classification into 837 populations and for endogenous LC3-II. Geometric mean of LC3-II intensity was quantified by 838 flow cytometry and mean of LC3-II geometric mean (+/-SEM) is shown for classical monocytes 839 (i), intermediate monocytes (ii), non-classical monocytes (iii), T cells (iv), B cells (v) and NK 840 cells (vi) for each non-IBD and IBD patient group. One-way ANOVA with Tukey's multiple 841 comparison was used to compare LC3-II geometric mean between patient groups in 842 untreated cells. Within each patient group paired, two tailed t test was used to compare LC3843 II geometric mean of untreated and azathioprine-treated cells. ${ }^{*} p<0.05,{ }^{* *} p<0.01$. 
1 The inflammatory bowel disease drug azathioprine induces

2 autophagy via mTORC1 and the unfolded protein response

3 sensor PERK

4 Kirsty M. Hooper, $\mathrm{PhD}^{1}$, Victor Casanova, $\mathrm{PhD}^{1}$, Sadie Kemp, BSc${ }^{1}$, Katherine A.

5 Staines, $\mathrm{PhD}^{1}$, Jack Satsangi, $\mathrm{FRSE}^{2,5}$, Peter G. Barlow, $\mathrm{PhD}^{1}$, Paul Henderson, $6 \mathrm{MBChB}, \mathrm{PhD}^{3,4}$ and Craig Stevens, $\mathrm{PhD}^{1 \uparrow *}$.

7 1. School of Applied Sciences, Edinburgh Napier University, Sighthill Campus, Sighthill Court, 8 Edinburgh, EH11 4BN.

9 2. Centre for Genomic \& Experimental Medicine, University of Edinburgh, Western General 10 Hospital Campus, Crewe Road, Edinburgh EH4 2XU.

11 3. Child Life and Health, University of Edinburgh, Edinburgh, EH9 1UW.

12 4. Department of Pediatric Gastroenterology and Nutrition, Royal Hospital for Sick Children, 13 Edinburgh, EH9 1LF.

14 5. Translational Gastroenterology Unit, Nuffield Department of Medicine, John Radcliffe 15 Hospital, Oxford OX3 9DU. 
17 Short title: The CD drug azathioprine induces autophagy

18

19 Address for correspondence

*Dr Craig Stevens

21 School of Applied Sciences, Edinburgh Napier University, Sighthill Campus, Sighthill Court,

22 Edinburgh, EH11 4BN.

23 Email: $\underline{\text { C.Stevens@napier.ac.uk }}$

24 Tel: 00441314552930

25

26 Summary

27

28 The aim of this study was to evaluate the effect of current inflammatory bowel disease drugs

29 on autophagy and investigate molecular mechanisms of action and functional outcomes in

30 relation to this cellular process. 


\section{Abstract}

33 Background: Genetic studies have strongly linked autophagy to Crohn's disease (CD) and

34 stimulating autophagy in CD patients may be therapeutically beneficial. The aim of this study

35 was to evaluate the effect of current inflammatory bowel disease (IBD) drugs on autophagy

36 and investigate molecular mechanisms of action and functional outcomes in relation to this

37 cellular process.

Methods: Autophagy marker LC3 was evaluated by confocal fluorescence microscopy and

flow cytometry. Drug mechanism of action was investigated by PCR Array with changes in signaling pathways examined by immunoblot and RT-qPCR. Clearance of adherent-invasive

41 Escherichia coli (AIEC) and levels of pro-inflammatory cytokine tumour necrosis factor alpha

42 (TNF $\alpha$ ) were evaluated by gentamicin protection assays and RT-qPCR respectively. LC3 was analysed in peripheral blood mononuclear cells (PBMC) from pediatric patients by flow cytometry.

Results: Azathioprine induces autophagy via mechanisms involving modulation of mechanistic target of rapamycin (mTORC1) signaling and stimulation of the unfolded protein response (UPR) sensor PERK. Induction of autophagy with azathioprine correlated with the enhanced clearance of AIEC and dampened AIEC-induced increases in TNF $\alpha$. Azathioprine induced significant increase in autophagosome bound LC3-II in PBMC populations ex vivo, supporting in vitro findings. In patients, the CD-associated ATG16L1 T300A single-nucleotide polymorphism did not attenuate azathioprine induction of autophagy. 
52 Conclusions: Modulation of autophagy via mTORC1 and the UPR may contribute to the

53 therapeutic efficacy of azathioprine in IBD.

54 Keywords: Azathioprine, autophagy, mTORC1, unfolded protein response, Adherent-invasive 55 E.coli. 


\section{Introduction}

59 The inflammatory bowel diseases (IBD), Crohn's disease (CD), ulcerative colitis (UC) and IBDunclassified (IBDU), are characterized by chronic inflammation of the gastrointestinal (GI) tract and have a prevalence of up to 400 per 100,000 people in the United Kingdom ${ }^{1}$. The pathogenesis of IBD is multifactorial in nature, with genetic predisposition, breakdown of the intestinal epithelial barrier, and concomitant interaction with environmental triggers in the lumen contributing to disease ${ }^{2}$. A dysregulated immune response to intestinal microflora has been heavily implicated, and examination of the disease-associated microbiome has identified several potentially causative agents ${ }^{3}$. Most notably Escherichia coli (E.coli) strains with an adherent and invasive phenotype (AIEC) have been consistently isolated by independent investigators from CD patients with ileal disease ${ }^{4}$.

Genome-wide association studies (GWAS) have identified 240 IBD susceptibility loci to date 5 and have confirmed association with previously recognized susceptibility genes including Nucleotide-binding oligomerisation domain-containing protein 2 (NOD2). Amongst genes identified are several linked to autophagy including autophagy-related protein (ATG)16L1, Immunity-related GTPase family M protein (IRGM) and leucine rich repeat kinase $2\left(\right.$ LRRK2) ${ }^{6}$. Autophagy is an intracellular homeostatic process that involves the formation and maturation of double membrane vesicles, known as autophagosomes, which engulf cargo that is degraded upon fusion with lysosomes ${ }^{7}$. Autophagy can be an important survival mechanism that is induced in response to a myriad of stresses. Autophagy plays an essential role in the innate and adaptive immune responses and the timely resolution of inflammation ${ }^{8}$, and loss of immune regulation is a key event leading to the chronic inflammation observed in $C D{ }^{9}$. Notably, impaired autophagy responses have been observed in a range of cell types derived 
81 from CD patients including the specialized intestinal epithelial cells (IECS) Paneth cells and

82 goblet cells, and leukocytes, such as macrophages and dendritic cells (DC) ${ }^{10}$.

83 Evidence suggests that inducing autophagy may have therapeutic benefit for the treatment

84 of IBD ${ }^{9}$. Mechanistic target of rapamycin complex 1 (mTORC1) is a master regulator of cell

85 growth and a potent inhibitor of autophagy ${ }^{10}$, therefore inhibition of mTORC1 with

86 rapamycin or its analogues, sirolimus and everolimus, strongly induces autophagy. In

87 previously reported case studies sirolimus improved symptoms and intestinal healing in a

88 patient with severe refractory $C D^{11}$ and everolimus controlled symptoms for 18 months in a

89 patient with refractory UC ${ }^{12}$. In a study of refractory pediatric IBD, sirolimus induced clinical

90 remission in $45 \%$ of UC patients and $100 \%$ of CD patients ${ }^{13}$.

91 Drugs currently approved for clinical use for IBD, including corticosteroids,

92 immunomodulators, aminosalicylates (5-ASAs) and biologics, target the immune system to

93 reduce inflammation and induce remission, however response to treatment often diminishes

94 over time, with $10-35 \%$ of CD patients requiring surgery within a year of diagnosis and up to

$9561 \%$ by 10 years ${ }^{14}$. A National Health Service review estimated IBD treatment costs of $f 720$

96 million $(\$ 940 \mathrm{~m})$ per year in the United Kingdom alone ${ }^{1}$, with roughly a quarter of these costs

97 directly attributed to drug treatments ${ }^{15}$. The Crohn's and Colitis Foundation has recently

98 highlighted the need for research into optimizing existing medical therapies ${ }^{16}$, with patient

99 stratification of key importance in this context ${ }^{13}$. In order to optimize therapies, a more

100 comprehensive understanding of drug mechanisms of action is required.

101 We aimed to evaluate current IBD drugs in the context of autophagy and show that the immunomodulator azathioprine induces autophagy via mechanisms involving modulation of 
103 mTORC1 and stimulation of the unfolded protein response (UPR) sensor PERK. Our results 104 suggest that in addition to well-characterized effects on DNA/RNA synthesis and T105 lymphocytes ${ }^{17,18}$, modulation of autophagy and the UPR may contribute to the therapeutic 106 efficacy of azathioprine. 
108 Materials and Methods

109 Cell culture, transfection, plasmids and reagents

110 HEK293 cells were grown in Dulbecco's modified Eagle medium (DMEM) (Gibco,

111 ThermoFisher Scientific, Paisley, UK) supplemented with $10 \%$ foetal bovine serum (FBS)

112 (Invitrogen, ThermoFisher Scientific) and penicillin streptomycin (Gibco). The monocytic THP-

1131 cell line was grown in RPMI 1640 (Sigma-Aldrich, Irvine, UK), supplemented with 10\% FBS,

114 penicillin streptomycin and 200mM L-glutamine (Gibco). For differentiation to macrophages,

115 THP-1 cells were incubated in RPMI growth media supplemented with $10 \mathrm{ng} / \mathrm{ml}$ phorbol

116 myristate acetate (PMA) (Sigma-Aldrich, Dorset, UK) for $48 \mathrm{hr}$, then rested for $24 \mathrm{hr}$ in fresh

117 RPMI growth media prior to experiments.

118 For transfection of HEK293 cells, a Nucleofector Kit V (Lonza Ltd, Manchester, UK) was used

119 according to the manufacturer's instructions. The GFP-LC3 ${ }^{19}$, GFP-RFP-LC3 ${ }^{20}$ and $x$-light EGFP

$120{ }^{21}$ plasmids have been described previously. All reagents used are detailed in supplementary

121 (Table S1). For nutrient deprivation, cells were incubated with Earle's Balanced Salt Solution

122 (EBSS) (Gibco).

123 Immunoblotting

124 Cells were lysed in ice-cold extraction buffer (50mM Tris [pH 7.6], 150mM NaCl, 5mM EDTA, $0.5 \%$ NP-40, $5 \mathrm{mM} \mathrm{NaF}, 1 \mathrm{mM}$ sodium vanadate, $1 \times$ Pierce Protease Inhibitor Cocktail [Thermo

126 Scientific]) for 30 min followed by centrifugation. Protein lysates were resolved by denaturing

127 electrophoresis on acrylamide/bisacrylamide gels and electro-transferred to Immobilon-FL

128 PVDF membrane (Merck Millpore EMD, Watford, UK). Membranes were incubated with 
primary antibodies overnight at $4^{\circ} \mathrm{C}$, and after washing, were incubated with a secondary

130 antibody for $1 \mathrm{hr}$ at room temperature (RT). Antibody details are provided in (Table S2).

131 Proteins were visualized by incubation with an ECL western blotting analysis system (GE

132 Healthcare) and imaged using a G: BOX system (Syngene, Cambridge, UK). Relative intensity

133 of bands were measured using Image J software ${ }^{22}$ (National Institutes of Health, Bethesda, $134 \mathrm{MD}, \mathrm{USA})$.

135 Confocal fluorescence microscopy

136 Cells were seeded on 21-mm borosilicate glass cover slips, 8 chamber polystyrene vessel

137 CultureSlides (Falcon, Fisher Scientific, Loughborough, UK) or 35mm imaging dishes (Ibidi,

138 Thistle Scientific, Uddingston, UK). Images were captured using Carl Zeiss LSM880 confocal

139 microscope (Jena, Germany) and images were analysed using Image J software ${ }^{18}$ (National

140 Institutes of Health).

141 For fixed cell imaging: Cells were fixed with 4\% paraformaldehyde (PFA) for 15 min,

142 permeabilized with PBS/0.2\% Triton X-100 (Sigma Aldrich) and blocked with PBS containing $14310 \%$ goat's serum (Gibco) and 2.5\% Human TruStain FcX (BioLegend, San Diego, USA). Primary

144 antibodies (Table S2) were incubated overnight at $4^{\circ} \mathrm{C}$ and conjugated secondary antibodies

145 for $1 \mathrm{hr}$ at RT. Where appropriate, cells were counterstained with $4^{\prime}, 6^{\prime}$-diamidino-2-

146 phenylindole (DAPI) or mounted with Vectashield mounting medium for fluorescence with

147 DAPI (Vector Laboratories, Peterborough, UK).

148 For live cell imaging: Cells were grown in $35 \mathrm{~mm}$ imaging dishes (Ibidi) and maintained at $37^{\circ} \mathrm{C}$ 149 and $5 \% \mathrm{CO}_{2}$ in live-cell imaging chamber attached to Carl Zeiss LSM880 confocal microscope. 
151 For autophagy assays in HEK293 GFP-LC3 stable cells: The basal threshold number of GFP-LC3

152 puncta per cell was established as 5 , and cells exhibiting $\geq 5$ puncta were regarded as having

153 enhanced autophagy activity.

154 For tandem fluorescent-tagged GFP-RFP-LC3 assays: Cells were transiently transfected with

155 the GFP-RFP-LC3 plasmid and following designated treatments, the fluorescent autophagy

156 markers GFP-RFP-LC3 or RFP-LC3 were observed using a confocal microscope and the number

157 of (RFP+GFP+) and (RFP+GFP-) puncta per cell determined.

\section{Flow cytometry}

159 Peripheral blood mononuclear cells (PBMC) were seeded in 96-well U-bottom plates and cell

160 lines were seeded in 12 -well plates. After treatments, cells were gently detached using $0.05 \%$

161 trypsin or Cell Dissociation Solution Non-enzymatic (Sigma Aldrich) at $37^{\circ} \mathrm{C}$ for $10 \mathrm{~min}$. Cells

162 were acquired using the BD Biosciences (Oxford, UK) Celesta flow cytometer or the FACSCalibur (BD) and data analysis performed using BD FACsDiva Software or FlowJo

164 software.

Autophagy assay: For HEK293 GFP-LC3, cells were collected then washed in $0.05 \% \mathrm{w} / \mathrm{v}$ saponin (Sigma), diluted in PBS to remove the unbound cytosolic LC3 ${ }^{23}$, which does not alter expression of membrane antigens ${ }^{24}$, prior to acquisition. For PBMC, cells were collected and blocked with 2.5\% Human TruStain FCX in PBS for 20 min, then incubated with PBMC surface markers or IgG isotypes diluted in Brilliant Stain Buffer (BD Horizon) for 25 min, both at RT.

170 Cells were then washed in $0.05 \% \mathrm{w} / \mathrm{v}$ saponin, diluted in PBS to remove the unbound cytosolic

171 LC3, and fixed with $1 \%$ PFA for 20 min at $4^{\circ} \mathrm{C}$. Cells were washed again with $10 \%$ goat serum

172 in $0.05 \%$ saponin before overnight incubation with primary LC3 antibody or Rb IgG Isotype 
173 control (Invitrogen) in $1 \%$ goat serum in $0.05 \%$ saponin at $4^{\circ} \mathrm{C}$. Secondary antibody in $1 \%$ goat

174 serum in $0.05 \%$ saponin was incubated for 30 min at $4{ }^{\circ} \mathrm{C}$ prior to washing and acquisition.

175 Annexin-V/PI assay. Cells were stained using the FITC Annexin V Apoptosis Detection Kit I (BD

176 Pharmingen) according to manufacturer's instructions.

177 RT-qPCR

178 Cells were scraped into RNAzol RT (Sigma-Aldrich) and total RNA extracted according to 179 manufacturer's instructions. Total RNA was quantified using a NanoDrop 2000 180 Spectrophotometer (Thermo Scientific) and integrity was assessed using an Agilent 2100 181 Bioanalyzer (Agilent Technologies, Stockport, UK) with RNA Nano Chips and Agilent RNA 6000 182 Nano Reagents (Agilent Technologies). mRNA was converted to cDNA using nanoScript 2, 183 Reverse Transcription Premix (PrimerDesign Ltd, Chandler's Ford, UK) according to 184 manufacturer's instructions. For qPCR analysis of gene expression PrecisionPLUS Mastermix 185 with SYBR green and ROX with inert blue dye (PrimerDesign) was used according to 186 manufacturer's instructions with RT-PCR Grade Water (Invitrogen) and the StepOnePlus Real187 time PCR System (Applied Biosystems, ThermoFisher). Primers are detailed in supplementary 188 (Table S3). A geNorm kit (PrimerDesign) was used for the selection of appropriate reference 189 genes (RPL13A [Ribosomal Protein L13a] and Actin) with the qbase+ software ${ }^{25} .2^{\text {-ddCT }}$ was 190 used for relative quantification of gene expression ${ }^{26}$. The $\mathrm{RT}^{2}$ Profiler PCR Array of Human 191 Autophagy genes (Qiagen, Crawley, UK) was performed according to manufacturer 192 instructions. 


\section{Bacterial infection assays}

194 For growth curves: LB was inoculated with E. coli strain CUICD541-10 ${ }^{27}$ isolated from the 195 ileum of a patient with CD (a kind gift from Prof Kenny Simpson, Cornell University, USA), from 196 an overnight culture to an optical density of 0.05 at $600 \mathrm{nM}$. Cultures were treated 197 appropriately, incubated at $37^{\circ} \mathrm{C}$ with $200 \mathrm{rpm}$ shaking, and optical density was measured at $198600 \mathrm{nM}$ every $30 \mathrm{~min}$.

199 For intracellular survival: Cells were infected with CUICD541-10 E. coli at a multiplicity of 200 infection (MOI) of 10 for $3 \mathrm{hr}$, incubated for $1 \mathrm{hr}$ in $100 \mu \mathrm{g} / \mathrm{ml}$ gentamicin (Gibco) to kill 201 extracellular bacteria, then maintained for a further $24 \mathrm{hr}$ in $20 \mu \mathrm{g} / \mathrm{ml}$ gentamicin, with 202 addition of appropriate treatments for the final 6hr. For colony forming unit (CFU) 203 enumeration, cells were lysed for 10 min using $1 \%$ Triton X100 in PBS. Lysates were serially 204 diluted and plated on LB agar plates for overnight incubation at $37^{\circ} \mathrm{C}$.

For immunofluorescence: CUICD541-10 E. coli transformed with an x-light mCherry plasmid were used and 30 min prior to immunostaining cells were incubated with $0.1 \mathrm{mM}$ isopropyl $\beta$ D-1-thiogalactopyranosid (IPTG) (Sigma) to promote bacterial fluorescence. IPTG and $5 \mu \mathrm{M}$ Cell Tracker Green BODIPY (Invitrogen) were added for the duration of the live-cell imaging of infected cells.

210 Patients

211 Patient recruitment and sample collection was performed at the Royal Hospital for Sick

212 Children in Edinburgh, and processing and analysis was performed at Edinburgh Napier 213 University. 
214 Inclusion criteria were: (1) aged 6-18 years on date of colonoscopy; (2) already confirmed CD,

215 UC or IBDU ${ }^{28}$ or undergoing first upper and lower GI endoscopy due to gastrointestinal

216 symptoms suggestive of possible bowel inflammation (e.g. abdominal pain, peri-rectal (PR)

217 bleeding, weight loss). Non-IBD patients were defined as those with both microscopically and

218 macroscopically normal colonoscopy. Patients were excluded if they had previously

219 undergone colonoscopy for anything other than known IBD, were diagnosed with anything

220 other than IBD following a full investigative cycle, or who could not provide written consent.

221 Whole blood samples (maximum 15ml), and saliva samples were collected from patients: 20

222 IBD cases and 9 non-IBD controls (Table S4). PBMC were isolated from whole blood using

223 Ficoll-Paque PLUS (GE Healthcare Bio-Sciences AB, Uppsala, Sweden) and cultured in RPMI

224 growth media. Saliva samples were collected using Oragene DNA kits (DNA Genotek, Ontario, 225 Canada).

226 Genotyping

227 Saliva samples were sent to the Wellcome Trust Clinical Research Facility in Edinburgh for 228 analysis. Once recruitment was completed, DNA was extracted using Isohelix kit and Taqman

229 genotyping for each sample was performed for the following SNPs: ATG16L1 T300A 230 (rs2241880), NOD2 L1007f/s (p.Leu1007fsX1008) (rs2066847), NOD2 R702W (rs2066844) and 231 NOD2 G908R (rs2066845).

\section{Statistical analysis}


233 Results are reported as the mean \pm SEM assuming normally distributed variables with 234 statistical analysis conducted by using one-way or two-way ANOVA, or paired t-test as 235 appropriate, with GraphPad Prism version 7.0 (GraphPad Software, CA, USA).

\section{Ethics}

237 All samples were collected with local institutional and NHS ethical approvals (reference 238 16/WW/0210). Eligible patients were approached at least 48hr prior to colonoscopy and 239 following consent were recruited to the study.

240 Data availability

241 The datasets generated during and/or analysed during the current study are available from

242 the corresponding author on reasonable request. 
244 Results

245 Azathioprine induces autophagosome accumulation

246 To evaluate the modulation of autophagy by IBD drugs we used HEK293 cells, a well-

247 characterized cell line used in autophagy research ${ }^{29}$ that were engineered to stably express

248 the autophagy marker LC3 fused to green fluorescent protein (GFP-LC3) ${ }^{30}$. GFP-LC3 puncta

249 accumulation was measured by live-cell imaging (Figure 1A). Significant increases in GFP-LC3

250 puncta number were observed after treatment with the immunomodulator azathioprine

251 (Figure 1A, panel iv and ix) and the biologic infliximab (Figure 1A, panel $v$ and ix) with an

252 optimal time-point of $6 \mathrm{hr}$ for both drugs (Figure 1A, panel $\mathrm{x}$ and xi). Significant increases in

253 GFP-LC3 puncta were also observed with EBSS to induce nutrient deprivation, a strong

254 activator of the autophagy pathway (Figure 1A, panel iii and ix). In contrast, the

255 immunomodulator methotrexate (Figure 1A, panel vi, ix and xii), the corticosteroid

256 methylprednisolone (Figure 1A, panel vii, ix and xiii) and the aminosalicylate sulfasalazine

257 (Figure 1A, panel viii, ix and xiv) had no significant effects on GFP-LC3 puncta accumulation.

258 Azathioprine activates the autophagy pathway

259 Autophagosomes can accumulate due to activation or inhibition of the autophagy pathway.

260 To distinguish between these processes, we first employed flow cytometric analysis. To

261 facilitate measurement of autophagy activation by flow cytometry, HEK293 GFP-LC3 cells

262 were washed with the glycoside saponin to permeabilize cell plasma membranes prior to

263 analysis. Plasma membrane permeabilization releases inactive cytosolic LC3, with only the

264 active lipidated form of LC3-II, which is tightly associated with autophagosome membranes, 
being retained ${ }^{23}$ (Supplementary Figure 1). Additionally, Bafilomycin A1 (BafA1), an inhibitor of autophagosome-lysosome fusion ${ }^{30}$, was used to augment LC3-II accumulation. Under these conditions azathioprine clearly enhanced the accumulation of autophagosome-bound GFPLC3-II (Figure 2A, panel ii and quantified in iv). In contrast, infliximab had only minor additional effect on GFP-LC3-II accumulation (Figure 2A, panel iii and iv).

To further validate that azathioprine-mediated activation of the autophagy pathway, we employed a tandem RFP-GFP-LC3 plasmid ${ }^{31}$. This RFP-GFP-LC3 plasmid utilises the $\mathrm{pH}$ difference between the acidic autolysosome (formed by fusion of an autophagosome and lysosome) and the neutral autophagosome, with the $\mathrm{pH}$ sensitivity differences exhibited by GFP (labile at acidic $\mathrm{pH}$ ) and RFP (stable at acidic $\mathrm{pH}$ ). Thus, this plasmid can be used to monitor progression from the autophagosome (RFP+GFP+) to the autolysosome (RFP+GFP-). HEK293 cells were transfected with RFP-GFP-LC3 plasmid and treated with BafA1, EBSS or azathioprine. As expected, all three treatments caused autophagosomes to accumulate (Figure 2B, panel xvi). Inhibition of autophagosome-lysosome fusion with BafA1 resulted in the accumulation of (RFP+GFP+) puncta, which appear as yellow in the merged image (Figure 2B, panel $x$, xiii and quantified in xvii), while activation of the pathway with EBSS resulted in an accumulation of (RFP+GFP-) puncta indicating that complete progression through the pathway was taking place (Figure 2B, panel xi, xiv and xvii). Azathioprine treatment resulted in an accumulation of (RFP+GFP-) puncta relative to untreated control (Figure 2B, panel xii, $x \mathrm{~V}$ and xvii) indicating that azathioprine activates the autophagy pathway.

Azathioprine induces autophagosome accumulation in macrophages independent of apoptosis 
287 As with other biological processes, autophagy is cell-type specific and it is therefore essential

288 to determine how azathioprine modulates the autophagy pathway in cell types of direct

289 relevance to IBD. For this purpose, macrophages derived from THP-1 cells were treated with

290 azathioprine and endogenous LC3 puncta accumulation measured by fixed-cell confocal

291 fluorescence microscopy. In line with our previous results (Figure 1A), azathioprine treatment

292 significantly increased the number of LC3 puncta in THP-1 derived macrophages (Figure 3A,

293 panel iv and v). Autophagy and apoptosis are intimately linked ${ }^{32}$, therefore it was also

294 important to determine the effect of azathioprine on apoptosis in these cells. Analysis of

295 Annexin V/PI staining by flow cytometry revealed that azathioprine had no effect on cell

296 viability at either $6 \mathrm{hr}$ or $24 \mathrm{hr}$ treatment (Figure 3B, panel ii, iv, and v). Together, these results

297 demonstrate that azathioprine induces autophagosome accumulation in THP-1 derived

298 macrophages independent of apoptosis.

\section{Azathioprine stimulates the UPR}

300 To gain insight into azathioprine mechanism of action, we used the Human Autophagy $\mathrm{RT}^{2}$

301 Profiler PCR Array. Gene expression was compared in THP-1 derived macrophages either left

302 untreated or treated with azathioprine (Figure S3). Among the genes significantly up-

303 regulated by azathioprine was the UPR-regulating kinase EIF2AK3 (also known as PERK). As

304 endoplasmic reticulum (ER)-stress/UPR genes are strongly associated with IBD this was

305 investigated further ${ }^{33}$. A time-course RT-qPCR experiment identified $6 \mathrm{hr}$ as the optimum

306 time-point for up regulation of PERK, which occurred in a dose-dependent manner (Figure 4,

307 panel $\mathrm{i}$ and ii). The expression of genes downstream from PERK (ATF4, and CHOP; Figure 4,

308 panel iii and iv), and the ER stress chaperon protein disulphide isomerase (PDI) (Figure 4, panel 
309 vi) were also up regulated after $6 \mathrm{hr}$ of azathioprine treatment in a dose dependent manner.

310 In contrast, expression of the ER stress chaperone protein binding immunoglobulin

311 protein/78-kDa glucose-regulated protein (BiP/Grp78) was not affected by azathioprine

312 treatment after $6 \mathrm{hr}$ (Figure 4, panel vii) however a minor increase was observed after $24 \mathrm{hr}$.

313 These results indicate that azathioprine stimulates the UPR.

\section{Azathioprine modulates mTORC1 signaling}

315 mTORC1 is a major regulatory hub balancing cell growth and protein translation with control

316 of autophagy ${ }^{34}$. When active, mTORC1 is a potent inhibitor of autophagy. Therefore, levels

317 of phosphorylated ribosomal protein S6 (p-rpS6), a surrogate marker of mTORC1 activity,

318 were evaluated in THP-1 derived macrophages treated with increasing concentrations of 319 azathioprine. Azathioprine treatment caused a dramatic decrease in p-rpS6 in a dose 320 dependent manner (Figure 5A, lanes 3-6 and quantified in ii). These results suggest that 321 azathioprine treatment inhibits mTORC1 activity.

322 Azathioprine modulates mTORC1 signaling independent of PERK

323 PERK has been shown to inhibit mTORC1 in response to ER stress as part of a mechanism to 324 induce autophagy ${ }^{34-36}$. To test whether modulation of mTORC1 observed in response to 325 azathioprine is dependent on PERK, THP-1 derived macrophages were treated in the absence or presence of a pharmacologic inhibitor of PERK. Azathioprine again caused a decrease in $p$ -

327 rpS6, and the PERK inhibitor did not significantly alter this effect (Figure 5B, panel i, compare 328 lanes 3 and 8, and quantified in ii). To confirm PERK inhibitor activity, phosphorylation of 329 elF2a, a well-characterized substrate of PERK, was assessed (Figure 5B, lanes 6-10 and 
quantified in iii). These results suggest that modulation of mTORC1 signaling by azathioprine

331 occurs independent of PERK.

\section{Azathioprine-induced autophagy is modulated by PERK}

333 To determine whether PERK is required for azathioprine-induced autophagy, THP-1 derived

334 macrophages were treated with azathioprine or EBSS in the absence or presence of PERK inhibitor. In the presence of PERK inhibitor, azathioprine-induced autophagy was specifically attenuated (Figure 5C, compare panel ii and v, and quantified in vii) compared to EBSSinduced autophagy (Figure 5C, compare panel iii and vi, and quantified in vii). These results indicate that PERK is an important factor regulating azathioprine-induced autophagy.

\section{Azathioprine enhances clearance of intracellular AIEC}

340 Evidence suggests that AIEC play a putative role in $\mathrm{CD}^{37}$. Therefore, we evaluated the survival

341 of the CD mucosa-associated AIEC strain CUICD541-10 27 in THP-1 derived macrophages.

342 Initially, it was determined that azathioprine had no direct effect on bacterial growth (Figure

343 S3). Azathioprine treatment did however cause a significant decrease in bacterial CFU in AIEC

344 infected cells (Figure 6A). Furthermore, immunofluorescence analysis showed a decrease in 345 the percentage of cells infected with bacteria (Figure 6B and C, compare panels iii and iv and 346 quantified in v), which correlated with an increased accumulation of LC3 puncta (Figure 6C 347 panel v) indicating that autophagy was being induced.

348 Infection of cells with AIEC elicits a strong inflammatory response; therefore, RT-qPCR was used to assess expression of the pro-inflammatory cytokine TNF $\alpha$ in THP-1 derived macrophages infected with AIEC. Expression was significantly up regulated by AIEC infection 
and this was reduced when cells were treated with azathioprine (Figure 6D, panel i).

352 Azathioprine also reduced the expression of TNF $\alpha$ in cells treated with bacterial

353 lipopolysaccharide (LPS) (Figure 6D, panel ii) suggesting that azathioprine may affect TNF $\alpha$

354 expression independent of decreased intracellular bacteria. These results demonstrate that

355 azathioprine enhances the clearance of intracellular AIEC and dampens the elevated cytokine

356 levels observed in response to infection.

357 Azathioprine activates autophagy in PBMC and monocytes from

358 pediatric patients

359 Non-IBD, CD and UC patients were genotyped for the CD-associated NOD2 (R702W, G908R,

360 L1007fs) and ATG16L1 T300A SNPs (Table 1). PBMC from the patient groups were then

361 assessed for autophagy activity by flow cytometry. No significant differences in basal

362 autophagy activity were observed, and azathioprine treatment resulted in an accumulation

363 of autophagosome-bound LC3-II in PBMC from all patient groups (Figure 7A, panel i). Analysis

364 of basal autophagy activity in untreated monocytes revealed no difference across the patient

365 groups and azathioprine treatment again enhanced the accumulation of autophagosome-

366 bound LC3-II (Figure 7A, panel ii). Similar results were observed in monocyte subsets, in

367 addition to T cells, B cells and NK cells (Figure S4). Interestingly, activation of autophagy by azathioprine was not attenuated in PBMC heterozygous or homozygous for the ATG16L1 T300A SNP (Figure 7A, panel iii). The low frequency of NOD2 SNPs present in the cohort precluded analysis of effect on azathioprine-induced autophagy. Taken together, these results demonstrate that azathioprine activates autophagy in primary cells ex vivo, supporting our in vitro findings. 


\section{Discussion}

375

376 The strong association of CD with autophagy genes has led to a substantial amount research

377 demonstrating several key functions for autophagy including regulation of the innate and

378 adaptive immune responses, regulation of the intestinal microbiome and resolution of ER-

379 stress $^{9,10}$. Impaired autophagy responses have been observed in a range of cell types derived

380 from $C D$ patients ${ }^{10}$, and there is mounting evidence that inducing autophagy can have

381 therapeutic benefits for the treatment of IBD in both pediatric and adult patients, with several

382 recent studies investigating the utility of mTORC1 inhibitors ${ }^{12,13,38}$. Despite these advances in

383 understanding, there is still little known about how drugs currently approved for clinical use

384 in IBD affect autophagy function.

385 To evaluate current IBD drugs in the context of autophagy we initially screened for the 386 accumulation of autophagosomes using live cell imaging and identified azathioprine and

387 infliximab as potential modulators of autophagy. However, further investigation using flow 388 cytometry to measure the active, lipidated form of LC3-II revealed that only azathioprine 389 activated the autophagy pathway. Furthermore, results with the GFP-RFP-LC3 plasmid 390 demonstrate that autophagic flux is enhanced in the presence of azathioprine.

391 Thiopurines are a class of immunosuppressant drugs that includes azathioprine, mercaptopurine (6-MP), and thioguanine (6-TG). It is well-established that thiopurines can

393 inhibit DNA/RNA synthesis and deactivate pro-inflammatory T-lymphocytes ${ }^{17,18}$, however, their mechanism of action is not fully understood. Interestingly, several previous studies have also found that thiopurines can activate autophagy primarily via DNA mismatched repair processes in response to DNA damage ${ }^{9}$. To date, only one study has shown autophagy 
induction mediated by azathioprine, in colorectal carcinoma cells ${ }^{39}$. The authors suggest that

increased autophagy associated with thiopurine exposure is a survival mechanism to compensate for a primary effect on apoptosis and mitochondrial damage. Mechanistically, we show an alternative autophagy-associated process whereby azathioprine increased the expression of several UPR genes including PERK, ATF4 and CHOP as well as expression of the ER-stress chaperone protein PDI. Importantly, we demonstrate that azathioprine induces autophagy independent of apoptosis.

404 The ER-stress/UPR pathways play an essential role in the maintenance of intestinal 405 homeostasis and genetic studies have identified several ER-stress/UPR genes associated with 406 IBD ${ }^{33}$. Significantly, ER-stress levels are increased in ileal and colonic biopsies from CD 407 patients ${ }^{40-43}$. The UPR acts to maintain ER-homeostasis, and cells that naturally secrete large amounts of protein, such as Paneth cells strongly linked to ileal CD are more susceptible to ER-stress and therefore rely heavily on the UPR ${ }^{44}$.

410 The UPR and autophagy are intimately linked processes ${ }^{45}$, to relieve ER-stress the UPR can

411 induce autophagy to degrade misfolded proteins and protein aggregates ${ }^{46-50}$. Importantly, 412 the major risk factors for CD, NOD2 and ATG16L1, functionally intersect with ER-stress and 413 the UPR ${ }^{51} 52$, and ER stress is a significant risk when autophagy or the UPR is not functional. 414 The convergence between autophagy and UPR pathways provides new opportunity for the 415 treatment of IBD and the modulation of the UPR in combination with autophagy is a promising 416 therapeutic strategy. In support of this idea, several recent studies have demonstrated 417 beneficial effects of enhancing UPR function for intestinal homeostasis ${ }^{53-55}$.

418 We also show that azathioprine modulates mTORC1 signaling. A growing body of work suggests that the UPR is regulated by diverse stimuli independently of ER-stress ${ }^{56}$ and 
420 stressors such as nutrient deprivation and hypoxia have been shown to activate UPR signaling

421 and inhibit mTORC1 ${ }^{57}$. UPR activation can occur both upstream and downstream of mTORC1

42257 , and mTORC1 inhibitors, including rapamycin, are reported to induce PERK and elF2 $\alpha$

423 activation ${ }^{58}$. Our finding that PERK inhibition did not affect the mTORC1 response to

424 azathioprine suggests that mTORC1 may be acting upstream or in parallel to PERK.

425 Significantly, azathioprine-induced autophagy was reduced in the presence of PERK inhibitor,

426 supporting others findings that PERK regulates LC3B and ATG5 expression ${ }^{59}$. Our results

427 suggest that azathioprine is acting through a pathway that involves both mTORC1 and PERK,

428 and may have synergistic outcomes; mTORC1 inhibition and PERK-elF2 $\alpha$ stimulation may

429 work together to inhibit global protein translation, while mTORC1 inhibition together with

430 increased expression of autophagy genes by PERK ${ }^{60,61}$, may result in a general increase in

431 autophagic activity.

432 AIEC are prevalent in ileal mucosa of CD patients ${ }^{62}$ and are able to survive and replicate within macrophages, resulting in sustained inflammatory responses ${ }^{63}$ and granuloma formation ${ }^{64}$.

434 Using a CD mucosa-associated strain of AIEC we show that azathioprine enhances the 435 clearance of intracellular bacteria from THP-1 derived macrophages independent of direct 436 effects on bacterial growth. Importantly, AIEC clearance correlated with increased autophagy 437 and reduced pro-inflammatory cytokine gene expression. These combined effects of 438 azathioprine may make it a preferred therapeutic option for subsets of patients with 439 confirmed AIEC infection.

440 Finally, we carried out an observational study of a clinical cohort of children. PBMC from non441 IBD patients or patients with the diagnosis of IBD were analysed to determine basal 442 autophagy levels and response to azathioprine treatment ex vivo. Our flow cytometry results 
443 revealed that basal autophagy levels and azathioprine-induced autophagy were similar in all

444 patient groups. Similar results were also observed when we analysed subsets of monocytes,

445 T cells, B cells and NK cells. Importantly, it has been shown that autophagy is required for the 446 differentiation of monocytes to macrophages ${ }^{65}$, and for the induction of macrophages which 447 display immunosuppressive and wound healing properties ${ }^{66}$. Our results suggest that 448 enhancing autophagy with azathioprine may promote the induction of macrophages with an 449 anti-inflammatory phenotype irrespective of diagnosis.

450 Greater understanding of the genetic factors that underlie CD pathogenesis are leading to 451 improvements in treatment, and genotyping for key SNPs in genes involved in both the 452 autophagy and ER-stress/UPR pathways may help to predict patient response to drugs. For 453 example, recent studies have identified an association between ATG16L1 T300A SNP and an 454 enhanced therapeutic effect of thiopurines ${ }^{67}$ and anti-TNF- $\alpha$ therapy ${ }^{68}$. Interestingly, the 455 immunoregulatory effects of these drugs were associated with autophagy stimulation $66,67,69$. 456 For instance, cytoskeletal defects that reduced mobility in autophagy-deficient DC harbouring 457 the ATG16L1 T300A SNP were reversed by thiopurine inhibition of Ras-related C3 botulinum 458 toxin substrate 1 (RAC1) ${ }^{67}$. Significantly, analysis of ATG16L1 genotype in our pediatric cohort 459 revealed that the autophagy response to azathioprine was not attenuated in PBMC from 460 patients carrying the CD-associated T300A SNP. The ATG16L1 T300A risk variant confers 461 greater risk for $C D$ in pediatric patients than in adult patients ${ }^{70,71}$, therefore it will be 462 interesting to compare results in PBMC from an adult cohort. Collectively, our studies suggest 463 that patients harbouring the ATG16L1 risk variant may benefit from thiopurines via 464 mechanisms involving RAC1 inhibition and the induction of autophagy.

\section{Conclusion}


466 Breakdown of the ER-stress/UPR and autophagy pathways has been strongly linked to

467 pathogenesis of IBD. Together, our results suggest that stimulation of autophagy and the UPR

468 may contribute to the therapeutic efficacy of azathioprine. Additional studies are now

469 required to further elucidate how thiopurines modulate these converging pathways; results

470 of these studies may pave the way for development of the next generation of drugs aimed at

471 modulation of the UPR in combination with autophagy.

472 Autophagy is a cell type specific process, therefore it is essential to assess whether

473 thiopurines modulate autophagy and the UPR in other cell types of direct relevance to IBD,

474 such as Paneth cells strongly linked to ileal CD. Specifically, studies conducted in cells from

475 patients with known CD-associated mutations in the genes regulating the ER-stress/UPR and

476 autophagy pathways will help to identify patients that are most likely to respond.

477

478

479

480 


\section{Acknowledgements}

482 We thank Prof Kenny Simpson (Cornell University, USA) for E.coli strains, Prof Ilan Rosenshine,

483 (The Hebrew University of Jerusalem) for the $\mathrm{x}$-light EGFP plasmid and David Hoole (Royal 484 Hospital for Sick Children) for Infliximab. We thank Dr Clare Taylor (Edinburgh Napier 485 University) for advice and continued support. This work was supported by a Crohn's in 486 Childhood Research Association (CICRA) PhD studentship to KMH and by an NHS Research 487 Scotland (NRS) Career Researcher Fellowship to PH.

\section{Authors contributions}

KMH, VC and SK conducted the experiments; PH collected clinical specimens.

$490 \mathrm{KMH}$ and CS wrote the manuscript.

491

$\mathrm{KMH}, \mathrm{VC}, \mathrm{SK}, \mathrm{KS}, \mathrm{JS}, \mathrm{PGB}, \mathrm{PH}$ and CS made substantial contributions to conception and

492 design, and/or analysis and interpretation of data.

$493 \mathrm{KMH}, \mathrm{VC}, \mathrm{SK}, \mathrm{KS}, \mathrm{JS}, \mathrm{PGB}, \mathrm{PH}$ and $\mathrm{CS}$ reviewed the manuscript critically for important 494 intellectual content.

495

496 Competing interests and financial disclosure

497 The authors declare that we have no competing interests. We have no financial relationships with any organisations that might have an interest in the submitted work. 
502

503

504

505

506

507

508

509

510

511

512

513

514

515

516

517

518

519

520

521

522

523

524

525

526

527

528

529

530

531

532

533

534

\section{References}

1. NHS CB. 2013/14 NHS Standard Contract for Colorectal: Complex Inflammatory Bowel Disease (Adult). 2013.

2. Boyapati R, Satsangi J, Ho GT. Pathogenesis of Crohn's disease. F1000Prime Rep. 2015;7:44.

3. Frank DN, Robertson CE, Hamm CM, et al. Disease phenotype and genotype are associated with shifts in intestinal-associated microbiota in inflammatory bowel diseases. Inflamm. Bowel Dis. 2011;17:179-184.

4. Darfeuille-Michaud A, Boudeau J, Bulois P, et al. High prevalence of adherent-invasive Escherichia coli associated with ileal mucosa in Crohn's disease. Gastroenterology. 2004;127:412-421.

5. Lange KM de, Moutsianas L, Lee JC, et al. Genome-wide association study implicates immune activation of multiple integrin genes in inflammatory bowel disease. Nat. Genet. 2017;49:256-261.

6. Franke A, McGovern DP, Barrett JC, et al. Genome-wide meta-analysis increases to 71 the number of confirmed Crohn's disease susceptibility loci. Nat Genet. 2010;42:1118-25.

7. Lamb CA, Yoshimori T, Tooze SA. The autophagosome: origins unknown, biogenesis complex. Nat. Rev. Mol. Cell Biol. 2013;14:759-774.

8. Deretic V, Saitoh T, Akira S. Autophagy in infection, inflammation and immunity. Nat ReV Immunol. 2013;13:722-37.

9. Hooper KM, Barlow PG, Stevens C, et al. Inflammatory Bowel Disease Drugs: A Focus on Autophagy. J. Crohns Colitis. 2017;11:118-127.

10. Ke $P$, Shao B-Z, Xu Z-Q, et al. Intestinal Autophagy and Its Pharmacological Control in Inflammatory Bowel Disease. Front. Immunol. 2017;7.

11. Massey DC, Bredin F, Parkes M. Use of sirolimus (rapamycin) to treat refractory Crohn's disease. Gut. 2008;57:1294-6.

12. Dumortier J, Lapalus M-G, Guillaud O, et al. Everolimus for refractory Crohn's disease: A case report: Inflamm. Bowel Dis. 2008;14:874-877.

13. Mutalib M, Borrelli $\mathrm{O}$, Blackstock $\mathrm{S}$, et al. The use of sirolimus (rapamycin) in the management of refractory inflammatory bowel disease in children. J. Crohns Colitis. 2014;8:1730-1734.

14. Bernstein CN, Loftus EV Jr, Ng SC, et al. Hospitalisations and surgery in Crohn's disease. Gut. 2012;61:622-9. 
535

536

537

538

539

540

541

542

543

544

545

546

547

548

549

550

551

552

553

554

555

556

557

558

559

560

561

562

563

564

565

566

567

568

15. Bassi A, Dodd S, Williamson $P$, et al. Cost of illness of inflammatory bowel disease in the UK: a single centre retrospective study. Gut. 2004;53:1471-8.

16. Denson LA, Long MD, McGovern DP, et al. Challenges in IBD research: update on progress and prioritization of the CCFA's research agenda. Inflamm Bowel Dis. 2013;19:677-82.

17. Tiede I, Fritz G, Strand S, et al. CD28-dependent Rac1 activation is the molecular target of azathioprine in primary human CD4+ T lymphocytes. J. Clin. Invest. 2003;111:11331145.

18. Swann PF, Waters TR, Moulton DC, et al. Role of Postreplicative DNA Mismatch Repair in the Cytotoxic Action of Thioguanine. Science. 1996;273:1109-1111.

19. Kabeya Y, Mizushima N, Ueno T, et al. LC3, a mammalian homologue of yeast Apg8p, is localized in autophagosome membranes after processing. EMBO J. 2000;19:5720-5728.

20. Kimura S, Noda T, Yoshimori T. Dissection of the autophagosome maturation process by a novel reporter protein, tandem fluorescent-tagged LC3. Autophagy. 2007;3:452-460.

21. Mills E, Baruch K, Aviv G, et al. Dynamics of the type III secretion system activity of enteropathogenic Escherichia coli. MBio. 2013;4:e00303-13.

22. Schindelin J, Arganda-Carreras I, Frise E, et al. Fiji: an open-source platform for biologicalimage analysis. Nat. Methods. 2012;9:676-682.

23. Eng KE, Panas MD, Karlsson Hedestam GB, et al. A novel quantitative flow cytometrybased assay for autophagy. Autophagy. 2010;6:634-641.

24. Jacob MC, Favre M, Bensa JC. Membrane cell permeabilization with saponin and multiparametric analysis by flow cytometry. Cytometry. 1991;12:550-558.

25. Vandesompele J, De Preter K, Pattyn F, et al. Accurate normalization of real-time quantitative RT-PCR data by geometric averaging of multiple internal control genes. Genome Biol. 2002;3:research0034.

26. Livak KJ, Schmittgen TD. Analysis of relative gene expression data using real-time quantitative PCR and the 2(-Delta Delta C(T)) Method. Methods San Diego Calif. 2001;25:402-408.

27. Simpson KW, Dogan B, Rishniw M, et al. Adherent and invasive Escherichia coli is associated with granulomatous colitis in boxer dogs. Infect. Immun. 2006;74:4778-4792.

28. Levine A, Koletzko S, Turner D, et al. ESPGHAN revised porto criteria for the diagnosis of inflammatory bowel disease in children and adolescents. J. Pediatr. Gastroenterol. Nutr. 2014;58:795-806.

29. Musiwaro $P$, Smith $M$, Manifava $M$, et al. Characteristics and requirements of basal autophagy in HEK 293 cells. Autophagy. 2013;9:1407-1417. 
569

570

571

572

573

574

575

576

577

578

579

580

581

582

583

584

585

586

587

588

589

590

591

592

593

594

595

596

597

598

599

600

601

602

603

30. Klionsky DJ, Abdelmohsen K, Abe A, et al. Guidelines for the use and interpretation of assays for monitoring autophagy (3rd edition). Autophagy. 2016;12:1-222.

31. Mizushima N, Yoshimori T, Levine B. Methods in Mammalian Autophagy Research. Cell. 2010;140:313-326.

32. Mariño G, Niso-Santano $M$, Baehrecke $E H$, et al. Self-consumption: the interplay of autophagy and apoptosis. Nat. Rev. Mol. Cell Biol. 2014;15:81-94.

33. McGuckin MA, Eri RD, Das I, et al. ER stress and the unfolded protein response in intestinal inflammation. Am. J. Physiol. - Gastrointest. Liver Physiol. 2010;298:G820-G832.

34. Laplante M, Sabatini DM. mTOR Signaling in Growth Control and Disease. Cell. 2012;149:274-293.

35. Avivar-Valderas A, Bobrovnikova-Marjon E, Diehl JA, et al. Regulation of autophagy during ECM detachment is linked to a selective inhibition of mTORC1 by PERK. Oncogene. 2013;32:4932-4940.

36. Ji G, Yu N, Xue X, et al. PERK-mediated Autophagy in Osteosarcoma Cells Resists ER Stressinduced Cell Apoptosis. Int. J. Biol. Sci. 2015;11:803-812.

37. Palmela C, Chevarin C, Xu Z, et al. Adherent-invasive Escherichia coli in inflammatory bowel disease. Gut. 2017:gutjnl-2017-314903.

38. Anon. Massey, D C OBredin, FParkes, MengG0800383/Medical Research Council/United KingdomEnglandGut. 2008 Sep;57(9):1294-6. doi.

39. Chaabane W, Appell ML, Chaabane W, et al. Interconnections between apoptotic and autophagic pathways during thiopurine-induced toxicity in cancer cells: the role of reactive oxygen species. Oncotarget. 2016;7:75616-75634.

40. Deuring JJ, de Haar C, Koelewijn CL, et al. Absence of ABCG2-mediated mucosal detoxification in patients with active inflammatory bowel disease is due to impeded protein folding. Biochem. J. 2012;441:87-93.

41. Kaser A, Lee A-H, Franke A, et al. XBP1 Links ER Stress to Intestinal Inflammation and Confers Genetic Risk for Human Inflammatory Bowel Disease. Cell. 2008;134:743-756.

42. Rolhion N, Barnich N, Bringer M-A, et al. Abnormally expressed ER stress response chaperone Gp96 in CD favours adherent-invasive Escherichia coli invasion. Gut. 2010;59:1355-1362.

43. Shkoda A, Ruiz PA, Daniel H, et al. Interleukin-10 Blocked Endoplasmic Reticulum Stress in Intestinal Epithelial Cells: Impact on Chronic Inflammation. Gastroenterology. 2007;132:190-207.

44. Adolph TE, Tomczak MF, Niederreiter $L$, et al. Paneth cells as a site of origin for intestinal inflammation. Nature. 2013;503(7475):272-6. 
604

605

606

607

608

609

610

611

612

613

614

615

616

617

618

619

620

621

622

623

624

625

626

627

628

629

630

631

632

633

634

635

636

637

45. Hooper KM, Barlow PG, Henderson P, et al. Interactions Between Autophagy and the Unfolded Protein Response: Implications for Inflammatory Bowel Disease. Inflamm. Bowel Dis. 2018; doi: 10.1093/ibd/izy380.

46. Hart LS, Cunningham JT, Datta T, et al. ER stress-mediated autophagy promotes Mycdependent transformation and tumor growth. J. Clin. Invest. 2012;122:4621-4634.

47. Li J, Ni M, Lee B, et al. The unfolded protein response regulator GRP78/BiP is required for endoplasmic reticulum integrity and stress-induced autophagy in mammalian cells. Cell Death Differ. 2008;15:1460-1471.

48. Ogata M, Hino S, Saito A, et al. Autophagy is activated for cell survival after endoplasmic reticulum stress. Mol Cell Biol. 2006;26:9220-31.

49. Shimodaira $Y$, Takahashi S, Kinouchi $Y$, et al. Modulation of endoplasmic reticulum (ER) stress-induced autophagy by C/EBP homologous protein (CHOP) and inositol-requiring enzyme $1 \alpha(\operatorname{IRE} 1 \alpha)$ in human colon cancer cells. Biochem. Biophys. Res. Commun. 2014;445:524-533.

50. Wang W, Kang H, Zhao $\mathrm{Y}$, et al. Targeting autophagy sensitizes BRAF-mutant thyroid cancer to vemurafenib. J. Clin. Endocrinol. Metab. 2016:jc.2016-1999.

51. Keestra-Gounder AM, Byndloss MX, Seyffert N, et al. NOD1 and NOD2 signalling links ER stress with inflammation. Nature. 2016;532:394-397.

52. Deuring JJ, Fuhler GM, Konstantinov SR, et al. Genomic ATG16L1 risk allele-restricted Paneth cell ER stress in quiescent Crohn's disease. Gut. 2014;63:1081-1091.

53. Cao SS, Zimmermann EM, Chuang B, et al. The Unfolded Protein Response and Chemical Chaperones Reduce Protein Misfolding and Colitis in Mice. Gastroenterology. 2013;144:989-1000.e6.

54. Boyce M, Bryant KF, Jousse C, et al. A selective inhibitor of elF2alpha dephosphorylation protects cells from ER stress. Science. 2005;307:935-939.

55. Okazaki T, Nishio A, Takeo M, et al. Inhibition of the dephosphorylation of eukaryotic initiation factor $2 \alpha$ ameliorates murine experimental colitis. Digestion. 2014;90:167178.

56. Rutkowski DT, Hegde RS. Regulation of basal cellular physiology by the homeostatic unfolded protein response. J. Cell Biol. 2010;189:783-794.

57. Appenzeller-Herzog C, Hall MN. Bidirectional crosstalk between endoplasmic reticulum stress and mTOR signaling. Trends Cell Biol. 2012;22:274-282.

58. Freis $P$, Bollard J, Lebeau J, et al. mTOR inhibitors activate PERK signaling and favor viability of gastrointestinal neuroendocrine cell lines. Oncotarget. 2017;8:20974-20987. 
638

639

640

641

642

643

644

645

646

647

648

649

650

651

652

653

654

655

656

657

658

659

660

661

662

663

664

665

666

667

668

669

670

671

672

59. Rouschop KMA, Beucken $T$ van den, Dubois $L$, et al. The unfolded protein response protects human tumor cells during hypoxia through regulation of the autophagy genes MAP1LC3B and ATG5. J. Clin. Invest. 2010;120:127-141.

60. B'chir W, Maurin A-C, Carraro V, et al. The elF2 $\alpha /$ ATF4 pathway is essential for stressinduced autophagy gene expression. Nucleic Acids Res. 2013;41:7683-7699.

61. Kouroku Y, Fujita E, Tanida I, et al. ER stress (PERK/elF2 [alpha] phosphorylation) mediates the polyglutamine-induced LC3 conversion, an essential step for autophagy formation. Cell Death Differ. 2007;14:230.

62. Thomazini CM, Samegima DAG, Rodrigues MAM, et al. High prevalence of aggregative adherent Escherichia coli strains in the mucosa-associated microbiota of patients with inflammatory bowel diseases. Int. J. Med. Microbiol. 2011;301:475-479.

63. Lapaquette $P$, Bringer M-A, Darfeuille-Michaud A. Defects in autophagy favour adherentinvasive Escherichia coli persistence within macrophages leading to increased proinflammatory response. Cell. Microbiol. 2012;14:791-807.

64. Meconi S, Vercellone A, Levillain F, et al. Adherent-invasive Escherichia coli isolated from Crohn's disease patients induce granulomas in vitro. Cell. Microbiol. 2007;9:1252-1261.

65. Zhang Y, Morgan MJ, Chen K, et al. Induction of autophagy is essential for monocytemacrophage differentiation. Blood. 2012;119:2895-2905.

66. Levin AD, Koelink PJ, Bloemendaal FM, et al. Autophagy Contributes to the Induction of Anti-TNF Induced Macrophages. J. Crohns Colitis. 2016;10:323-329.

67. Wildenberg ME, Koelink PJ, Diederen K, et al. The ATG16L1 risk allele associated with Crohn's disease results in a Rac1-dependent defect in dendritic cell migration that is corrected by thiopurines. Mucosal Immunol. 2017;10:352-360.

68. Wildenberg M, Levin A, Vos C, et al. P668 ATG16L1 genotype is associated with response to anti-TNF in vitro. J. Crohns Colitis. 2013;7:S279.

69. Vos ACW, Wildenberg ME, Arijs I, et al. Regulatory macrophages induced by infliximab are involved in healing in vivo and in vitro. Inflamm. Bowel Dis. 2012;18:401-408.

70. Amre DK, Mack DR, Morgan K, et al. Autophagy gene ATG16L1 but not IRGM is associated with Crohn's disease in Canadian children. Inflamm. Bowel Dis. 2009;15:501-507.

71. Zhang H-F, Qiu L-X, Chen Y, et al. ATG16L1 T300A polymorphism and Crohn's disease susceptibility: evidence from 13,022 cases and 17,532 controls. Hum. Genet. 2009;125:627-631.

72. Levine A, Griffiths A, Markowitz J, et al. Pediatric modification of the Montreal classification for inflammatory bowel disease: the Paris classification. Inflamm. Bowel Dis. 2011;17:1314-1321. 


\section{Abbreviations}

\begin{tabular}{|c|c|c|}
\hline 676 & 5-ASA & Aminosalicylates \\
\hline 677 & AIEC & Adherent Invasive $E$. coli \\
\hline 678 & ATF6 & Activating transcription factor 6 \\
\hline 679 & ATG16L1 & Autophagy-related protein $16-1$ \\
\hline 680 & BafA1 & Bafilomycin A1 \\
\hline 681 & BiP/Grp78 & Binding immunoglobulin protein/78-kDa glucose-regulated protein \\
\hline 682 & $C D$ & Crohn's disease \\
\hline 683 & CFU & Colony forming units \\
\hline 684 & DAPI & 4',6'-diamidino-2-phenylindole \\
\hline 685 & DC & Dendritic cell \\
\hline 686 & DMEM & Dulbecco's modified Eagle medium \\
\hline 687 & EBSS & Earle's Balanced Salt Solution \\
\hline 688 & E. coli & Escherichia coli \\
\hline 689 & EIF2a & Eukaryotic translation initiation factor $2 \mathrm{~A}$ \\
\hline 690 & ER & Endoplasmic Reticulum \\
\hline 691 & FBS & Foetal bovine serum \\
\hline 692 & GI & Gastrointestinal tract \\
\hline 693 & GWAS & Genome-wide association studies \\
\hline 694 & IBD & Inflammatory Bowel Disease \\
\hline 695 & IBDU & IBD-unclassified \\
\hline 696 & IPTG & isopropyl $\beta$-D-1-thiogalactopyranosid \\
\hline 697 & IRE1 $\alpha$ & Inositol-requiring enzyme $1 \alpha$ \\
\hline
\end{tabular}


698 IRGM Immunity-related GTPase family M protein

699 LC3 MAP1LC3B

700 mTORC1 Mechanistic target of rapamycin

701 MOI Multiplicity of infection

702 NOD2 Nucleotide-binding oligomerisation domain-containing protein 2

703 PBMC Peripheral blood mononuclear cells

704 PDI Protein disulphide isomerase

705 PERK Protein kinase R (PKR)-like endoplasmic reticulum kinase

706 PFA Paraformaldehyde

707 PMA Phorbol myristate acetate

708 RAC1 Ras-related C3 botulinum toxin substrate 1

709 p-rpS6 Phosphorylated ribosomal protein S6

710 TNF- $\alpha \quad$ Tumour necrosis factor alpha

711 UC Ulcerative colitis

712 UPR Unfolded protein response

$713 \quad$ XBP1 $\quad x$-box-binding protein 1

714

715 Table 1. Pediatric patient genotype

716 CD Crohn's disease, UC Ulcerative colitis, IBDU IBD unclassified. ATG16L1 T300A genotype:

717 rs2241880. *NOD2 genotype SNPs: L1007fs (rs2241880), G908R (rs2066845) and R702W 718 (rs2066844) 


\begin{tabular}{|c|c|c|c|c|}
\hline & Non-IBD & CD & UC & IBDU \\
\hline Cohort (n=29) & 9 & 12 & 7 & 1 \\
\hline \multicolumn{5}{|c|}{ Genotype ATG16L1 T300A (n=26) } \\
\hline Wildtype & 1 & 2 & 1 & N/A \\
\hline Heterozygous risk & 3 & 6 & 3 & N/A \\
\hline Homozygous risk & 3 & 4 & 3 & N/A \\
\hline \multicolumn{5}{|c|}{ Genotype NOD2 L1007fs ( $n=27)$} \\
\hline Wildtype & 8 & 12 & 7 & N/A \\
\hline Heterozygous risk & 0 & 0 & 0 & N/A \\
\hline Homozygous risk & 0 & 0 & 0 & N/A \\
\hline \multicolumn{5}{|c|}{ Genotype NOD2 G908R (n=27) } \\
\hline Wildtype & 8 & 11 & 7 & N/A \\
\hline Heterozygous risk & 0 & 0 & 0 & $\mathrm{~N} / \mathrm{A}$ \\
\hline Homozygous risk & 0 & 1 & 0 & $\mathrm{~N} / \mathrm{A}$ \\
\hline \multicolumn{5}{|c|}{ Genotype NOD2 R702W (n=27) } \\
\hline Wildtype & 7 & 11 & 6 & N/A \\
\hline Heterozygous risk & 0 & 1 & 0 & N/A \\
\hline Homozygous risk & 1 & 0 & 1 & $\mathrm{~N} / \mathrm{A}$ \\
\hline
\end{tabular}




\section{Figure Legends}

721 Figure 1: Modulation of autophagy by current IBD drugs

722 HEK293 GFP-LC3 cells were untreated (i) or treated with DMSO (ii), EBSS (iii), 120 $\mu$ M

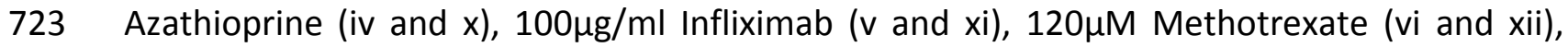
$724100 \mu \mathrm{M}$ methylprednisolone (vii and xiii) or $150 \mu \mathrm{M}$ sulfasalazine (viii and xiv) and assessed by 725 live-cell confocal microscopy up to $12 \mathrm{hr}$. 50 cells counted from 3 fields of view and percentage 726 cells with >5 GFP-LC3 puncta quantified (+/- SEM) for all time-points ( $x$-xiv) with 6hr time727 point highlighted ${ }^{* *} \mathrm{p}<0.01 ; * * * * p<0.0001$ (ix).

Figure 2: Azathioprine activates the autophagy pathway

A) HEK293 GFP-LC3 cells were treated for 6hr with 160nM BafA1 only or BafA1 plus EBSS (i), BafA1 plus $120 \mu \mathrm{M}$ azathioprine (ii) or BafA1 plus $100 \mu \mathrm{g} / \mathrm{ml}$ Infliximab (iii). Geometric mean of GFP-LC3-II intensity was assessed by flow cytometry. Fold-change in GFP-LC3-II geometric mean from BafA1 only was quantified (+/-SEM) (iv).

B) HEK293 cells were transfected with GFP-RFP-LC3 plasmid and left untreated (i, v, ix) or treated with 160nM BafA1 (ii, vi, x), EBSS (iii, vii, xi), or 120 $\mu$ M azathioprine (iv, viii, xii) for 6hr, and imaged by confocal microscopy. Percentage of transfected cells exhibiting $>10$ LC3 puncta was quantified (+/-SEM) $(n=5)(x i i) * p<0.05$. Number of (RFP+GFP+) and (RFP+GFP-) LC3 puncta were quantified (+/-SEM) $(\mathrm{n}=5)(\mathrm{xiv}) * * \mathrm{p}<0.01, * * * \mathrm{p}<0.001$. 
739 A) THP-1-derived macrophages were untreated (i), or treated with DMSO (ii), EBSS (iii), or $740120 \mu \mathrm{M}$ azathioprine (iv) for 6hr. Cells were then immunostained for endogenous LC3 and 741 imaged by confocal microscopy. 30 cells were counted from 3 fields of view and percentage

742 cells with $>5$ GFP-LC3 puncta quantified (+/- SEM) *p $<0.05 ; * * p<0.01$ (v).

743 B) THP-1-derived macrophages were left untreated (i, v) or treated with DMSO (ii, vi), $120 \mu M$ 744 azathioprine (iii, vii) or $30 \mu \mathrm{M}$ camptothecin (iv, viii) for $6 \mathrm{hr}$ (i-iv) and $24 \mathrm{hr}$ (v-vii). Cells were

745 stained with Annexin-V/PI and analysed by flow cytometry. Mean percentage population in 746 each quadrant was quantified (+/- SEM) **p value $<0.01, * * *$ p value $<0.001, * * * *$ value $747<0.0001$ (ix) compared to untreated for corresponding time-point and quadrant.

$748 \quad$ Figure 4: Azathioprine stimulates the UPR

749 THP-1-derived macrophages were left untreated, or treated with DMSO, $60 \mu \mathrm{M}$ or $120 \mu \mathrm{M}$ 750 azathioprine, or EBSS for 2, 4, 6, 16 and 24hr. Expression of PERK was determined by RT-qPCR 751 and is displayed in $\log _{10}$ scale (i). $6 \mathrm{hr}$ time-point, including treatment with $0.5 \mu \mathrm{g} / \mathrm{ml}$ Brefeldin 752 A quantification (+/- SEM) is shown for PERK (ii), ATF4 (iii), CHOP (iv), PDI (vi) and BiP (vii). 753 Using $2^{\text {-ddct }}:{ }^{*} p<0.05, * * p<0.01, * * * * p<0.0001$.

754 Figure 5: Azathioprine modulates autophagy via mechanisms involving mTORC1 and PERK.

755 A) THP-1-derived macrophages were left untreated or treated with DMSO, azathioprine (60$120 \mu \mathrm{M})$, EBSS or the mTORC1 inhibitor rapamycin $(100 \mathrm{nM})$ for $6 \mathrm{hr}$. Protein lysates were

757 immunoblotted for rpS6, phosphorylated rpS6 (p-rpS6 (S235/236)) and actin (i). rpS6/p-rpS6 758 density normalized to actin was quantified as a percentage of untreated (ii). Representative 759 blot from $n=3$. 
760

B) THP-1-derived macrophages were left untreated, or treated with DMSO, $120 \mu \mathrm{M}$

761 azathioprine, EBSS, or $0.5 \mu \mathrm{g} / \mathrm{ml}$ Brefeldin A for $6 \mathrm{hr}$ in the absence or presence of PERK

762 inhibitor. Protein lysates were immunoblotted for rpS6, phosphorylated rpS6 (p-rpS6

763 (S235/236)), phosphorylated elF2 $\alpha$ (p-elF2 $\alpha$ (S51) and tubulin (i). rpS6/p-rpS6 density (ii) and

764 p-elF2 $\alpha$ density (iii) normalized to tubulin was quantified. Representative blot from $n=3$.

765 C) THP-1-derived macrophages were left untreated, or treated with $120 \mu \mathrm{M}$ azathioprine, or

766 EBSS for $6 \mathrm{hr}$ in the absence (i-iii) and presence (iv-vi) of PERK inhibitor and immunostained

767 for LC3. 100 cells were counted per treatment and percentage cells with >5 GFP-LC3 puncta

768 quantified (+/- SEM) *p $<0.05$ (vii).

769 Figure 6: Azathioprine enhances clearance of intracellular AIEC and dampens the 770 inflammatory response.

771 A) THP-1-derived macrophages were infected with AIEC and gentamicin protection assay

772 performed in the absence or presence of DMSO or $120 \mu \mathrm{M}$ azathioprine. CFU/ml of cell lysates

773 were enumerated, and fold-change mean CFU/ml from untreated was calculated (+/- SEM),

$774 * * p<0.01$.

775 B and C) THP-1-derived macrophages were infected with AlEC-mCherry and gentamicin

776 protection assay performed in the absence or presence of DMSO or $120 \mu \mathrm{M}$ azathioprine.

777 Fluorescent AIEC were enumerated and percentage cells with intracellular bacteria quantified

778 (+/- SEM), $* p<0.05, * * p<0.01, * * * p<0.001$

779 D) THP-1-derived macrophages were infected with AIEC (i) or treated with 200ng/ml LPS (ii)

780 and left untreated or treated with DMSO or $120 \mu \mathrm{M}$ azathioprine for 6hr. Expression of TNF- $\alpha$ 
was normalized to untreated and mean fold-change expression quantified from $n=3$ (+/-SEM)

782 (i-ii). Using $2^{- \text {ddct }}:{ }^{*} p<0.05$.

783

Figure 7: Azathioprine activates autophagy in PBMC and monocytes from pediatric patients.

784 PBMC isolated from non-IBD control and IBD patients were left untreated or treated with 785 $120 \mu \mathrm{M}$ azathioprine for $6 \mathrm{hr}$. PBMC were stained with surface markers for classification into populations and for endogenous LC3-II. Geometric mean of LC3-II intensity was quantified by flow cytometry and mean of LC3-II geometric mean (+/-SEM) is shown for total PBMC (I, iii) and total monocytes (ii) for each non-IBD and IBD patient group (i-ii) and each ATG16L1 genotype (iii). One-way ANOVA with Tukey's multiple comparison was used to compare LC3II geometric mean between patient groups in untreated cells. Within each patient group paired, two tailed t test was used to compare LC3-II geometric mean of untreated and azathioprine-treated cells. ${ }^{*} p<0.05,{ }^{* *} p<0.01$

Table S1: Concentration and manufacturer details of reagents used for cell treatments.

Working concentrations were diluted in appropriate growth media.

Table S2: Antibody details

796

WB western blot, IF immunofluorescent staining, $F$ flow cytometry, IHC 797 immunohistochemistry. All primary and secondary antibodies were prepared in $1 \%$ FBS or 798 goat serum.

Table S3: qPCR Primer Details

$800 \quad F W$ forward and $R V$ reverse primer sequences. 
802

803

804

805

806

807

808

809

810

811

812

813

814

815

816

817

818

819

820

821

822

823

824

825

826

827

828

$C D$ Crohn's disease, UC Ulcerative colitis, IBDU IBD unclassified. SD Standard deviation. *NonIBD diagnosis included normal (4 patients), mild constipation (1 patient), Irritable Bowel Syndrome (IBS) (3 patients) and threadworms (1 patient). aParis Classification for CD: $L 1$ ileal, L2 colonic, $L 3$ ileocolonic, $L 4 a$ upper disease proximal to ligament of Treitz; B1 non-stricturing and non-penetrating, $B 2$ stricturing, $B 3$ penetrating, $p$ perianal disease modifier ${ }^{72}$. ${ }^{b}$ Paris Classification for UC: E1 ulcerative proctitis, E2 left-sided UC (distal to splenic flexure), E3 extensive (hepatic flexure distally), E4 pancolitis (proximal to hepatic flexure); SO never severe, $S 1$ ever severe as defined by Pediatric Ulcerative Colitis Activity Index (PUCAI) ${ }^{72} .5-$ ASA 5-aminosalisylates.

\section{Figure S1: GFP-LC3 Flow Cytometry in HEK293 GFP-LC3 cells.}

Schematic diagram showing cell permeabilization with $0.05 \%$ saponin to remove cytosolic GFP-LC3 to allow flow cytometery analysis ${ }^{23}$ (i). HEK293 GFP-LC3 cells were either untreated or treated with 160nM bafilomycin for 6 hours. Cells were washed without (ii) or with (iii) cell permeabilization with $0.05 \%$ saponin to remove cytosolic GFP-LC3 before fixation. Geometric mean of GFP-LC3 fluorescent intensity of cells was quantified by flow cytometry and analysed using FlowJo software (ii-iii).

Figure S2: Differentially Expressed Genes from $\mathrm{RT}^{2}$ Profiler ${ }^{\mathrm{TM}} \mathrm{PCR}$ Array for Human Autophagy Genes when treated with Azathioprine

THP-1-derived macrophages were untreated or treated with $120 \mu \mathrm{M}$ azathioprine for 6 hours. mRNA was extracted and converted to cDNA for RT-qPCR analysis using the $\mathrm{RT}^{2}$ Profiler $^{\mathrm{TM}} \mathrm{PCR}$ Array for Human Autophagy genes according to manufacturer instructions. The calibrating sample was untreated cells and relative expression for azathioprine treatment is displayed as fold-change, with upregulated genes calculated as $2^{\text {-ddCT }}$ and downregulated genes as $2^{\text {ddCT }}$. Differentially expressed genes are shown, with 1.5-fold change in expression considered as the threshold for differential expression.

Figure S3: Effect of azathioprine on growth of AIEC, clearance of intracellular AIEC and proinflammatory cytokine responses 
829 LB broth was inoculated from an overnight culture of AIEC to an optical density of 0.05 at

$830600 \mathrm{~nm}$. The cultures were untreated, or treated with DMSO, or $120 \mu \mathrm{M}$ of azathioprine and

831 incubated at $37^{\circ} \mathrm{C}$ with shaking at 200RPM. Optical density at $600 \mathrm{~nm}$ was measured every 0.5

832 hours and plotted in logarithmic scale to show growth phases.

833 Figure S4: Azathioprine activates autophagy in monocyte subsets, T cells, B cells and NK 834 cells from pediatric patients.

835 PBMC isolated from non-IBD control and IBD patients were left untreated or treated with $836120 \mu \mathrm{M}$ azathioprine for $6 \mathrm{~h}$. PBMC were stained with surface markers for classification into 837 populations and for endogenous LC3-II. Geometric mean of LC3-II intensity was quantified by 838 flow cytometry and mean of LC3-II geometric mean (+/-SEM) is shown for classical monocytes 839 (i), intermediate monocytes (ii), non-classical monocytes (iii), T cells (iv), B cells (v) and NK 840 cells (vi) for each non-IBD and IBD patient group. One-way ANOVA with Tukey's multiple 841 comparison was used to compare LC3-II geometric mean between patient groups in 842 untreated cells. Within each patient group paired, two tailed t test was used to compare LC3-

843 II geometric mean of untreated and azathioprine-treated cells. ${ }^{*} p<0.05,{ }^{* *} p<0.01$.

844

845

846 

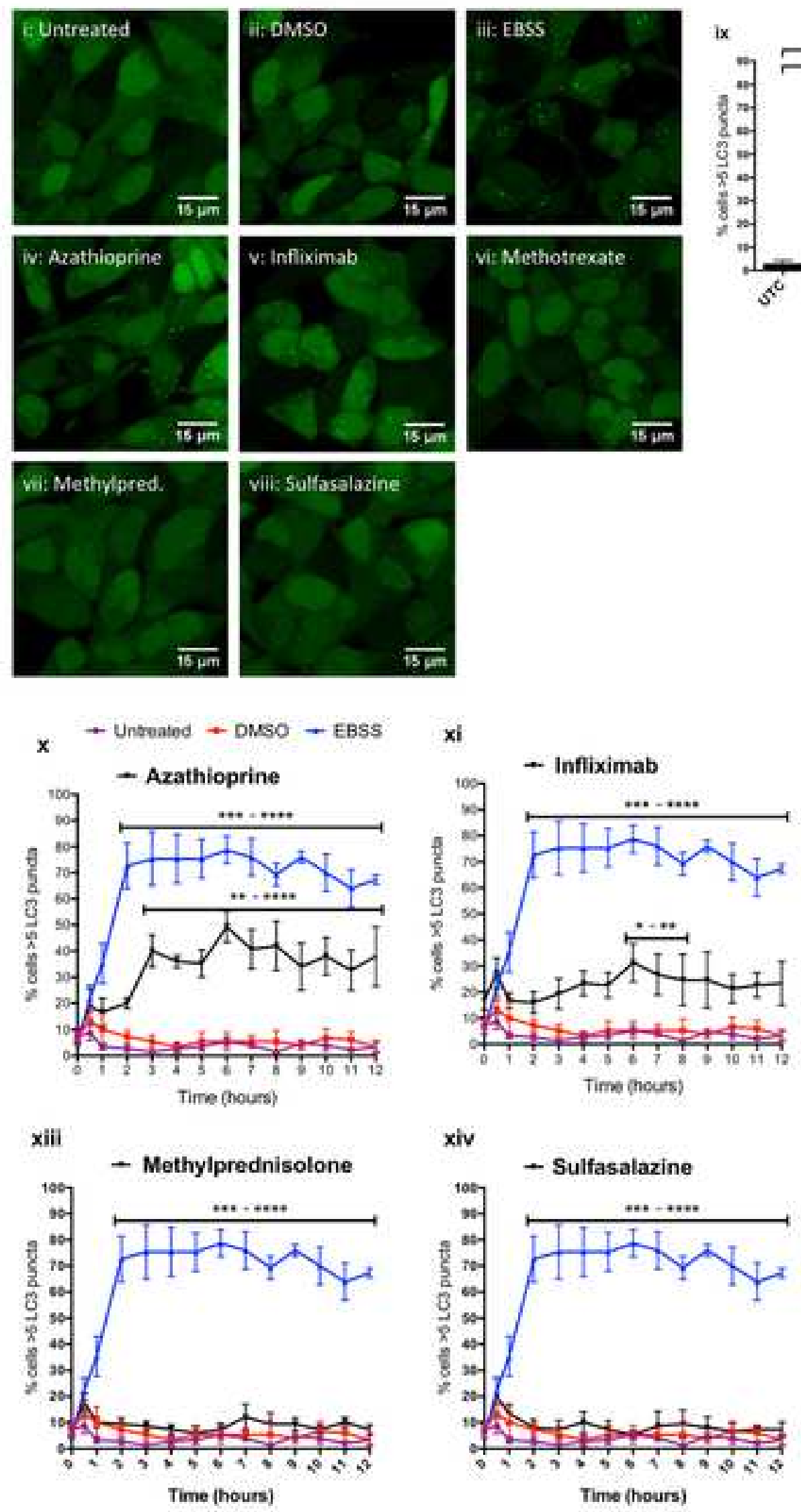
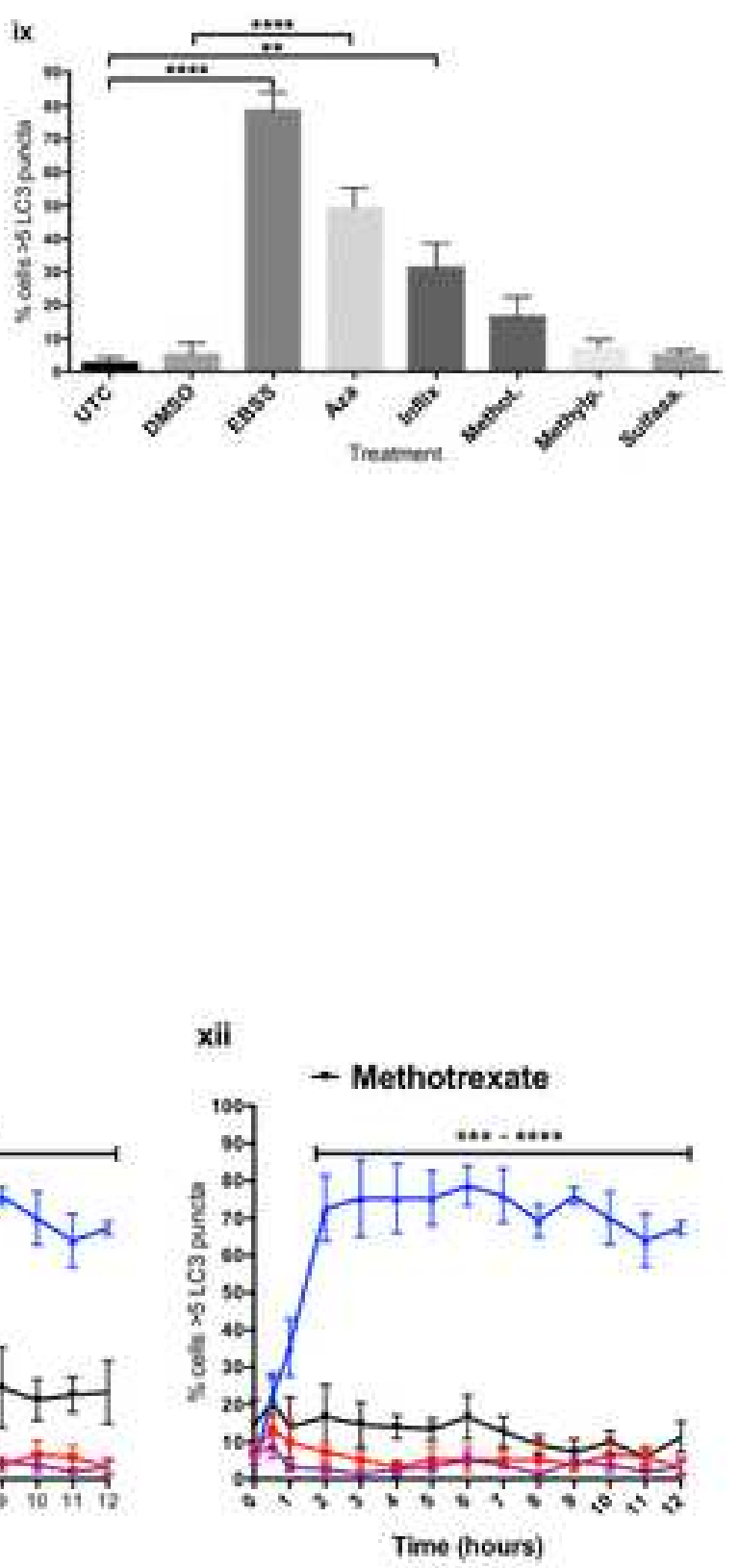
a
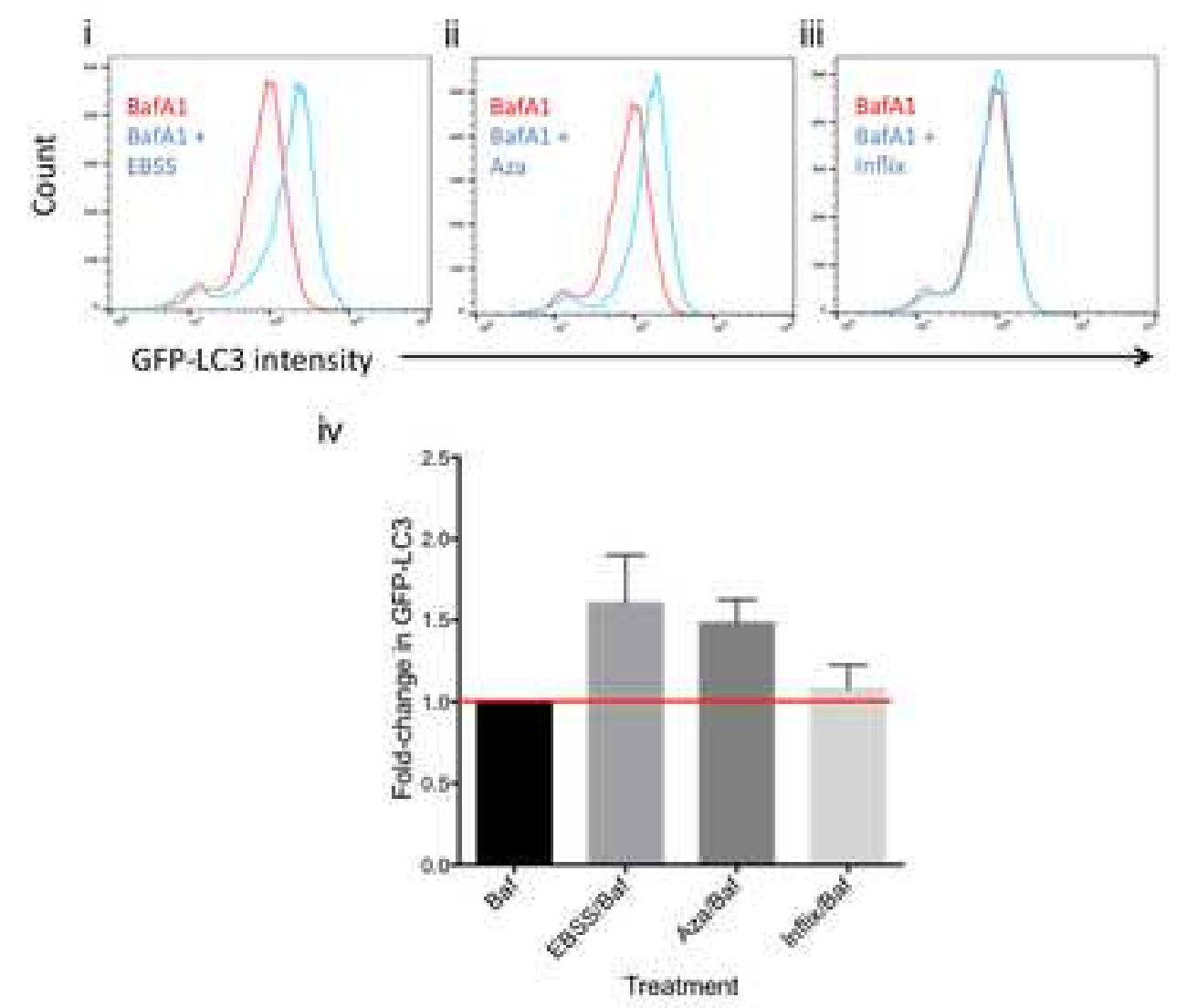

b
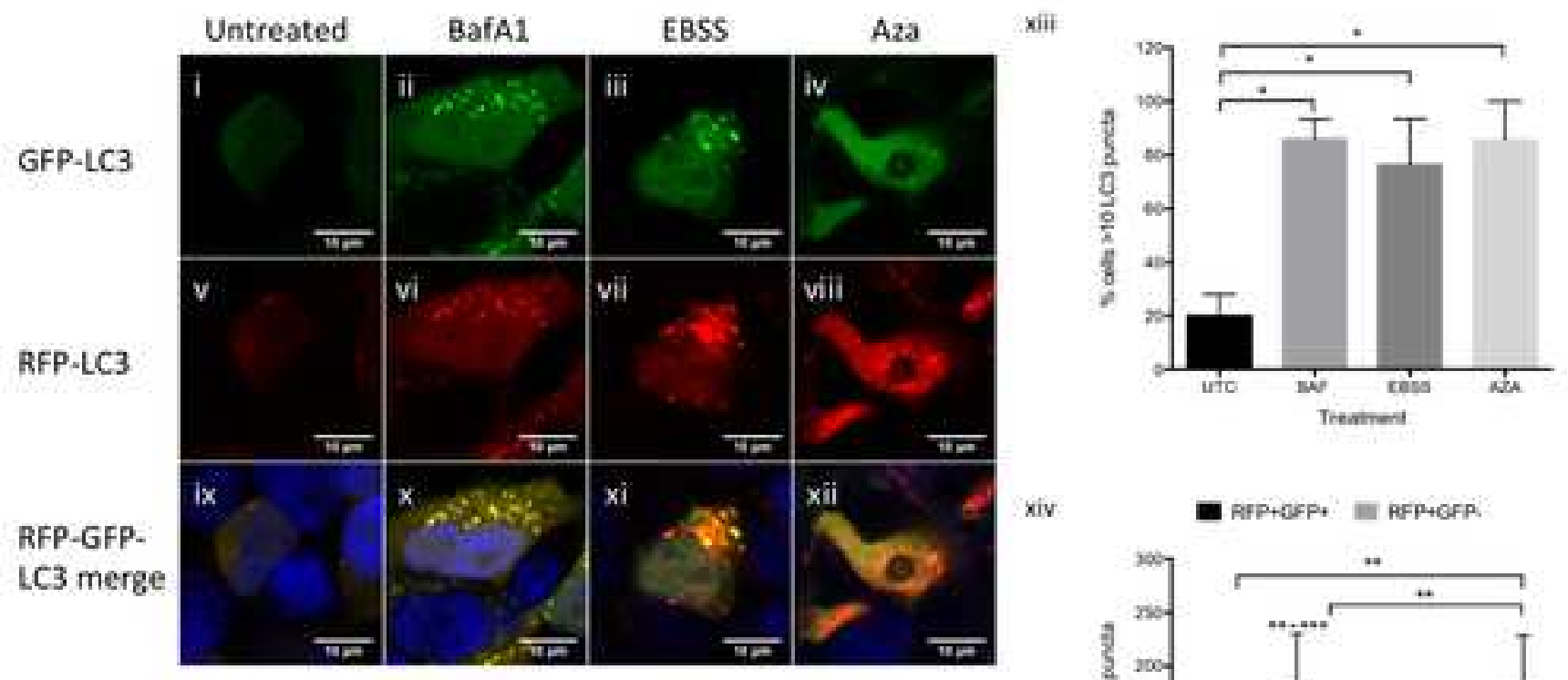

xiv

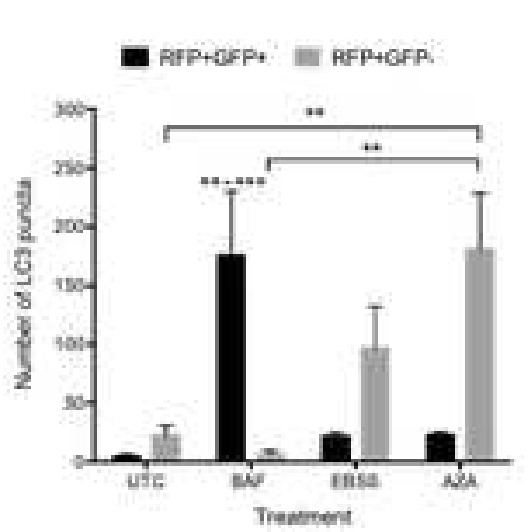

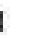

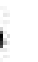


a
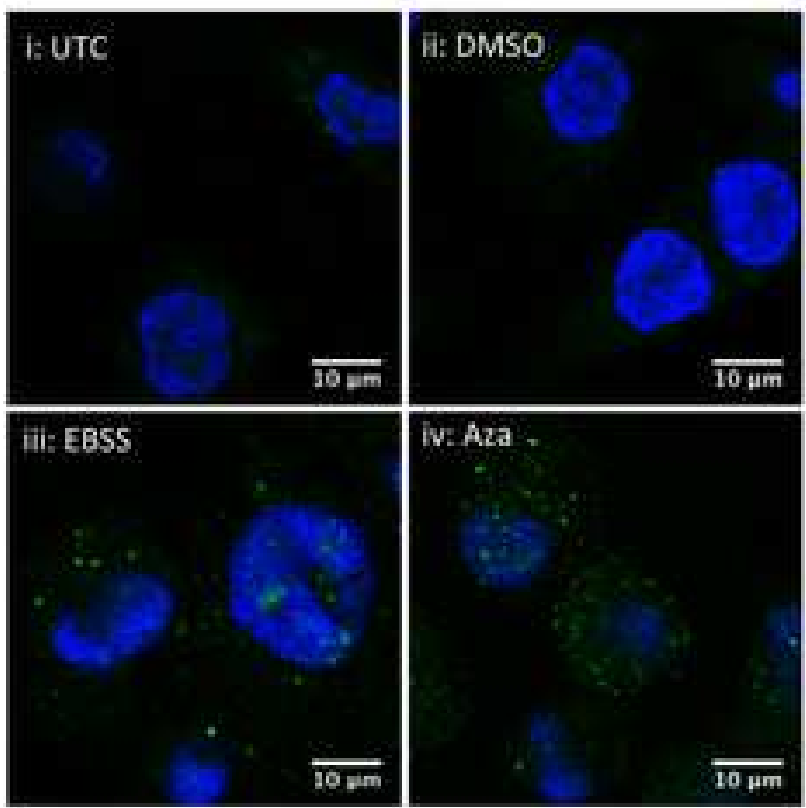

6 hours
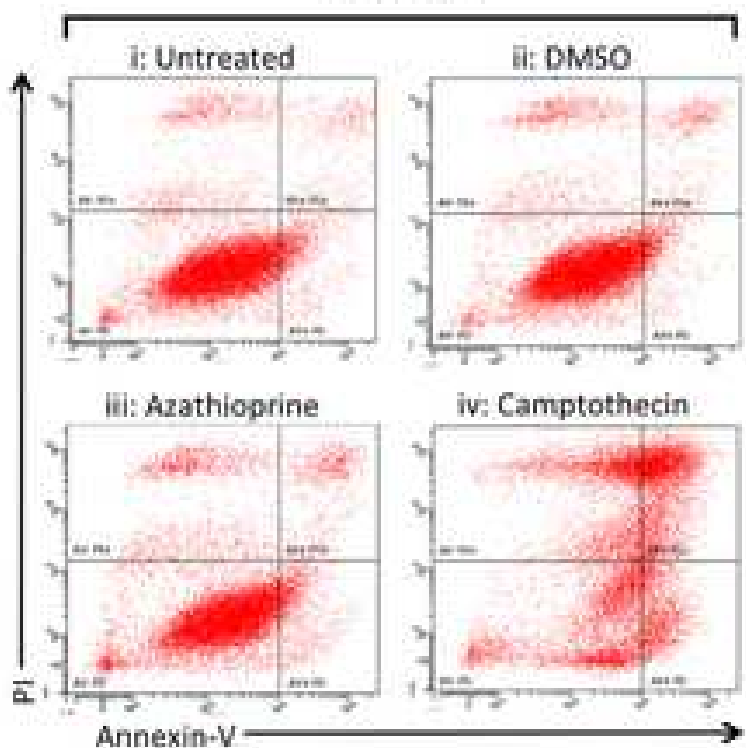

ix

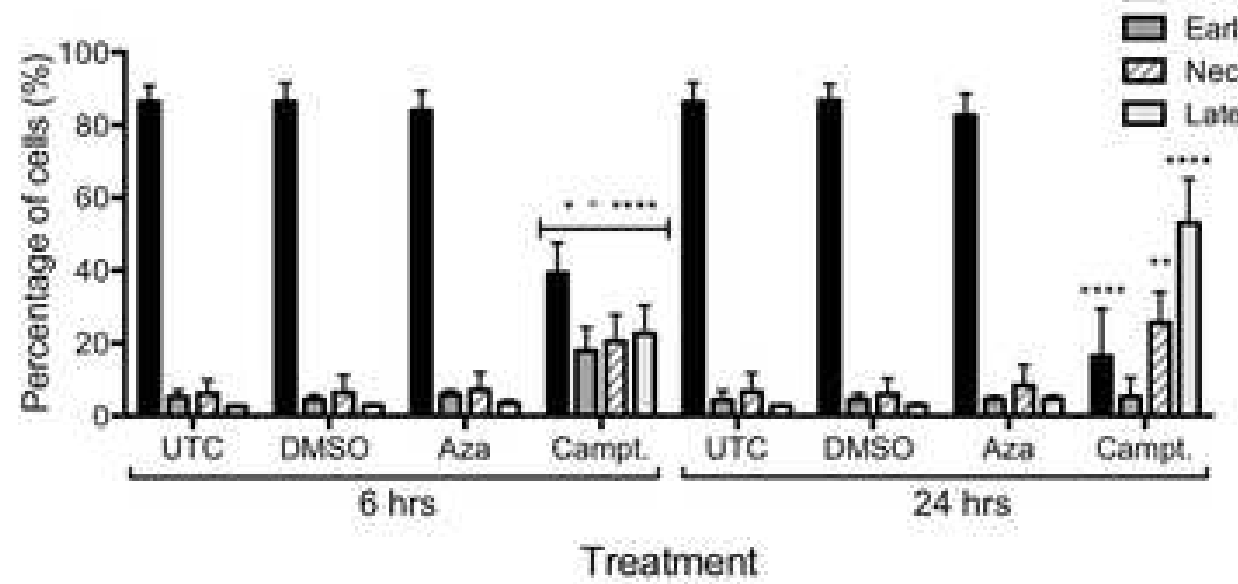

Treatment

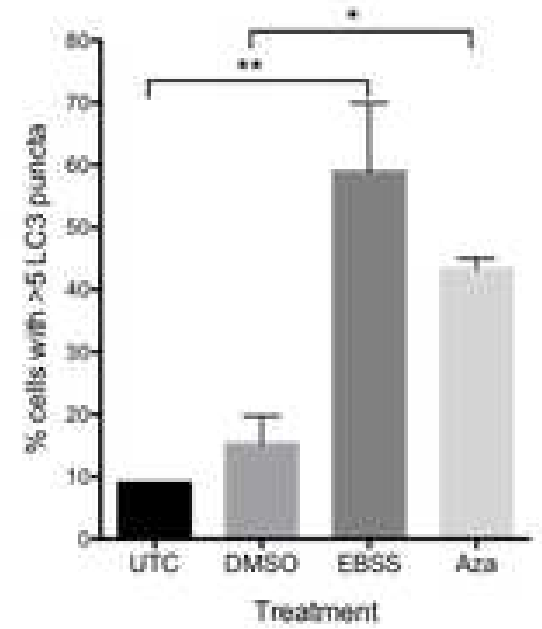

24 hours
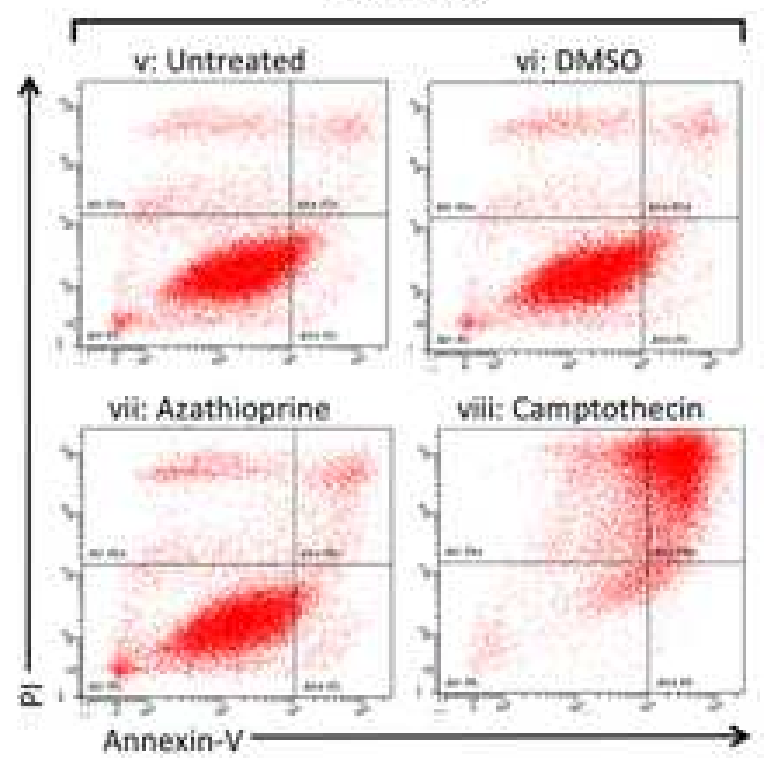

Viable

Earty Apoptotic

Late Apoptotic 

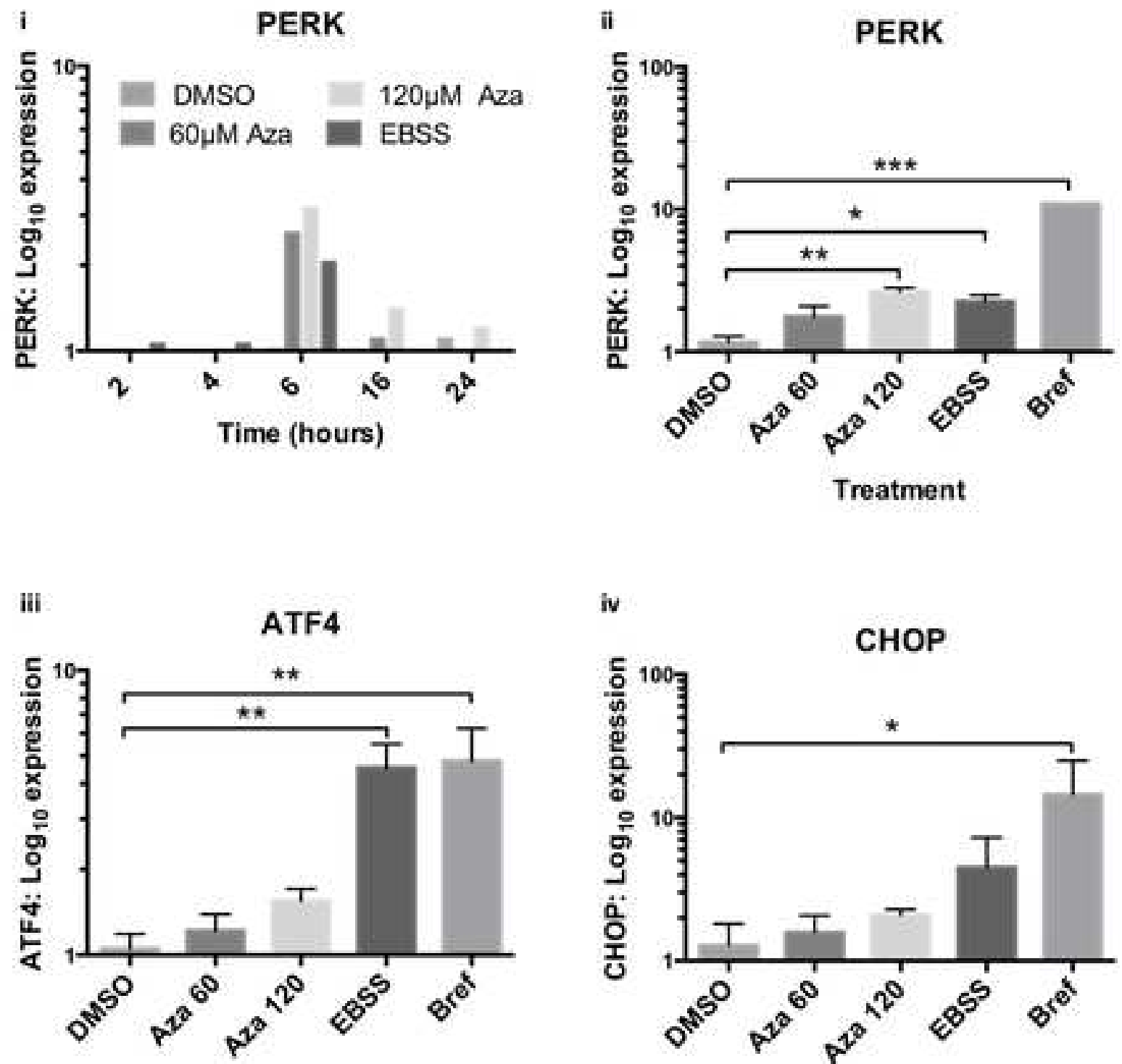

Treatment

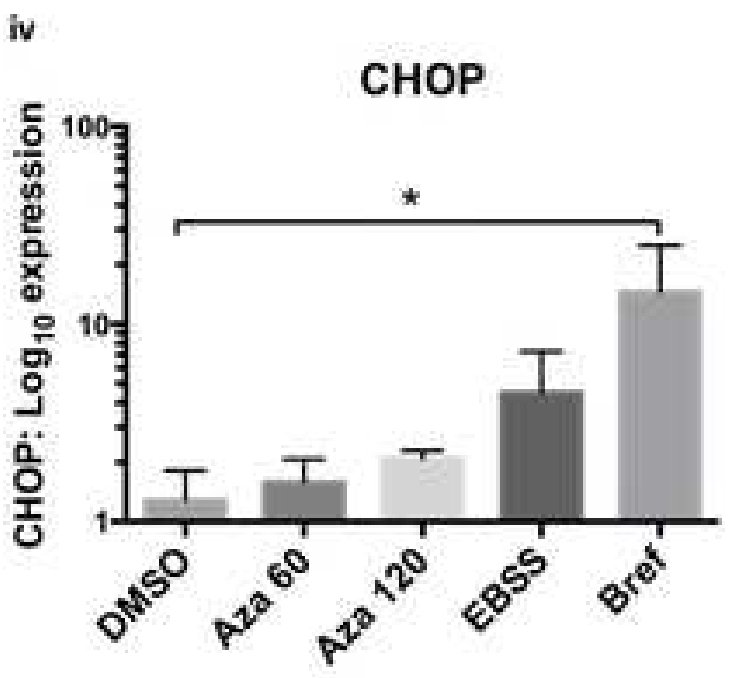

\section{Treatment}
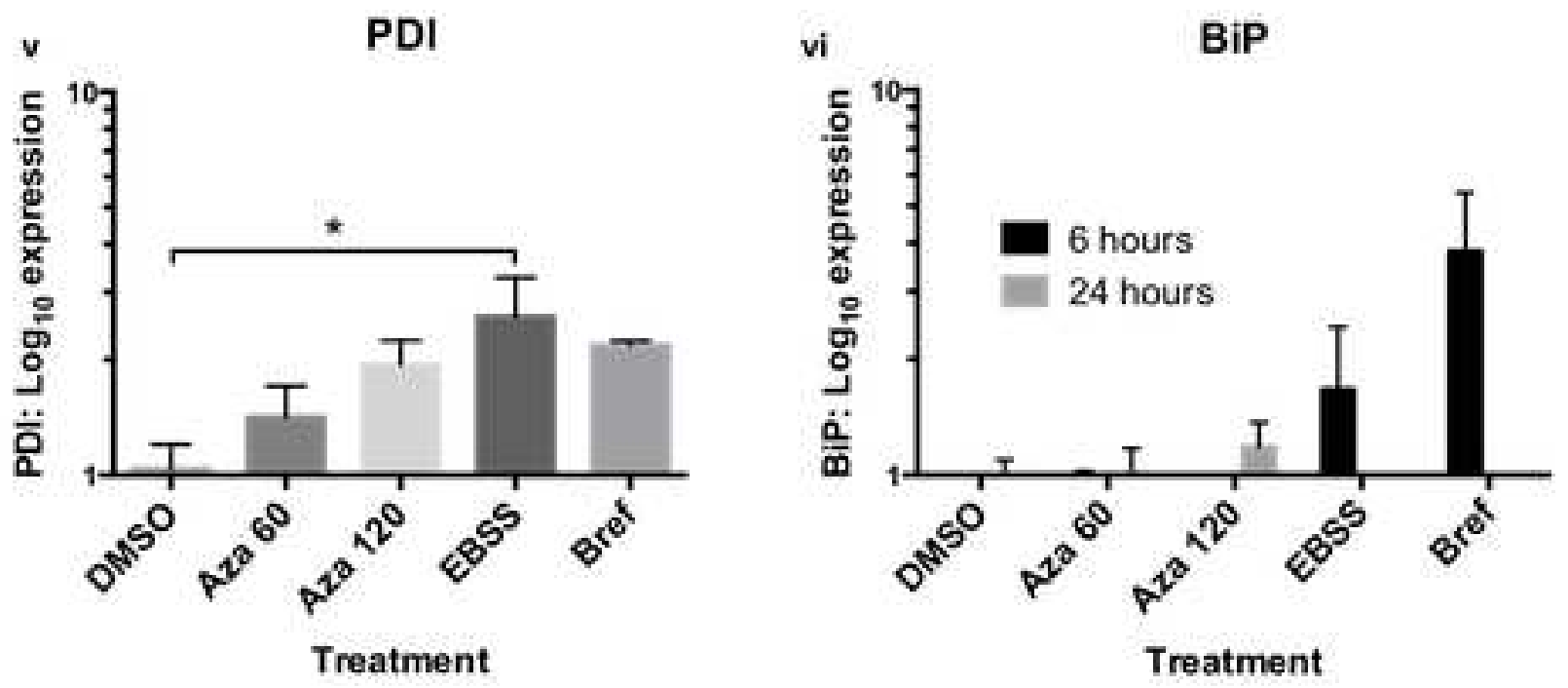

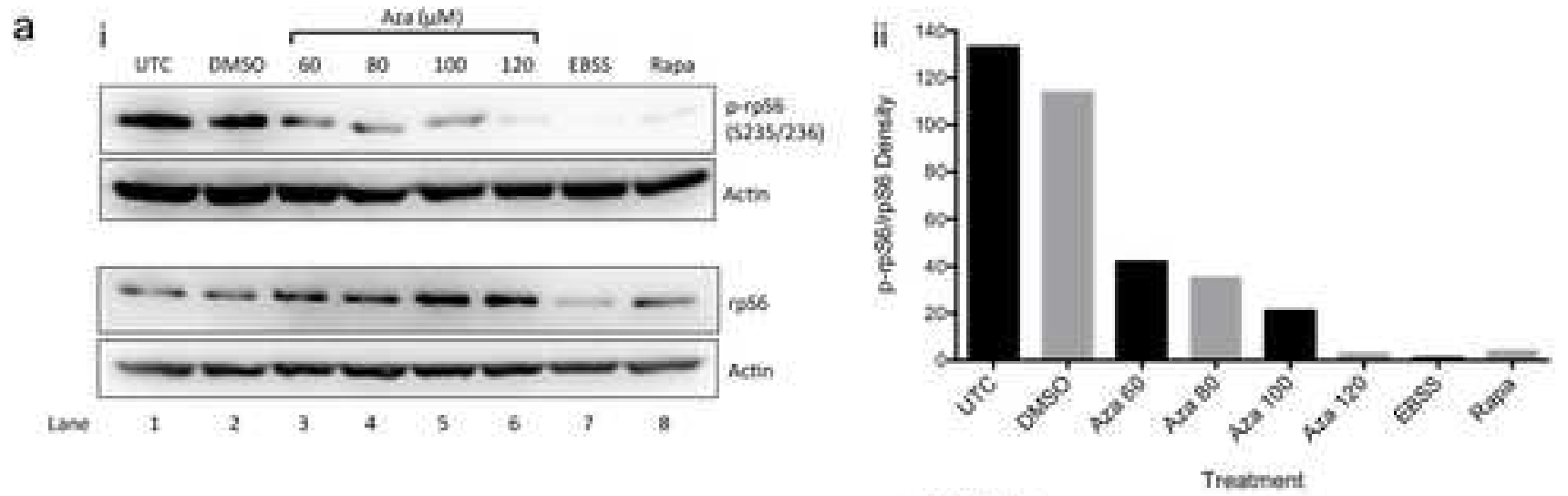

b

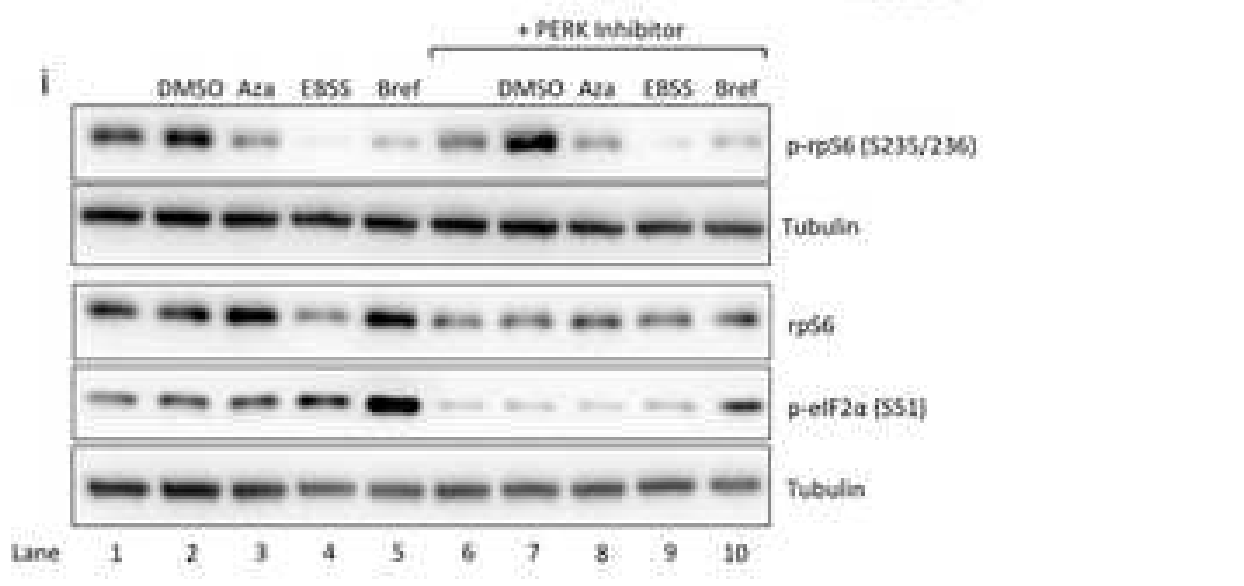

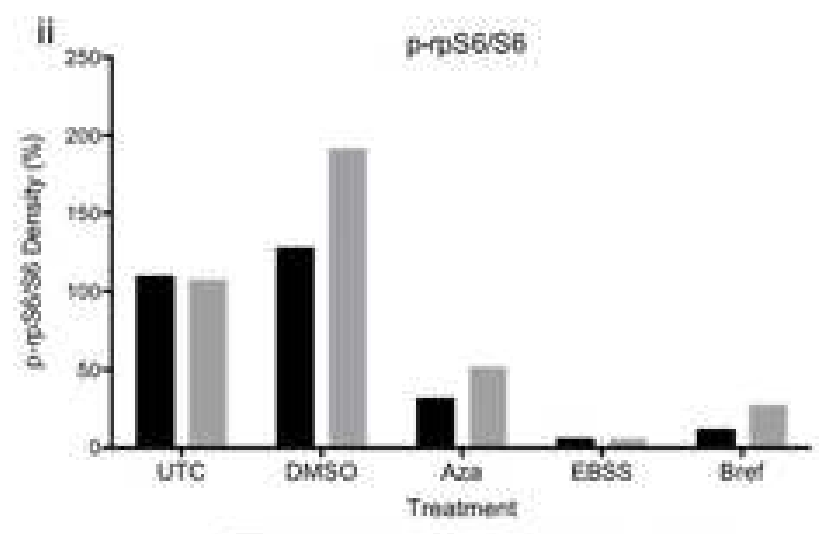

- wio PERK inhiber :

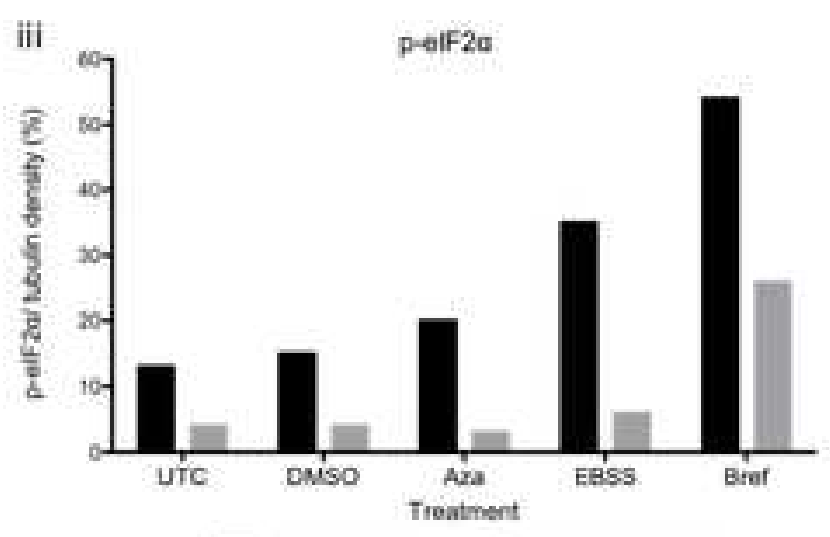

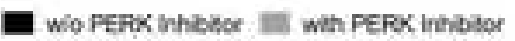

C

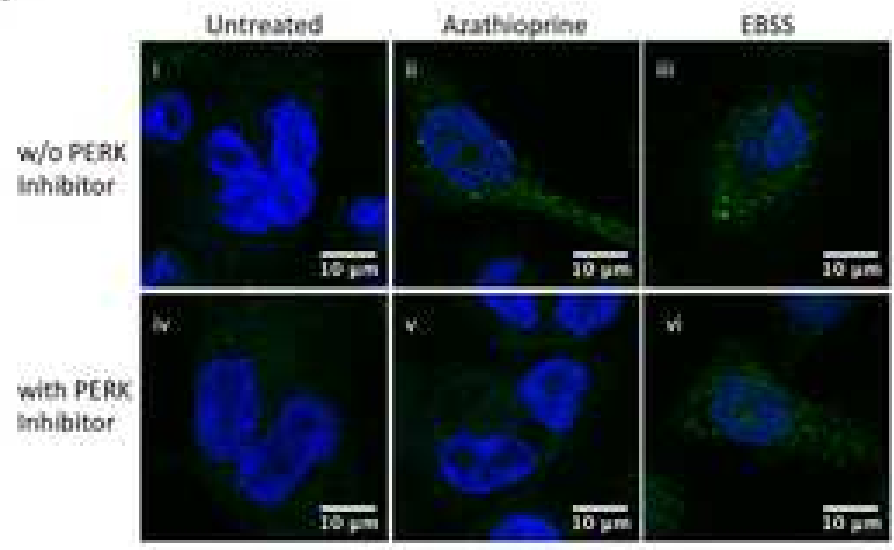

vii

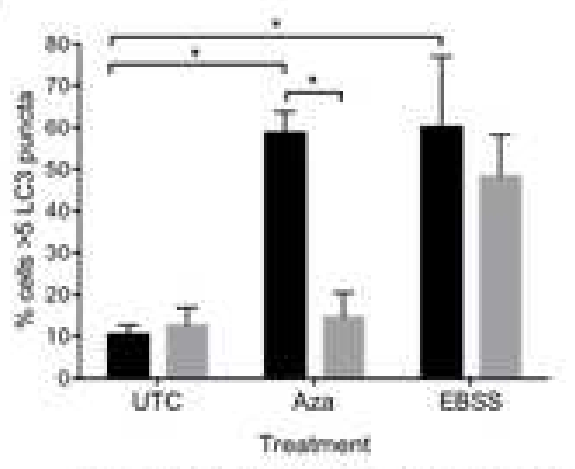

wio PERK inhbeor III wis PERK inhiodot 
a

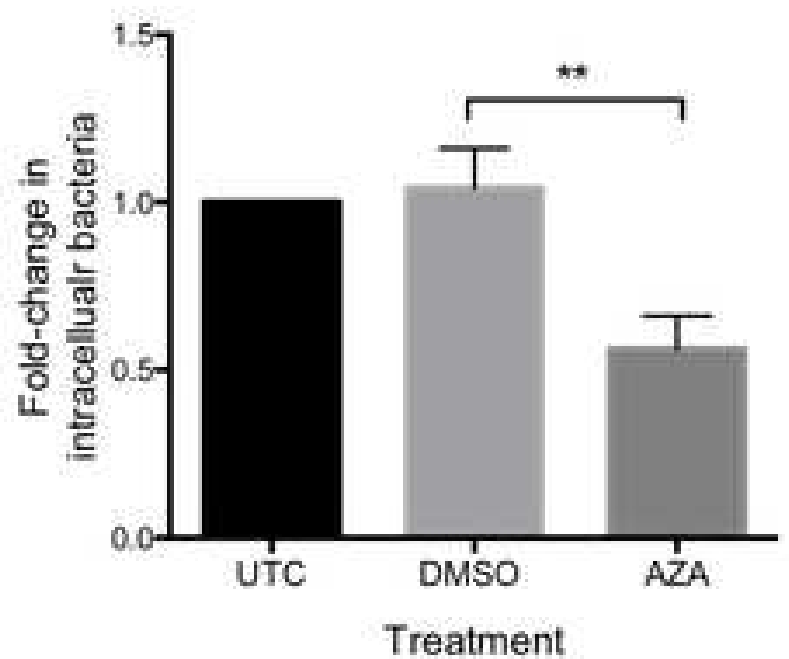

C
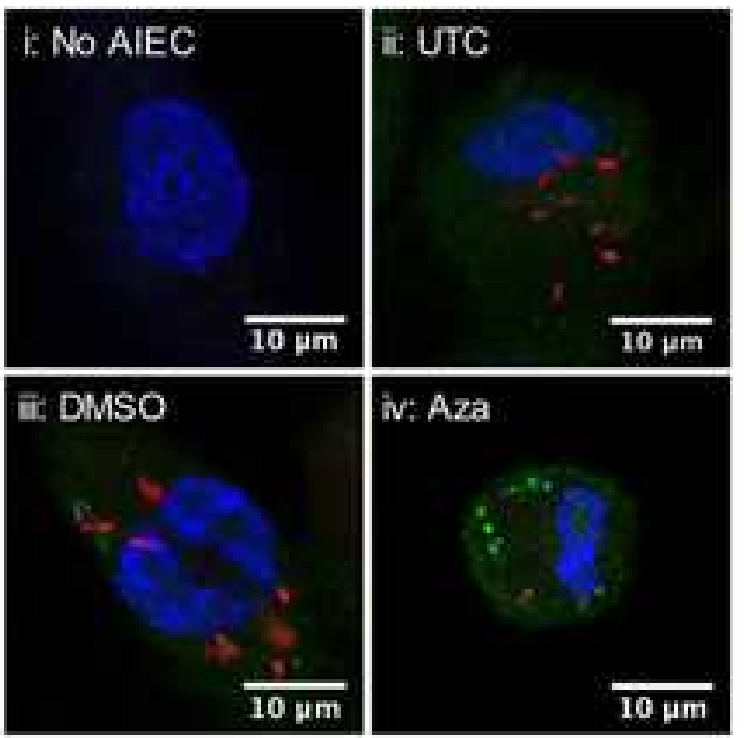

d

i

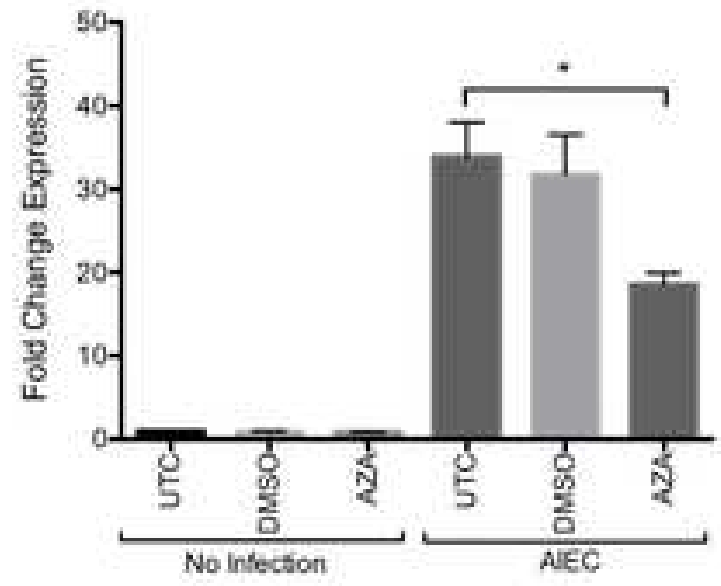

Infection and Treatment b
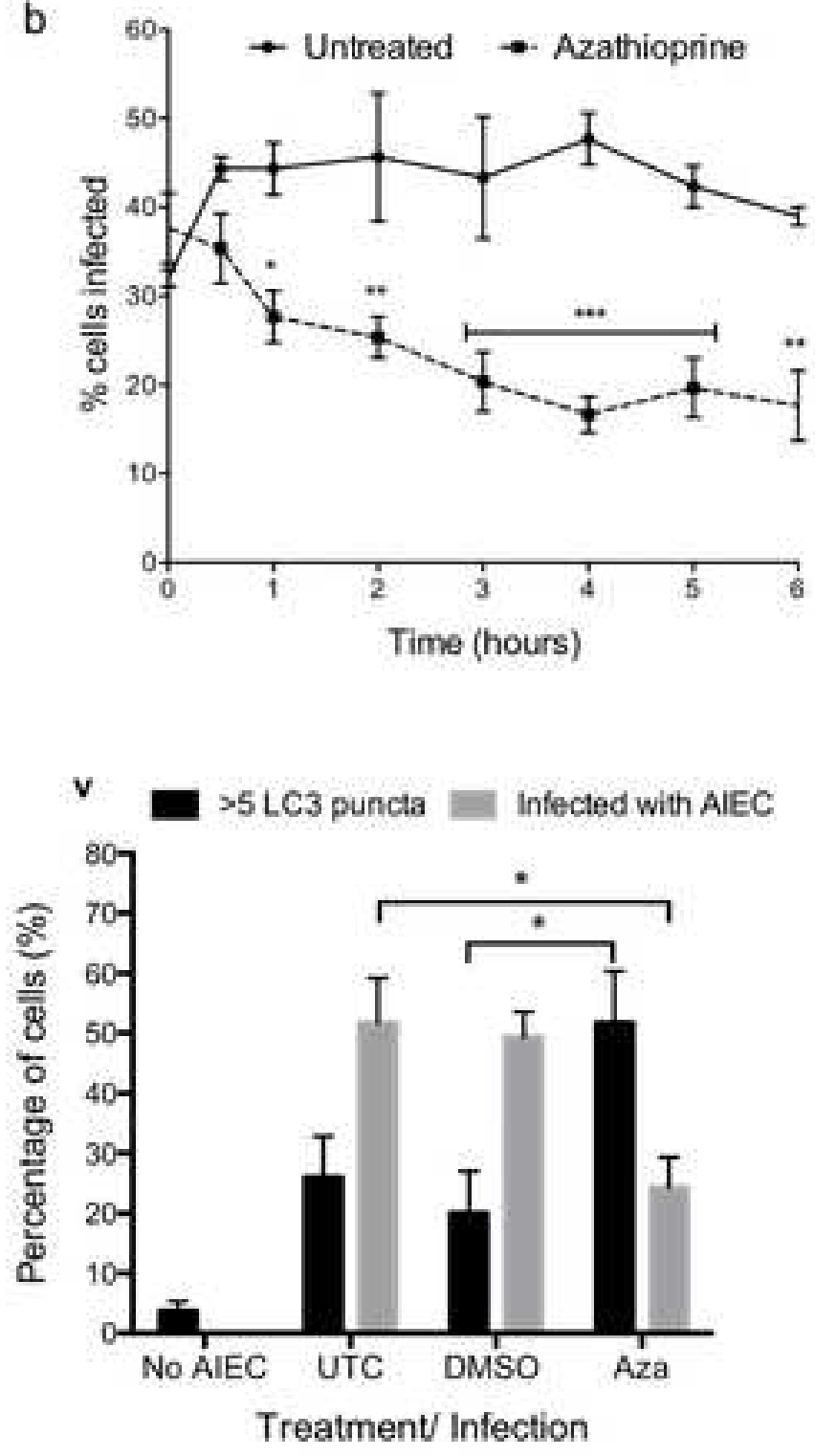

白

TNF-et

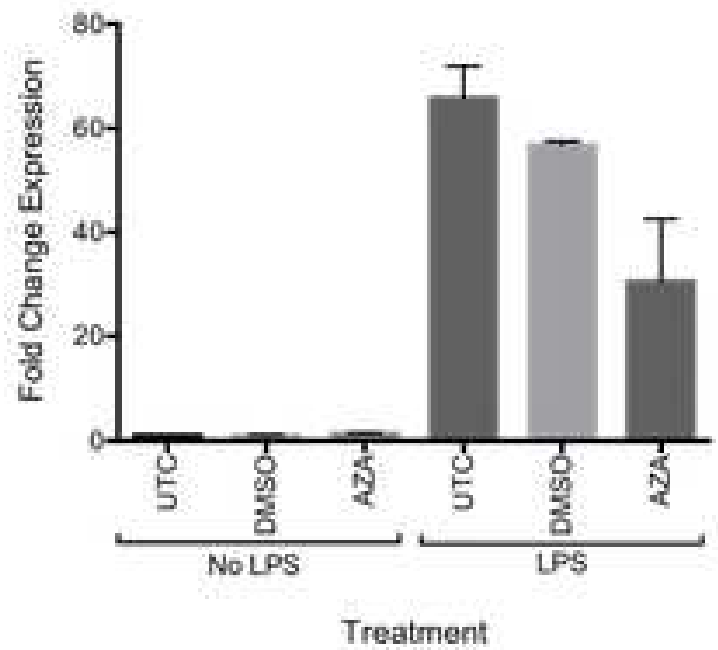



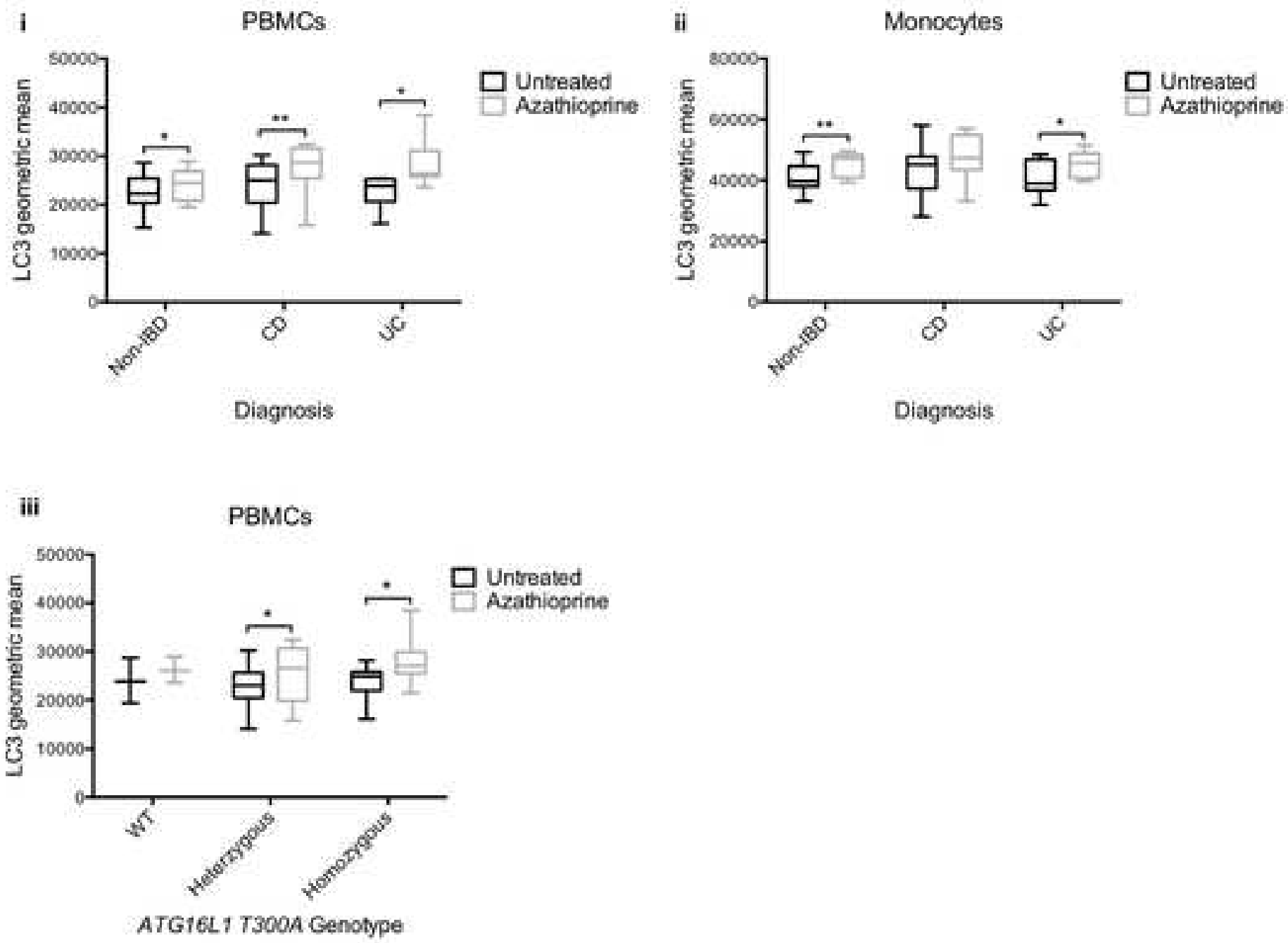


\begin{tabular}{|c|c|c|c|}
\hline Reagents & Stock conc. & $\begin{array}{l}\text { Working } \\
\text { conc. }\end{array}$ & Manufacturer \\
\hline $\begin{array}{l}\text { Azathioprine, 6-mercaptopurine, } \\
\text { methotrexate, } \\
\text { methylprednisolone, } \\
\text { sulfasalazine }\end{array}$ & $\begin{array}{l}400 \mathrm{mM} \text { in } \\
\text { DMSO }\end{array}$ & $1-150 \mu \mathrm{M}$ & $\begin{array}{l}\text { Tocris, Abingdon, } \\
\text { UK }\end{array}$ \\
\hline Bafilomycin A1 & $\begin{array}{l}1 \mathrm{mg} / \mathrm{ml} \text { in } \\
\mathrm{DMSO}\end{array}$ & $160 \mathrm{nM}$ & $\begin{array}{l}\text { Santa Cruz } \\
\text { Biotechnology, } \\
\text { Dallas, Texas, USA }\end{array}$ \\
\hline $\begin{array}{l}\text { Brefeldin A from Penicillium } \\
\text { brefeldianum }\end{array}$ & $\begin{array}{l}10 \mathrm{mg} / \mathrm{ml} \text { in } \\
\text { DMSO }\end{array}$ & $0.5 \mu \mathrm{g} / \mathrm{ml}$ & $\begin{array}{l}\text { Sigma-Aldirch, } \\
\text { Irvine, UK }\end{array}$ \\
\hline PERK inhibitor I (GSK2606414) & $5 \mu \mathrm{M}$ in DMSO & $50 \mathrm{nM}$ & $\begin{array}{l}\text { Calbiochem }{ }^{\circ} \text {, } \\
\text { Merck Millipore, } \\
\text { Watford, UK }\end{array}$ \\
\hline Rapamycin & $2 \mathrm{mg} / \mathrm{ml}$ & $100 \mathrm{nM}$ & $\begin{array}{l}\text { Sigma, Life } \\
\text { Sciences, UK }\end{array}$ \\
\hline Remicade $^{\circ}$ (infliximab) & $\begin{array}{l}10 \mathrm{mg} / \mathrm{ml} \text { in } \\
\mathrm{dH}_{2} \mathrm{O}\end{array}$ & $5-100 \mu \mathrm{g} / \mathrm{ml}$ & $\begin{array}{l}\text { A gift from David } \\
\text { Hoole, RHSC }\end{array}$ \\
\hline
\end{tabular}




\begin{tabular}{|c|c|c|c|c|}
\hline Type & Antibody & $\begin{array}{l}\text { Clone } \\
\text { (Isotype) }\end{array}$ & Use (Conc.) & Manufacturer \\
\hline \multirow[t]{8}{*}{$\begin{array}{l}\text { Primary } \\
\text { Antibodies }\end{array}$} & Ms actin & ACTN05 [C4] & WB ( 1 in 5000$)$ & $\begin{array}{l}\text { Abcam, Cambridge, } \\
\text { UK }\end{array}$ \\
\hline & $\begin{array}{l}\text { Rb phospho-elF2 } \alpha \\
\text { (S51) }\end{array}$ & 119A11 & WB ( 1 in 1000$)$ & $\begin{array}{l}\text { Cell Signalling, Hitchin, } \\
\text { UK }\end{array}$ \\
\hline & Ms LC3 & $2 \mathrm{G6}$ & WB 1 in 1000) & $\begin{array}{l}\text { NanoTools Teningen, } \\
\text { Germany }\end{array}$ \\
\hline & $\mathrm{Rb} L \mathrm{LC} 3$ & PM036 & $\begin{array}{l}\text { IF, IHC ( } 1 \text { in } \\
1000)\end{array}$ & MBL Intl., MA, USA \\
\hline & Rb cleaved-PARP & D214 & WB (1 in 1000) & Cell Signalling \\
\hline & Ms rpS6 & $54 \mathrm{D} 2$ & WB ( 1 in 1000) & Cell Signalling \\
\hline & $\begin{array}{l}\text { Rb phospho-rpS6 } \\
\text { (S235/236) }\end{array}$ & $2 \mathrm{Fg}$ & WB ( 1 in 1000$)$ & Cell Signalling \\
\hline & Rb Tubulin & GR187587-1 & WB ( 1 in 5000$)$ & Abcam \\
\hline \multirow{6}{*}{$\begin{array}{l}\text { PBMC } \\
\text { surface } \\
\text { markers }\end{array}$} & $\begin{array}{l}\text { PE-Cy }{ }^{T M} 7 \text { Ms Anti- } \\
\text { Human CD3 }\end{array}$ & $\begin{array}{l}\text { UCHT1 (MOPC- } \\
21)\end{array}$ & $F(1$ in 40$)$ & $\begin{array}{l}\text { BD Pharmingen }{ }^{\mathrm{ms}} \text {, } \\
\text { Oxford, UK }\end{array}$ \\
\hline & $\begin{array}{l}\text { PE-Ms Anti-Human } \\
\text { CD14 }\end{array}$ & M5E2 & $F(1$ in 10$)$ & BD Pharmingen ${ }^{\mathrm{TM}}$ \\
\hline & $\begin{array}{l}\text { PerCP-Cy }{ }^{\mathrm{m}} 5.5 \mathrm{Ms} \\
\text { Anti-Human CD16 }\end{array}$ & $3 \mathrm{G} 8$ & $F(1$ in 40$)$ & BD Pharmingen ${ }^{\mathrm{m}}$ \\
\hline & $\begin{array}{l}\text { BV786 Ms Anti- } \\
\text { Human CD19 }\end{array}$ & HIB19 (X40) & $F(1$ in 40$)$ & $\begin{array}{l}\text { BD Horizon }{ }^{\text {Tu}} \text {, Oxford, } \\
\text { UK }\end{array}$ \\
\hline & $\begin{array}{l}\text { BV650 Ms Anti- } \\
\text { Human CD56 }\end{array}$ & $\begin{array}{l}\text { NCAM16.2 (27- } \\
35)\end{array}$ & $F(1$ in 40$)$ & BD Horizon ${ }^{\text {Ts }}$ \\
\hline & $\begin{array}{l}\text { BV421 Ms Anti- } \\
\text { Human HLA-DR }\end{array}$ & $\begin{array}{l}\text { G46-6 } \\
\text { (Polycional) }\end{array}$ & $F(1$ in 40$)$ & BD Horizon ${ }^{\mathrm{Tu}}$ \\
\hline \multirow[t]{2}{*}{$\begin{array}{l}\text { Secondary } \\
\text { Antibodies }\end{array}$} & $\begin{array}{l}\text { Goat anti-Rb and } \\
\text { goat anti-Ms } \\
\text { IgG/HRP }\end{array}$ & $F: 1.0$ and $F: 1.5$ & WB ( 1 in 5000$)$ & $\begin{array}{l}\text { Dako, Glostrup, } \\
\text { Denmark }\end{array}$ \\
\hline & $\begin{array}{l}\text { Goat anti-Rb lgG- } \\
\text { FITC }\end{array}$ & & $\begin{array}{l}\text { IF }(1 \text { in } 1000), F \\
(1 \text { in } 500)\end{array}$ & Sigma \\
\hline
\end{tabular}




\begin{tabular}{|c|c|c|c|}
\hline $\begin{array}{l}\text { Target } \\
\text { Gene }\end{array}$ & FW Primer & RV Primer & Manufacturer \\
\hline Actin & GGACTTCGAGCAAGAGATGG & AGGAAGGAAGGCTGGAAGAG & $\begin{array}{l}\text { Eurofins } \\
\text { Genomics, } \\
\text { Ebersberg, } \\
\text { Germany }\end{array}$ \\
\hline ATF4 & CTCCGGGACAGATTGGATGIT & GGCTGCTTATTAGTCTCCTGGAC & Eurofins Genomics \\
\hline $\begin{array}{l}\text { BiP } \\
\text { (GRP78) }\end{array}$ & TATGGTGCTGCTGTCCAGG & CTGAGACTTCTTGGTAGGCAC & Eurofins Genomics \\
\hline CHOP & AGCTGGAAGCCTGGTATGAGG & GTGCTTGTGACCTCTGCTGG & Eurofins Genomics \\
\hline PERK & GGAAACGAGAGCAGGATTTATT & ACTATGTCCATTATGGCAGCTTC & Eurofins Genomics \\
\hline PDI & TGCCCAAGAGTGTGTCTGAC & CTGGTTGTCGGTGTGGTC & Eurofins Genomics \\
\hline RPL13A & Primer Mix & Primer Mix & $\begin{array}{l}\text { PrimerDesign Ltd, } \\
\text { Chandler's ford, } \\
\text { UK }\end{array}$ \\
\hline$T N F \alpha$ & GCTGCACTITGGAGTGATCG & GCTTGAGGGITTGCTACAACA & Eurofins Genomics \\
\hline
\end{tabular}




\begin{tabular}{|c|c|c|c|c|c|}
\hline & & Non-IBD* & CD & UC & IBDU \\
\hline \multicolumn{2}{|l|}{ Cohort $(n=29)$} & 9 & 12 & 7 & 1 \\
\hline \multicolumn{2}{|c|}{ Age years (mean $+/-$ SD) } & $10.7+/-3.3$ & $12.8+/-2.7$ & $13.4+/-2.5$ & $9.7+1-0$ \\
\hline \multicolumn{2}{|c|}{$\begin{array}{l}\text { Disease duration: years } \\
\text { (mean }+/- \text { SD) }\end{array}$} & N/A & $1.4+/-2.3$ & $1.9+/-3.4$ & 0 \\
\hline \multicolumn{6}{|l|}{ Gender } \\
\hline \multicolumn{2}{|l|}{$\begin{array}{l}\text { Male } \\
\text { Female }\end{array}$} & $\begin{array}{l}6 \\
3\end{array}$ & 11 & $\begin{array}{l}3 \\
4\end{array}$ & $\begin{array}{l}0 \\
1\end{array}$ \\
\hline \multicolumn{6}{|c|}{ Disease Location } \\
\hline $\begin{array}{l}L 1^{a} \\
L 2^{a} \\
L 3^{a} \\
L 1 / L 4 a^{a} \\
L 2 / L 4 a^{a} \\
L 3 / L 4 a^{a}\end{array}$ & $\begin{array}{l}E 1^{b} \\
E 2^{b} \\
E 3^{b} \\
E 4^{b}\end{array}$ & $\begin{array}{l}\text { N/A } \\
\text { N/A } \\
\text { N/A } \\
\text { N/A } \\
\text { N/A } \\
\text { N/A }\end{array}$ & $\begin{array}{l}1^{a} \\
1^{a} \\
2^{a} \\
1^{a} \\
1^{a} \\
5^{a}\end{array}$ & $\begin{array}{l}0^{b} \\
3^{b} \\
1^{b} \\
3^{b} \\
\text { N/A } \\
\text { N/A }\end{array}$ & $\begin{array}{l}0^{b} \\
1^{b} \\
0^{b} \\
0^{b} \\
\text { N/A } \\
\text { N/A }\end{array}$ \\
\hline \multicolumn{6}{|c|}{ Disease Behaviour ${ }^{\text {a }}$} \\
\hline $\begin{array}{l}B 1^{\mathrm{a}} \\
\mathrm{B}^{\mathrm{a}} \\
\mathrm{B}^{\mathrm{a}} \\
\mathrm{B} 1 \mathrm{p}^{\mathrm{a}}\end{array}$ & $\begin{array}{l}\mathrm{SO}^{\mathrm{b}} \\
\mathrm{S} 1^{\mathrm{b}}\end{array}$ & $\begin{array}{l}\text { N/A } \\
\text { N/A } \\
\text { N/A } \\
\text { N/A }\end{array}$ & $\begin{array}{l}8^{a} \\
1^{a} \\
0^{a} \\
2^{a}\end{array}$ & $\begin{array}{l}5^{b} \\
2^{b} \\
\text { N/A } \\
\text { N/A }\end{array}$ & $\begin{array}{l}1^{\mathrm{b}} \\
0^{\mathrm{b}} \\
\text { N/A } \\
\text { N/A }\end{array}$ \\
\hline \multicolumn{6}{|l|}{ Therapy (n) } \\
\hline None & & N/A & 7 & 4 & 1 \\
\hline Immunos & essants & N/A & 1 & 0 & 0 \\
\hline Biologics & & N/A & 3 & 0 & 0 \\
\hline Biologics, & ourines & N/A & 1 & 0 & 0 \\
\hline Biologics, & & N/A & 0 & 1 & 0 \\
\hline 5-ASA, th & ines & N/A & 0 & 2 & 0 \\
\hline
\end{tabular}


i

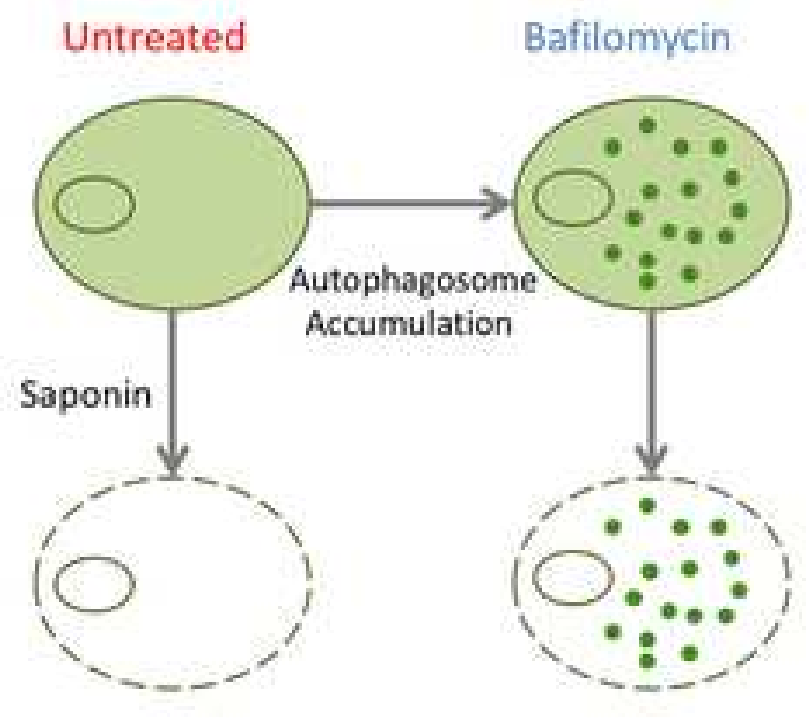

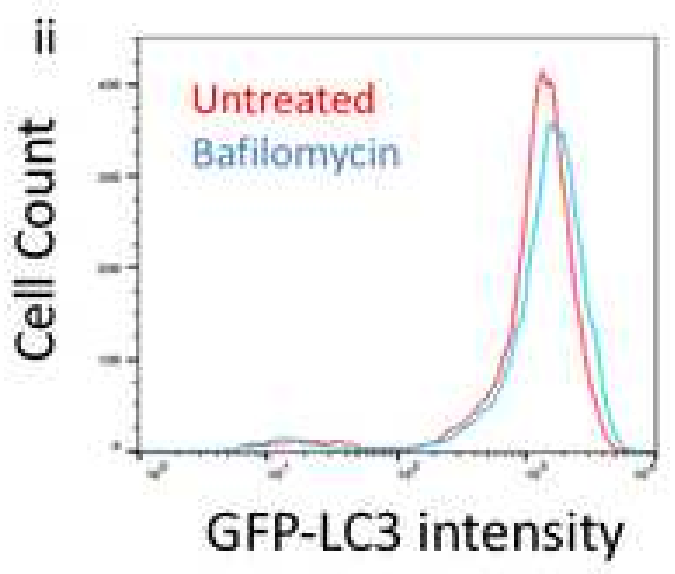

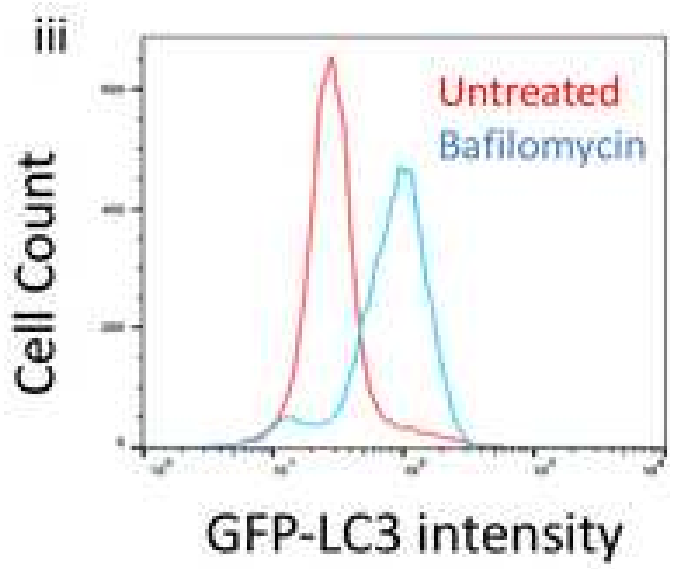




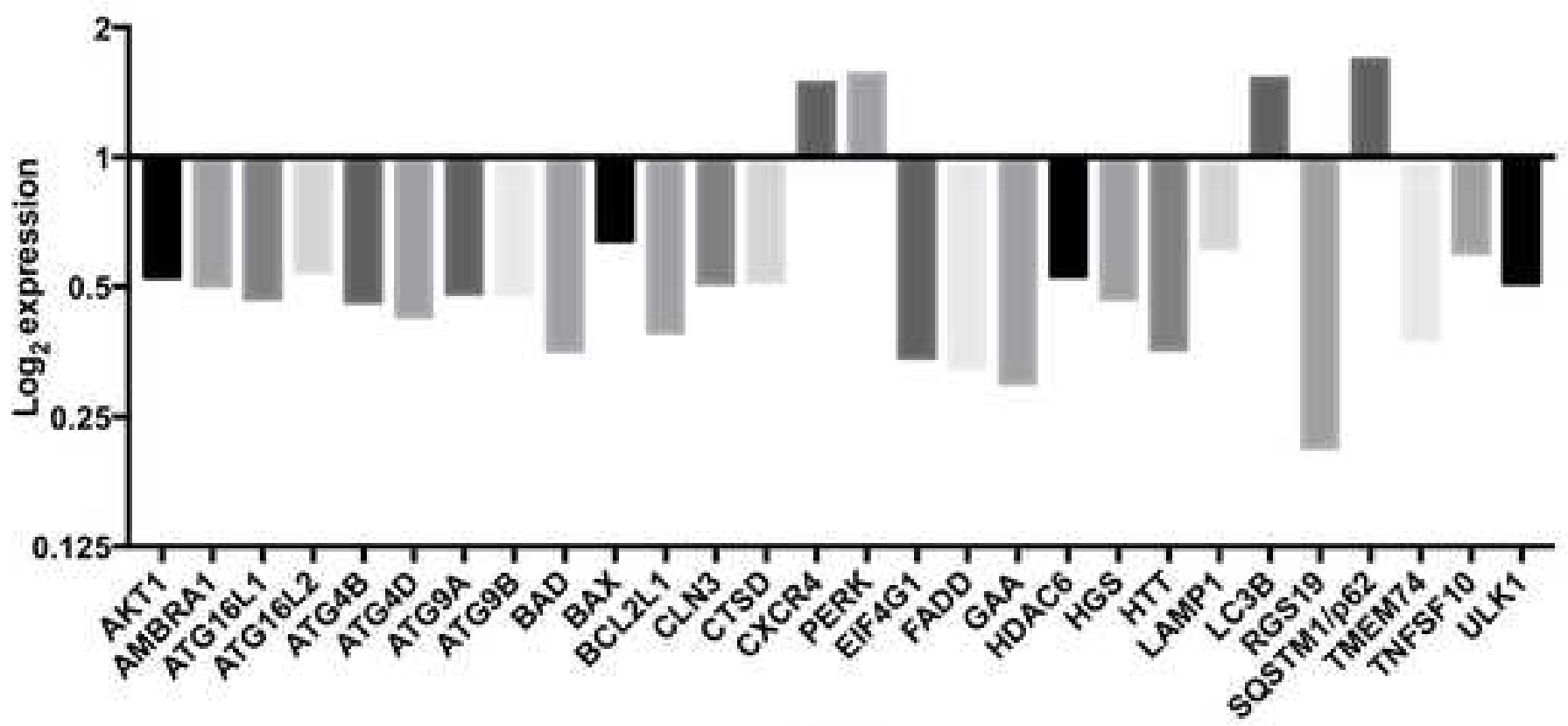

Genes 
Fig S3

Click here to access/download;Supplementary Material For

Review;Fig S3.tiff

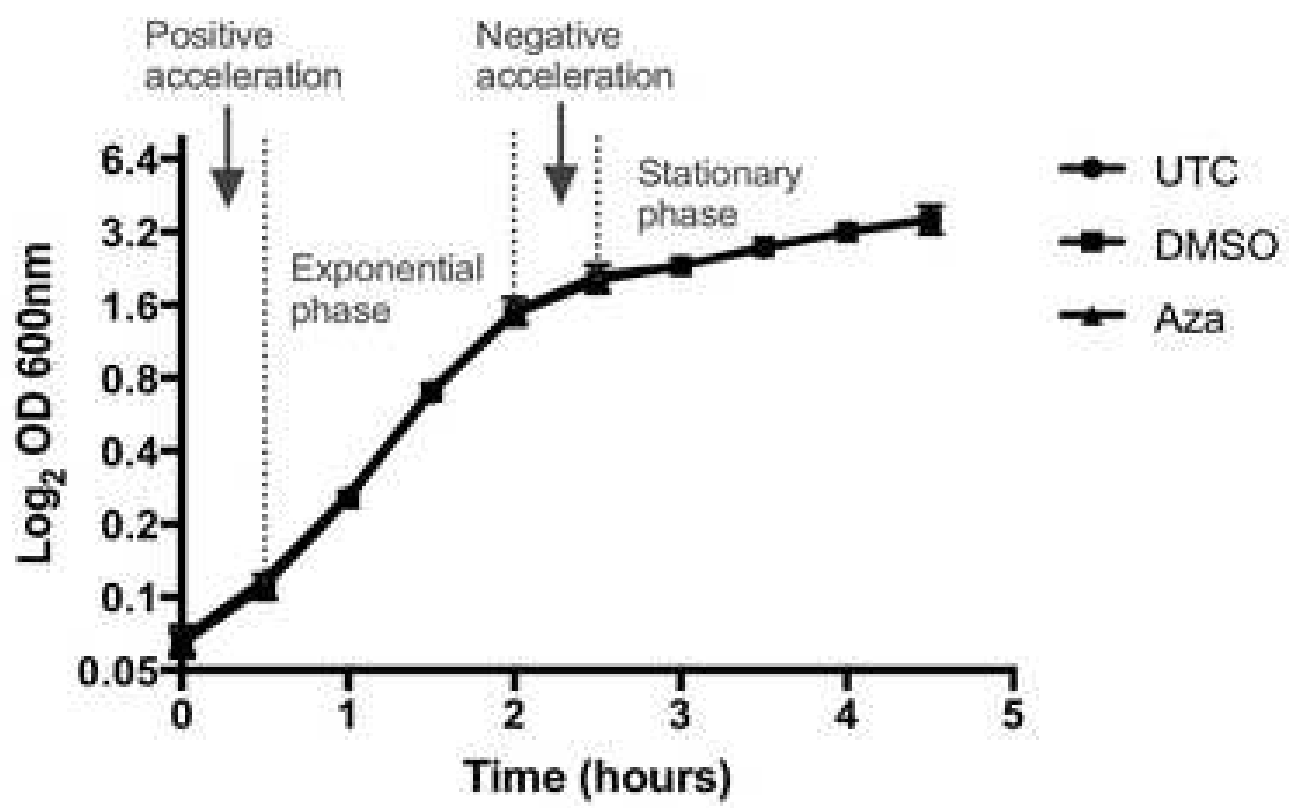



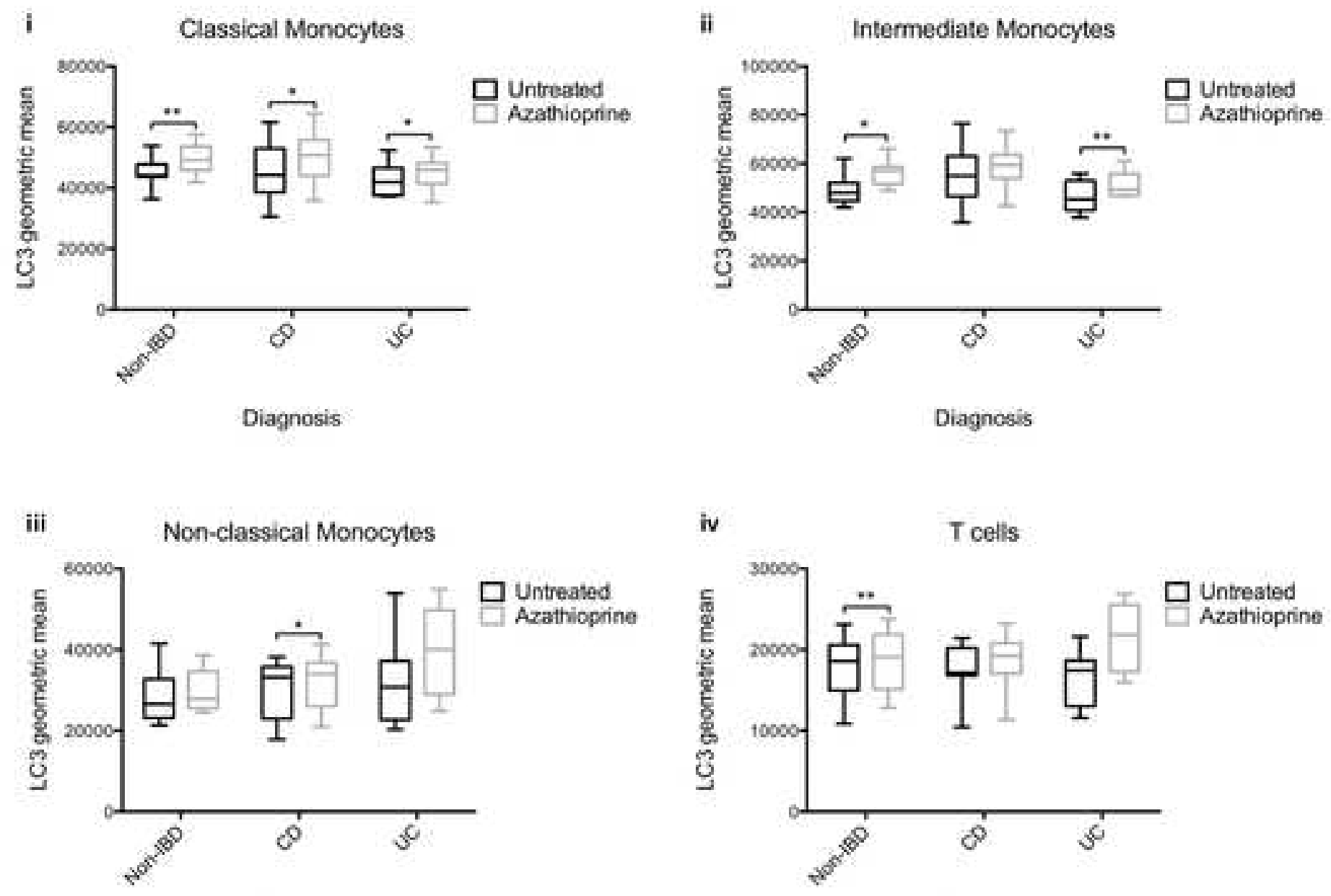

Diagnosis

Diagnosis

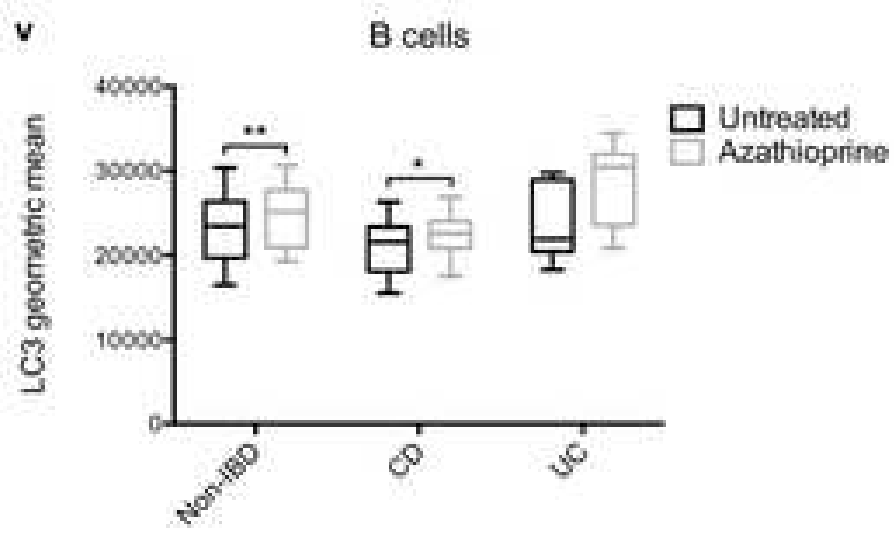

Diagnosis

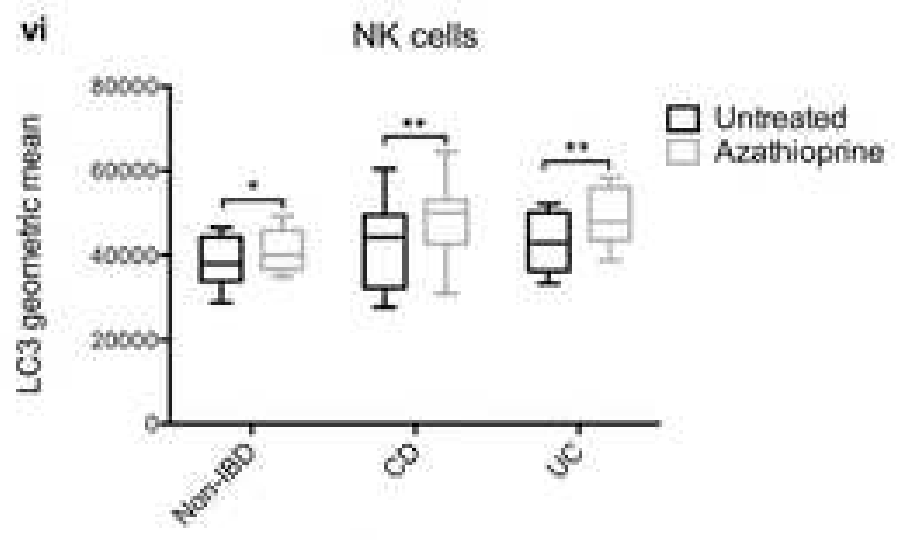

Diagnosis 